\title{
THE EFFECT OF EXTERNAL GAS/SLURRY CONTACT ON THE FLOTATION OF FINE PARTICLES
}

by

\author{
Joseph Patrick Tortorelli
}

A thesis submitted to the School of Graduate Studies in conformity with the requirements for the degree of Master of Applied Science

Department of Metallurgy and Materials Science

University of Toronto

Toronto, Canada

스 Copyright by Joseph P. Tortorelli 1997 
The author has granted a nonexclusive licence allowing the National Library of Canada to reproduce, loan, distribute or sell copies of this thesis in microform, paper or electronic formats.

The author retains ownership of the copyright in this thesis. Neither the thesis nor substantial extracts from it may be printed or otherwise reproduced without the author's permission.
L'auteur a accordé une licence non exclusive permettant à la Bibliothèque nationale du Canada de reproduire, prêter, distribuer ou vendre des copies de cette thèse sous la forme de microfiche/film, de reproduction sur papier ou sur format électronique.

L'auteur conserve la propriété du droit d'auteur qui protège cette thèse. $\mathrm{Ni}$ la thèse ni des extraits substantiels de celle-ci ne doivent être imprimés ou autrement reproduits sans son autorisation. 
"The Effect of External Gas/Slurry Contact on the Flotation of Fine Particles"

Masters of Applied Science (1997) Joseph P. Tortorelli

Department of Metallurgy and Materials Science, University of Toronto

\section{ABSTRACT}

The aim of this work was to investigate an external contact device and its ability to recover fine particles. For this purpose, a flotation column was equipped with a flow-through sparger/contactor. The device was fitted on a slurry recycle stream and consisted of a porous stainless steel tube around which an air-tight rigid jacket is sealed. The device acts as a bubble generator and a bubbleparticle interaction chamber.

Variables such as device length, pore size, collection tubing length, device placement, column length, and superficial slurry rate (inside the porous tube) were investigated. Size-by-size recovery plots were generated using a Brinkmann particle size analyzer.

Results show that the contact device parameters can be varied to provide optimum recovery of fine particles. Slurry rate plays a significant role in recovery of fines; probably due to bubble size and turbulence effects. Other parameters, such as collection tubing length, porous tube length and pore size, all play a role in fine particle recovery to varying extents. Also, the Brinkmann particle size analyzer proved to be a precise means by which accurate particle size distributions could be determined.

It is concluded that a combination of conventional internal bubble-coursing and external contact is ideal in recovering a wide range of particle sizes. 


\section{ACKNOWLEDGEMENTS}

First of all I would like to thank Professor J.M. Toguri for accepting me into his Chemical Metallurgy Research Group at the University of Toronto. The deeply appreciated support and guidance provided over the past two years demonstrates his superiority and dedication as a supervisor.

My gratitude to Dr. G.S. Dobby for first introducing me to the Mineral Processing field while I was an undergraduate, and for suggesting the topic addressed in this thesis.

Many thanks to Dr. G.E. Agar for his valuable technical advice and assistance before and during the course of this research.

Recognition and my deep appreciation goes to John Craven for constructing the flotation column and providing me with important and useful suggestions, while completing his Ph.D. at the University of Toronto.

In addition, I would like to acknowledge: John Mitchell and Highland Valley Copper for providing me with the material used in this investigation; Victor Itkin for his assistance with the Brinkmann particle size analyzer; and my laboratory assistants, Anita Hervas and Hussein Ali.

Finally I would like to recognize the financial support of the Haultain Graduate Fellowship in Mineral Engineering from 1994 to 1996. 


\section{TABLE OF CONTENTS}

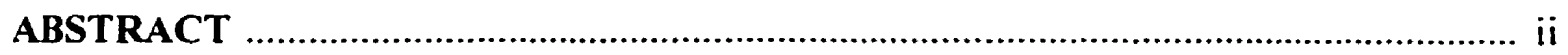

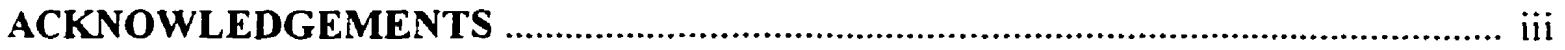

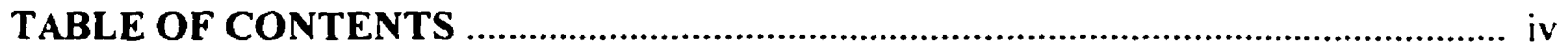

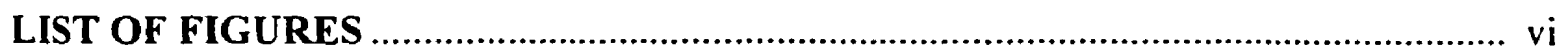

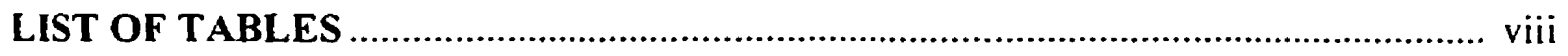

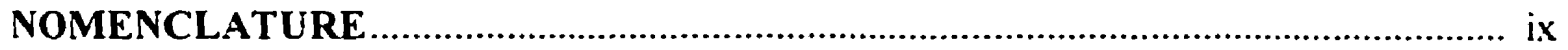

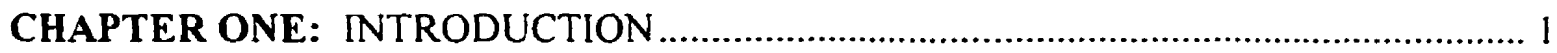

1.1 Froth Flotation .............................................................................................

1.2 The Outline and Focus of This Work ................................................................ 2

CHAPTER TWO: OVERVIEW OF COLUMN FLOTATION .................................... 4



2.1.1 Superficial Velocity and Bubble Flow...................................................... 5





2.1.3.1 External Spargers..................................................................... 9

2.1.3.2 The Contact Device .................................................................... 14

2.2 Collection and the Bubble-Particle System .................................................... 17

2.2.1 Surface Effects and Forces................................................................... 18

2.2.1.1 The Electrical Double Layer......................................................... 19

2.2.1.2 The Surface and Structure of Molybdenite ....................................... 21

2.2.2 Bubble Size and Particle Size Effects ........................................................ 22



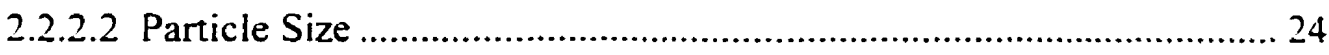

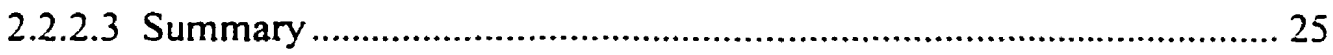

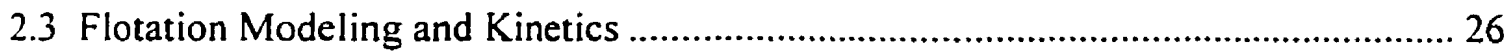

CHAPTER THREE: FINE PARTICLE FLOTATION ............................................... 3 I

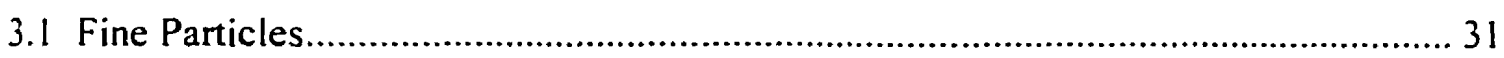

3.2 The Difficulties Encountered in Fine Particle Flotation ......................................... 33

3.3 Additional Problems Created by Fine Particles.................................................... 37 


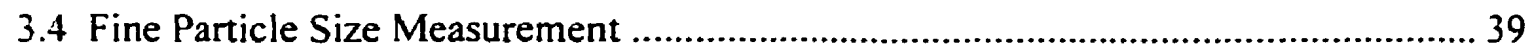

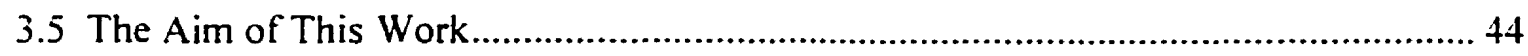

CHAPTER FOUR: EXPERIMENTAL DESIGN. SETUP. AND PROCEDURE............. +6

4.1 The Laboratory Flotation Column and Contact Device........................................ 46

4.1.1 Design and Setup of the Column ............................................................ 47

4.1.2 Design of the Contact Device .............................................................. 50

4.2 Column Experimental procedure. Conditions and Materials ................................ 52

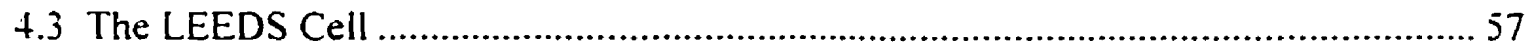

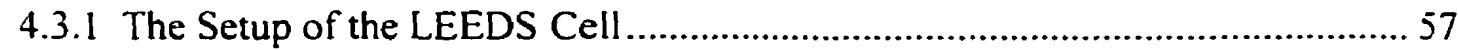



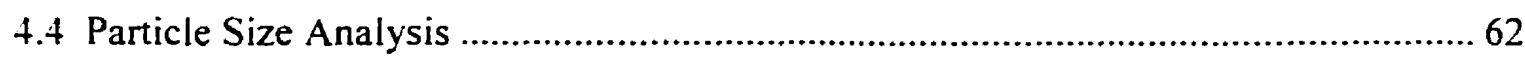

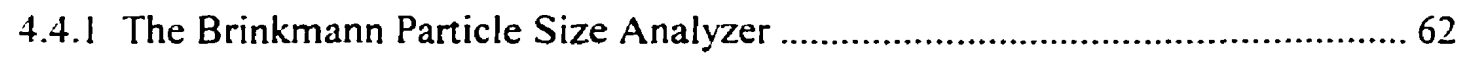

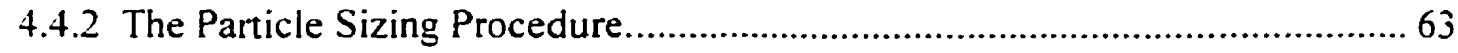

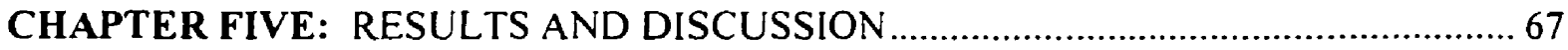

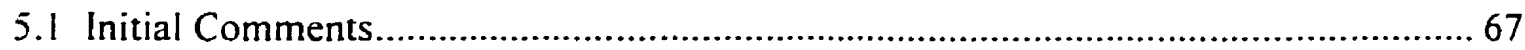

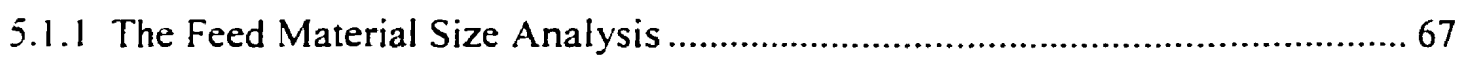

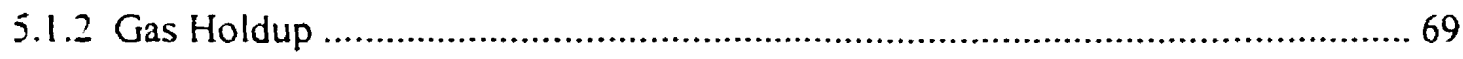

5.1 .3 A Note on Graph Presentation ............................................................... 71

5.2 The Effect of Slurry Superficial Velocity .......................................................... 72

5.3 The Effect of Porous Tube Dimensions................................................................ 75

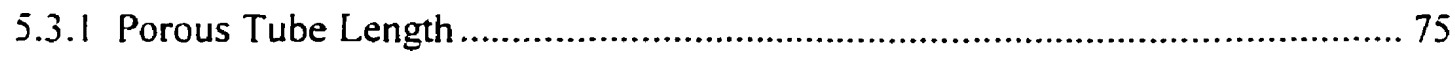

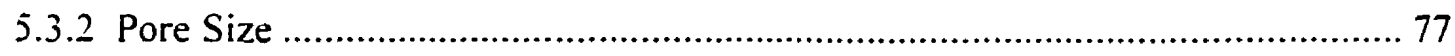

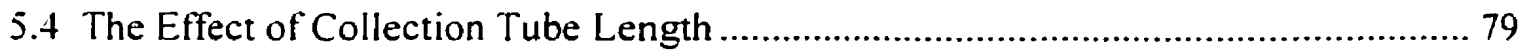

5.5 Comparison With a Conventional Cell .......................................................... 81

5.6 Conventional Bubble Coursing Versus External Collection .................................. 83

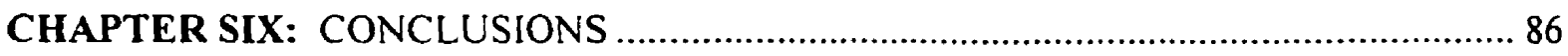



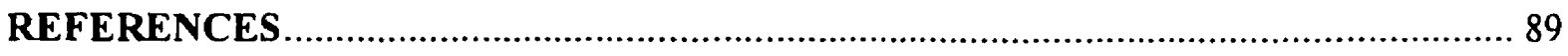






\section{LIST OF FIGURES}

Figure 2.1 The relationship between gas holdup and superficial gas velocity (Finch and Dobby, 1990, p. 13) 6

Figure 2.2 The Jameson Cell showing hydrodynamic regimes (Evans, Atkinson, and Jameson, 1996). 10



Figure 2.4 The mixing component inside a Microcel ${ }^{\mathrm{TM}}$; an in-line static mixer.... 11

Figure 2.5 A Venturi type aerator (Meyer, 1994) ............................................... 12

Figure 2.6 The Davcra cell (Wills, 1988, p. 519) …............................................... 13

Figure 2.7 The Contact Device .......................................................................... 15

Figure 2.8 A particle approaching a bubble ...................................................... 18

Figure 2.9 The structure of the electrical double layer (Gaudin, 1957, p. 104).... 20

Figure 2.10 A variation of fig.2.9 with a spherical particle (Gaudin, 1957, p.100)...20

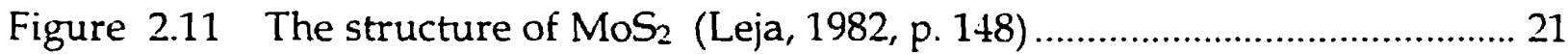

Figure 2.12 The effect of bubble diameter on collection efficiency vs. particle

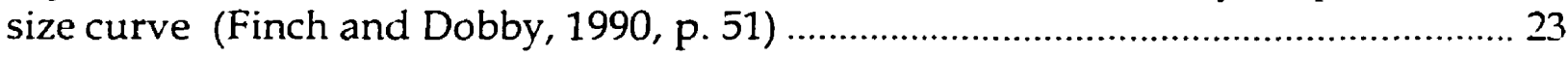

Figure 2.13 The size-by-size recovery of some common sulfide minerals



Figure 3.1 A typical size-by-size recovery plot........................................................ 32

Figure 3.2 The influence of inertia of particles on their trajectory in the vicinity of a bubble (Derjaguin and Dukhin, 1979) ................................................................. 35

Figure 3.3 The relationship between the physical and chemical properties of fine particles and their behavior in flotation (Fuerstenau, 1980) 38 
Figure 3.4 A laser diffraction particle size analyzer.............................................. 40

Figure 3.5 The components of the Brinkmann particle size analyzer ................... 42

Figure 4.1 The laboratory flotation column ……................................................ 49

Figure 4.2 The process flowsheet of the column tests............................................ 54



Figure 4.4 The particle size analyzing procedure....................................................64

Figure 5.1 The volume percent size distribution of the feed material ................... 68

Figure 5.2 Gas holdup and overall recovery versus superficial slurry velocity ... 70

Figure 5.3 The effect of superficial slurry velocity on overall recovery................ 73

Figure 5.4 The size-by-size recovery at various slurry superficial velocities........ 73

Figure 5.5 Particle size versus superficial slurry velocity ..................................... 74

Figure 5.6 The effect of porous tube length on recovery - slurry velocity plots... 76

Figure 5.7 The effect of porous tube length on size-by-size recovery ……............76

Figure 5.8 The effect of pore size on recovery for various tube lengths ................ 78

Figure 5.9 The effect of pore size on size-by-size recoveries ............................... 78

Figure 5.10 The effect of collection tube length, or pre-column residence time,

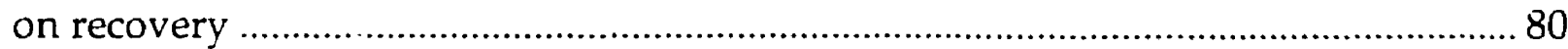

Figure 5.11 Comparison of size-by-size recovery results between the contact device-column system and a conventional flotation cell ............................................ 82

Figure 5.12 The size-by-size effect of removing the bubble coursing component, by contacting the feed and shortening the column. 


\section{LIST OF TABLES}

Table 4.1 The six contact devices used in testing ............................................. 51

Table 4.2 The conditions and parameters of the column flotation tests .............. 56

Table 4.3 Conditions for the LEEDS cell flotation tests .....................................60 


\section{NOMENCLATURE}

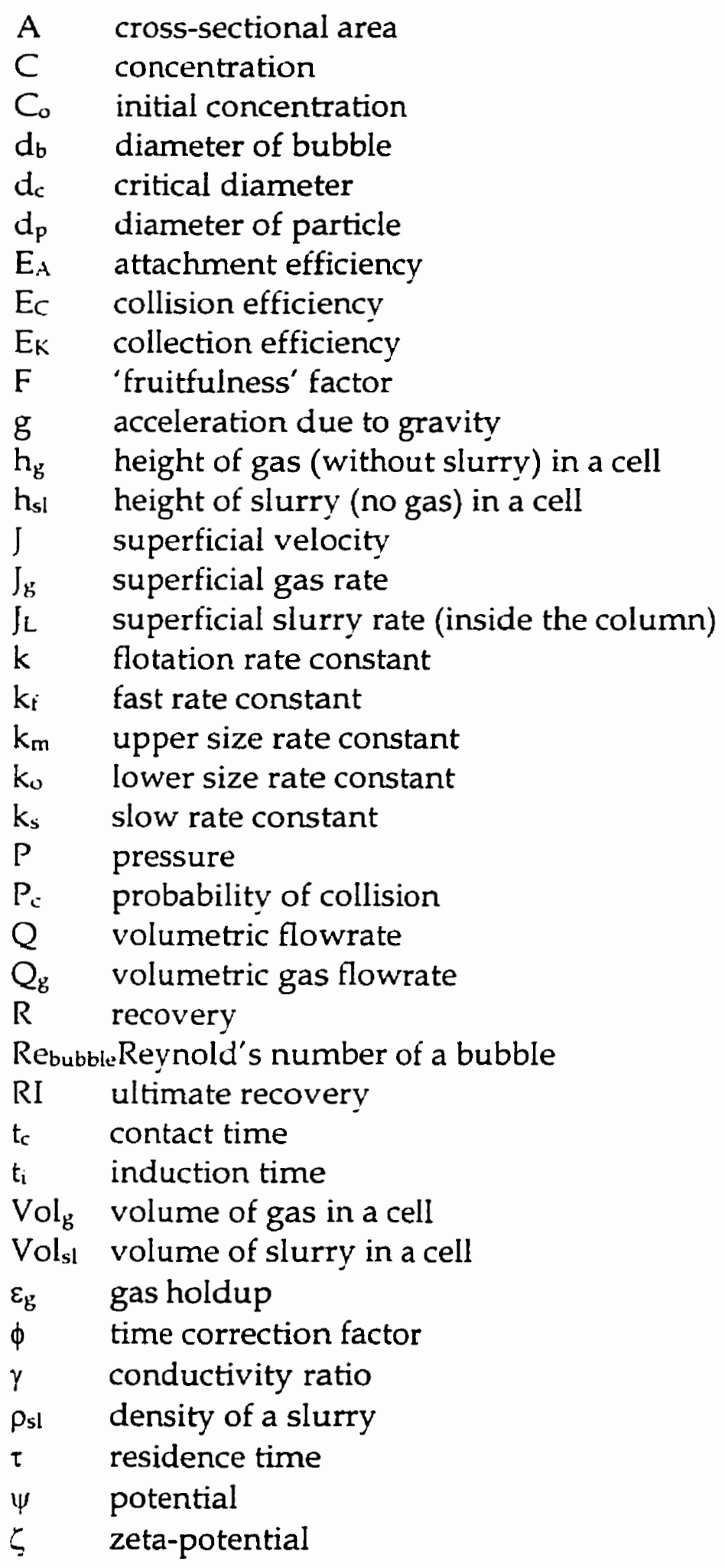




\section{Chapter One}

\section{INTRODUCTION}

\subsection{Froth Flotation}

Flotation is an invaluable separation method available to the minerals industry. It is a physio-chemical technique by which components of a mineral slurry are separated based on differences in their surface properties. The key to flotation lies in the natural or induced surface-hydrophobicity of a certain mineral. Reagents are used to adjust the surface properties of the slurry components such that there exists a difference in the wetting characteristics of these components. Bubbles are generated and come in contact with the solid/liquid slurry. The hydrophobic particles will attach to the bubbles while the hydrophilic particles will not. The loaded bubbles rise to form a froth. This froth is subsequently removed and the separation is completed. For most of this century conventional mechanical flotation machines have been utilized in sometimes very complex circuits to achieve good separations.

Since the 1960's a different type of flotation cell has gradually been implemented into many plants: The Flotation Column is basically a much taller 
and narrow cell that lacks the mechanical component that is present in conventional cells. The bubbles are created by spargers that can be placed internally at the bottom of the column, or externally. The key to bubble-particle interaction in the internally sparged column is the long collection zone where the bubbles flow upward, countercurrently to the feed. In an externally sparged column most of the collection takes place outside the column where the slurry and gas are contacted.

\subsection{The Outline and Focus of This Work}

This investigation deals with an external gas-slurry contact/bubble generating device. The device consists of an airtight jacket that seals around a porous tube; it will be described fully in the following chapters. This 'sparger-contactor' will be referred to as the Contact Device.

The aim of this work is to investigate the contact device and its ability to recover fine particles. This is done by investigating the effect of varying different parameters such as device length, pore size, placement and slurry velocity. In this work an attempt is not made to specifically compare this contact device with other external spargers, or with a conventional column. But, rather, it is hoped to gain an understanding of what sort of conditions are required to maximize the efficiency of this device in collecting particles in the finer size ranges. To this date, few investigations have been conducted that look specifically at the 
growing number of external contact devices and the role they play in fine particle flotation.

The next chapter gives a theoretical overview of flotation that is essential in any work of this type; including bubble generation, gas hold-up, bubble-particle contact, and flotation modelling. Chapter three specifically addresses fine particles. It deals with the inherent problems associated in fine particle flotation along with fine particle sizing techniques. Also in chapter three, the contact device used in this work is looked at in its capacity of, theoretically, overcoming these problems and being advantageous in the flotation of fines. In chapter four the device is looked at quantitatively; the design of the flotation column, the conventional cell, and the particle size analyzer is reviewed. In addition, a review of the experimental flotation and particle sizing procedures are given in chapter four. In chapter five the results of the flotation tests are presented along with a discussion and an analysis. Finally, in chapters six and seven, the main conclusions of this investigation are summarized and possible future work on the subject is suggested. 


\section{Chapter Two}

\section{AN OVERVIEW OF COLUMN FLOTATION}

Over the past 15 years column flotation has quickly become an important asset to the mineral processing industry. Over this time, interest in columns has increased dramatically. It has been readily accepted by most experts that columns are, at the least, very effective cleaners. As a result, they have been implemented into many plants throughout the world.

Some of the advantages of column flotation include: The lower cost of operation of a column because it lacks the mechanical parts that conventional cells possess. Less plant space is needed for columns than for conventional cells. The possibility of automated control, or logical control using an expert system. In terms of the froth product, the column will give a 'cleaner' product because of the increase in selectivity. This increase is mainly due to the use of wash water that readily cleans the froth of entrained particles. 


\subsection{The Gas Phase}

\subsubsection{Superficial Velocity and Bubble Flow}

Before any discussion is started it is important to define a term in which the flow of a gas, liquid, or slurry can be quantified. The superficial velocity (J) of a fluid stream is the volumetric flowrate $(Q)$ of the stream divided by the crosssectional area (A) of the cell through with it flows. In the case of a gas the superficial gas velocity is given as:

$$
J_{x}=\frac{Q_{x}}{A}
$$

where $J_{g}$ can be expressed as $\left(\mathrm{cm}^{3} / \mathrm{s}\right) /\left(\mathrm{cm}^{2}\right)$ or $\mathrm{cm} / \mathrm{s}$. This term is frequently used because it is valuable as a design parameter. For example, the superficial velocity of a slurry inside a tube is the same for a $1 \mathrm{~cm}$ diameter piece of tubing in the lab as it is for a $1 \mathrm{~m}$ pipe in a full sized industrial operation.

The key to effective (conventional) column flotation is the generation of a homogeneous distribution of small bubbles that flow up through the column at a more or less uniform rate. This type of flow is called bubbly flow. Figure 2.1 shows the relationship between the gas holdup and the superficial gas velocity is linear throughout this type of flow. 


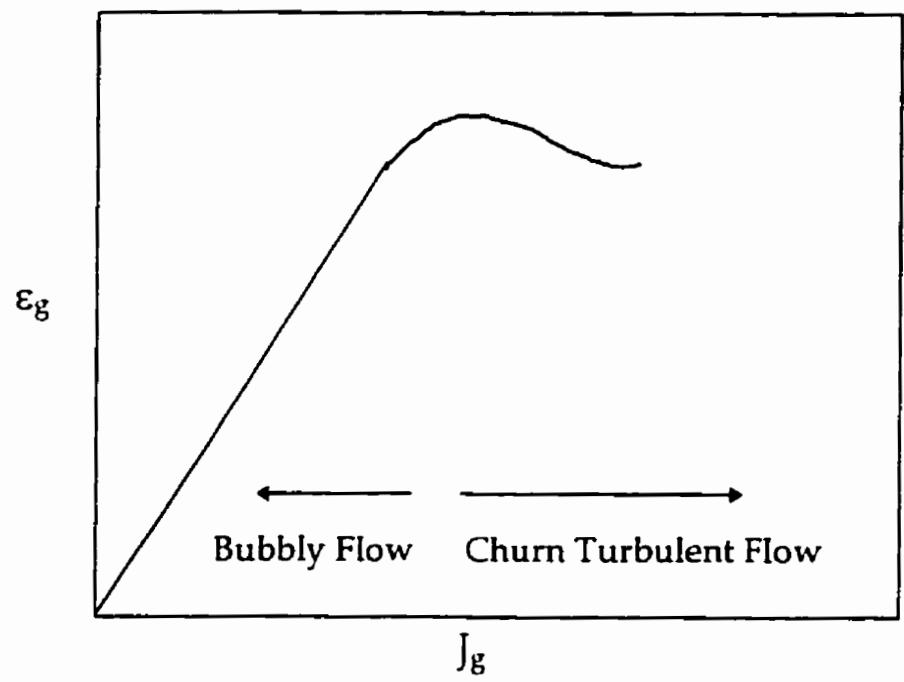

Figure 2.1 The general relationship between gas holdup $\left(\varepsilon_{\mathrm{g}}\right)$ and superficial gas velocity $\left(J_{g}\right.$ ) (Finch and Dobby, 1990, p. 13).

\subsubsection{Gas Holdup}

Gas holdup is defined as the volumetric fraction of gas in a mixture. For example, in a flotation column there exists a volume of slurry $\left(\mathrm{Vol}_{\mathrm{sl}}\right)$ and a volume of gas $\left(\mathrm{Vol}_{\mathrm{g}}\right)$. Thus the gas hold up $\left(\varepsilon_{\mathrm{g}}\right)$ is:

$$
\varepsilon_{g}=\frac{\mathrm{Vol}_{\mathrm{g}}}{\mathrm{Vol}_{\mathrm{g}}+\mathrm{Vol}_{\mathrm{s}}}
$$

There are a number of conventional methods by which gas holdup can be measured: The first is displacement. This simply involves taking the level with and without the presence of gas as follows: 


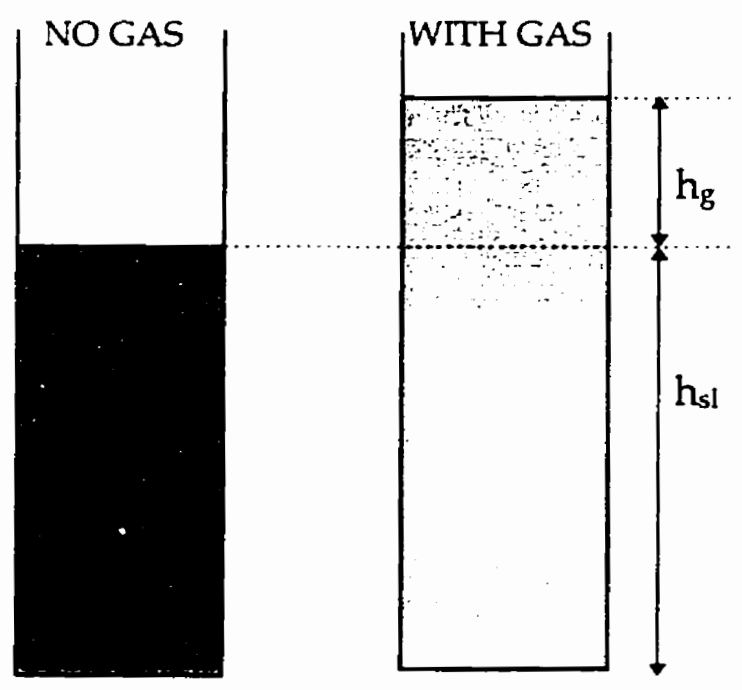

Thus the gas holdup would be: $\quad \varepsilon_{g}=\frac{h_{g}}{h_{g}+h_{s l}}$

This method cannot be used when the column is in a continuous flotation mode and, of course, when there is a froth. Thus, its use is rather limited.

Another method by which gas holdup can be determined is a pressure method. Here, the gas holdup can be determined by pressure readings taken at two points in the column; and using the following equation,

$$
P_{A}=P_{B}+\Delta L g\left(\varepsilon_{g} \rho_{g}+\left(1-\varepsilon_{g}\right) \rho_{s l}\right)
$$


where; $\rho_{s 1}$ is the slurry density, $\rho_{\mathrm{g}}$ is the gas density $(\sim 0), \Delta \mathrm{L}$ is the vertical distance between the pressure reading points and $\mathrm{g}$ is the acceleration due to gravity.

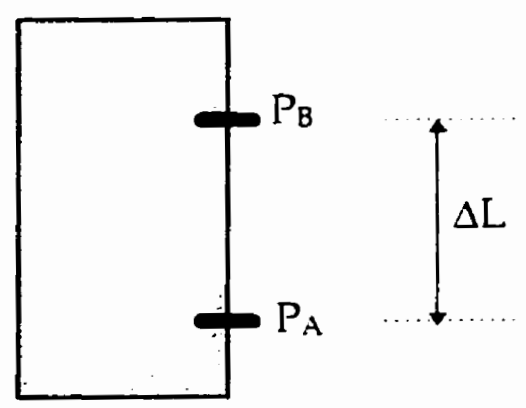

The equation simplifies to, $\quad \varepsilon_{\mathrm{g}}=1-\frac{\Delta \mathrm{P}}{\Delta \mathrm{Lg} \rho_{\mathrm{sl}}}$

Finch et al. (1995) discuss another method by which gas holdup can be determined; this method involves conductivity measurements. Basically, if the conductivity of the slurry can be attained with and without gas, then Maxwell's model can be used to calculate gas holdup.

Maxwell's model; $\quad \varepsilon_{\mathrm{g}}=\frac{1-\gamma}{1+0.5 \gamma}$

where $\gamma$ is the ratio of conductivity of the slurry + gas to the conductivity of the slurry alone. Of course the problem here would be the difficulty in measuring gas holdup of the slurry alone while during operation. There are, though, 'siphon' cells designed for plant use that solve this problem. 


\subsubsection{Bubble Generation}

Conventional flotation columns use bubble generators (or spargers) that are internally placed near the bottom of the column. In a modified column system the sparger can be placed outside the column. Here, a slurry stream and the gas can be brought into intimate contact before even entering the column. It is a type of this external sparging-contacting system that is investigated in this thesis. The following section reviews some external sparging devices.

\subsubsection{External Spargers}

External sparging is a very viable alternative to internal sparging for numerous reasons: First of all there is the ease of maintenance of a device that is separate from the column. A multiple sparger system can be utilized to ensure easy maintenance of any one sparger that may need replacing, fixing or cleaning. Also because the sparger is not inside the column it is less prone to becoming plugged with solids (Finch and Dobby, 1990, p. 35).

As will be discussed later, these types of external contactors usually create more turbulent conditions than those that exist inside a conventional flotation cell. This naturally leads to more (and higher energy) bubble-particle interactions which, in turn, will assist in the flotation of 'hard to float' particles like fines. 
One device of this type is the Jameson cell (Jameson and Manlapig, 1991), shown in figure 2.2. Here a 'downcomer', in which feed is injected at high pressure, will cause a vacuum and entrain air (which is drawn through an opening below the feed injection orifice). Contact is made and attachment between bubbles and hydrophobics is achieved due to the intensive shear: The bubbles are trying to rise while the downcomer forces them down. This jet of slurry-air mixture is discharged at the base of a cell. The collected particles are allowed to separate into a froth, while the uncollected particles fall to the tails, like in a conventional cell. Also, wash water is used to clean the froth.

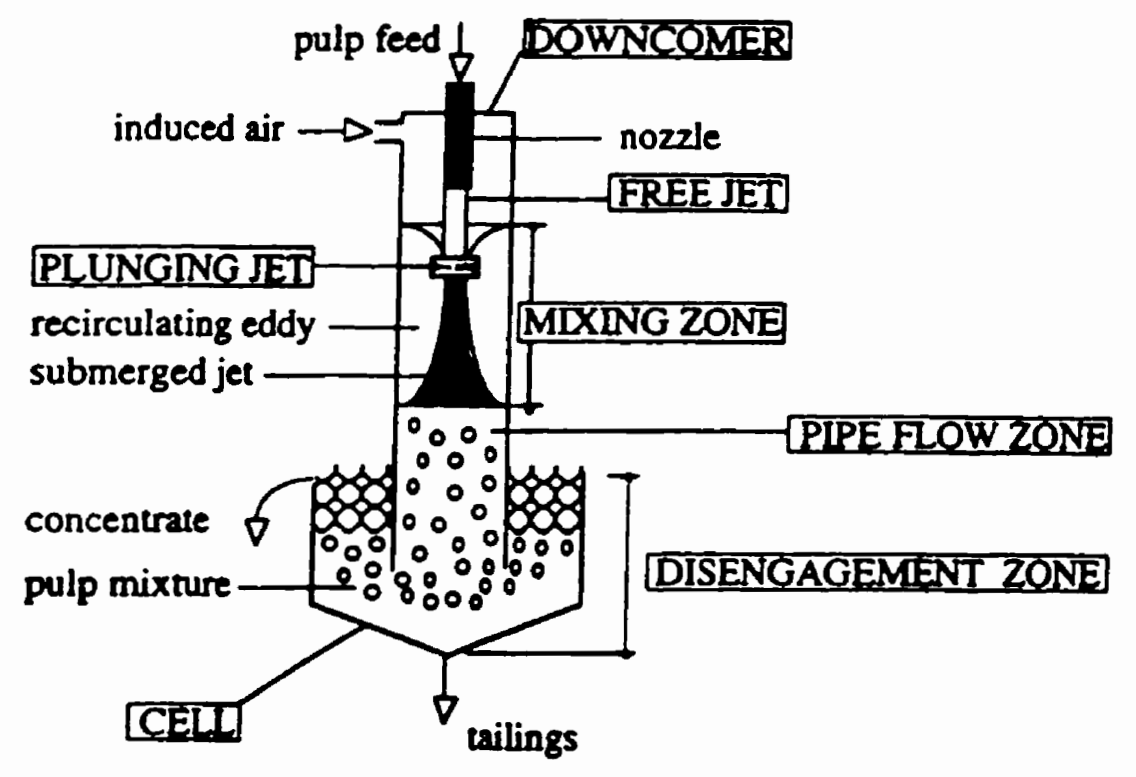

Fig. 2.2 The Jameson Cell showing hydrodynamic regimes (Evans, Atkinson, and Jameson, 1996.) 
The V.P.I. Microcel ${ }^{\text {m }}$ set-up is similar to a conventional column with a continuous recycle stream added. It was developed by a group at Virginia Polytechnic Institute (Yoon, 1993). The reactor itself is basically a tubing within which there are static mixing elements (see figures 2.3 and 2.4). Air is added just as the slurry enters these mixers. The great shear created here produces very fine bubbles. The slurry stream that flows through the external static in-line mixer is not the feed stream, but rather a recycle stream taken from near the bottom of the column.

Fig. 2.3 The Microcel ${ }^{\mathrm{TM}}$ recycle system.


Fig 2.4 The mixing component inside the Microcel ${ }^{\text {mM; }}$ An in-line static mixer. 
There have been investigations using the static in-line mixer by a number of authors, including Hood and Jordan (1993), Xu et al. (1994), and Meyer (1994). Hood and Jordan (1993) looked at the ability of the mixer to act as a collection device. They compared a set-up in which a slurry is sent through the mixer to a conventional flotation operation. They found that the flotation rate was 7 times faster using the mixer, than in conventional flotation. Also Xu et al. (1994) concluded that significant collection takes place inside the mixer. The findings of these authors are summarized by Meyer (1994).

Meyer (1994) compared the in-line static mixer to a Venturi Type Aerator. This basically uses the principle that when the path of a flowing fluid stream is constricted, the increase in velocity at the point of constriction corresponds with a decrease in pressure at that point. Thus if gas is allowed to enter at this point, it breaks up into small bubbles. This surface area increase is ideal for contact and subsequent collection of particles by the bubbles. A schematic of the device used by Meyer (1994) is shown in fig. 2.5.

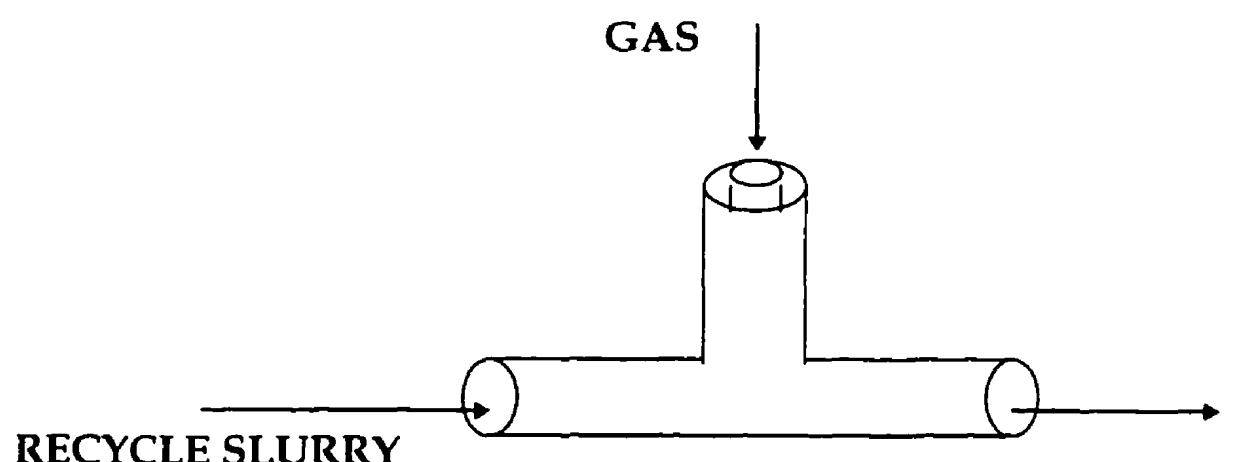

Fig 2.5 A Venturi Type Aerator (Meyer, 1994). 
In the Venturi, the size of bubbles created should depend on, among other things, the superficial velocity of the slurry flowing through the tube. As the velocity increases, the amount of cavitation and shear will increase and thus there should be more fine bubbles created. In addition to the high number of bubble-particle impacts, there is also possibility for bubble nucleation to take place on the surface of the particles in the low pressure region.

The Davcra cell is composed of a flotation cell separated into two sections by a vertical baffle (see figure 2.6). The external sparging takes place in a cyclone contactor which has a tangential feed inlet and an axially mounted gas inlet tube. The feed slurry and a gas stream are introduced under high pressures into this cyclone. The centrifugal force of the feed will shear off the air. Mixing takes place and fine bubbles are created when the mixture is released into the flotation cell. To the left of the baffle, contact takes place between bubbles and particles. When the slurry flows over to the right of the baffle it separates into froth and tails products (Wills, 1988, p. 519).

Fig. 2.6 The Davcra Cell

(Wills, 1988, p. 519)

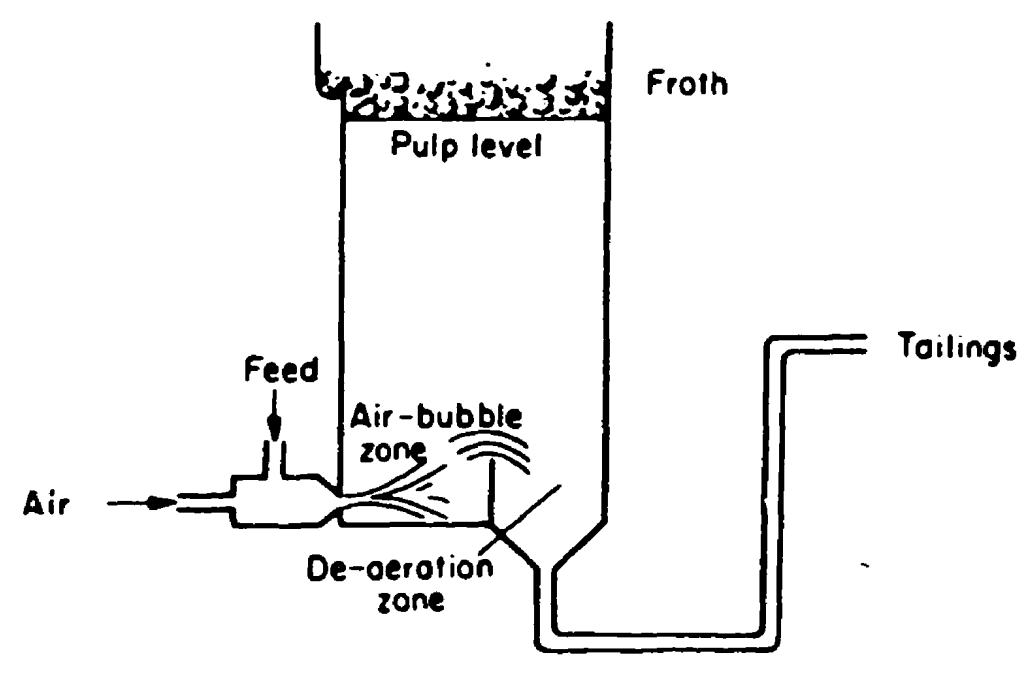




\subsubsection{The Contact Device}

In this work a type of external contactor called a flow-through bubble-particle contact cell or, for simplicity, a contact device is investigated. A quantitative explanation of the device and its construction is given in the experimental part (section 4.1.2) of this thesis. The basic concept is simple: A porous stainless steel tube is connected to tubing through which, in this case, a recycle slurry stream is directed. Gas is introduced through the pores of the tube via an inlet in an airtight jacket which is fitted around it. The gas will flow through the pores and begin to nucleate on the inside wall of the tube. The slurry stream, flowing inside the tube at high superficial velocities, will shear off the bubbles that have formed on the inner wall. A schematic of the device used is shown in figure 2.7.

Theoretically, the velocity of the recycle stream will determine the size of the bubbles that are formed because a faster slurry will shear off bubbles while they are still small. Thus, as with the Venturi, the superficial velocity of the stream flowing through the device should prove to be critical in optimizing flotation performance. 
THE CONTACT DEVICE



Fig. 2.7 
Ding (1993) worked with the contact device and concluded the following: 1 . An increase in the length of the porous tube will have a slight increase in recovery; 2 . Collection is directly influenced by the slurry superficial velocity; 3 . Lengthening of the tubing that connects the contact device to the column (after contact) has a negative effect on recovery. These findings, in addition to other operating parameters, are investigated in this work. However, this work is geared toward evaluating the contact device in its capacity as a fine particle collector. Thus, in addition to overall recovery, the 'size-by-size' recovery results are also thoroughly investigated. 


\subsection{Collection and the Bubble-Particle System}

When a bubble and particle approach each other, there are two main events that must take place before collection can take place. These are; effective collision and subsequent attachment. When a collision takes place, the particle approaches the bubble and begins to slide around it. The time that the bubble and particle are in contact is called the contact time $\left(\mathrm{t}_{c}\right)$. The particle then has to break through the liquid film layer that forms around the bubble (film thinning) and form a three phase contact. The time for this to take place is called the induction time $\left(t_{i}\right)$. If contact time is greater than induction time $\left(t_{c}>t_{i}\right)$, then attachment occurs. Thus the collection efficiency $\left(\mathrm{E}_{K}\right)$ can be expressed as:

$$
E_{K}=E_{C} E_{A}
$$

where $E_{C}$ is the collision efficiency and $E_{A}$ is the attachment efficiency.

Figure 2.8 shows a particle of diameter $d_{p}$ approaching a bubble of diameter $d_{b}$. If the particle flows within the critical diameter $d_{c}$ around the bubble, it will contact the bubble. The probability of collision $\left(P_{C}\right)$ is dependent on $d_{b}$, and $d_{p}$. Under stokes flow $\left(\operatorname{Re}_{b u b b l e}<1\right)$ the relationship is given as:

$$
P_{c}=1.5 \frac{d_{p}^{2}}{d_{h}^{2}}
$$


For bubbles with larger Reynold's number (intermediate flow) the relationship given by Yoon and Luttrell (1989) is:

$$
P_{c}=\left(1.5+0.27 \operatorname{Re}_{h}{ }^{072}\right) \frac{d_{p}^{2}}{d_{h}^{2}}
$$

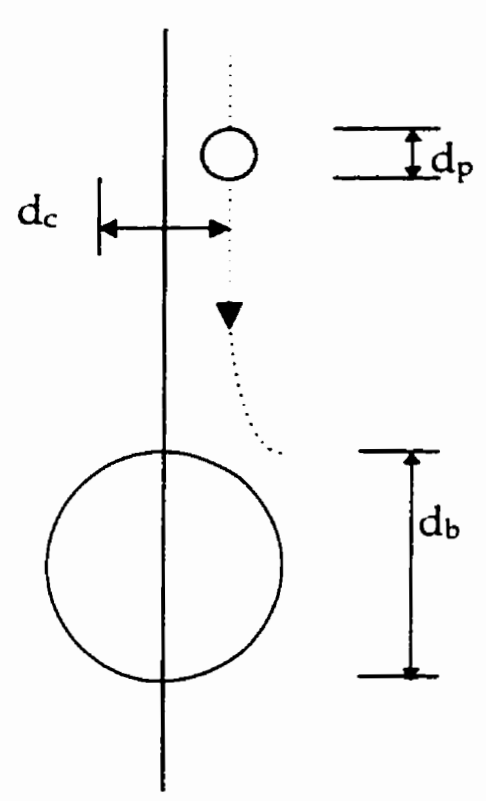

Figure 2.8 A particle approaching a bubble.

\subsubsection{Surface Effects and Forces}

The key to bubble-particle attachment, as described earlier, is ensuring that the induction time required for attachment is no longer than the contact time. Differences in induction time arise from differences in the surface forces acting between the particle and the bubble (Anfruns and Kitchener, 1977). Electrical double layer forces are detectable up to $200 \mathrm{~nm}$ (film layer thickness). (These 
double layer forces are described in the next section.) This energy barrier created by the overlapping double layers acts to repel the bubble and particle, and thus lengthen induction time. When the liquid film is much smaller, there may exist London-Van der Waals dispersion forces, these also oppose attachment. In addition, other forces that are associated with the molecular structural changes in the water exist when the film is just about to rupture.

\subsubsection{The Electrical Double Layer}

When the characteristics of interfaces are examined, one must always look at the electrical surface properties. Surface charges are especially important when looking at fine particles because of the small effect of other forces, like inertia, have on them. When a new solid surface is formed in a liquid or gaseous environment, as, for example, during dry or wet grinding, it either becomes charged at the moment of rupture of ionic or covalent bonds or picks up a charge by a subsequent adsorption of ions (Leja, 1982, p. 433). If the surface of a minera! picks up a negative charge then positive ions from the solution will be attracted to it. This forms a bound layer of positive ions, called the Stern layer and beyond that, a diffuse layer of counter-ions. These counter-ions basically extend out (in decreasing concentration) until equilibrium is attained in the bulk liquid. The bound Stern layer and the diffuse layer make up the Double Layer. Figures 2.9 and 2.10 show this double layer in relation to the particle surface. 


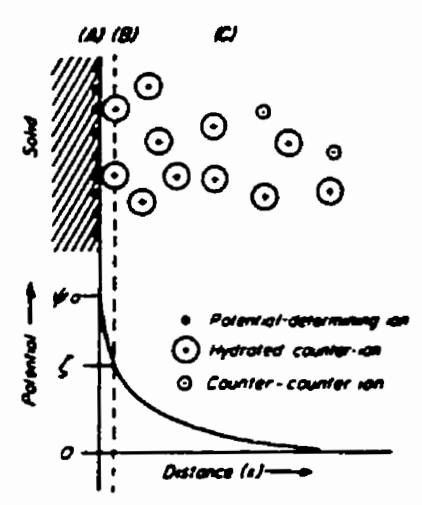

Figure 2.9 A Schematic of the structure of the electrical double layer with (A) the surface of the solid; $(B)$ the Stern plane; and $(C)$ the diffuse layer. The zetapotential ( $\zeta)$ is shown at the stern plane. (Gaudin, 1957, p. 104)

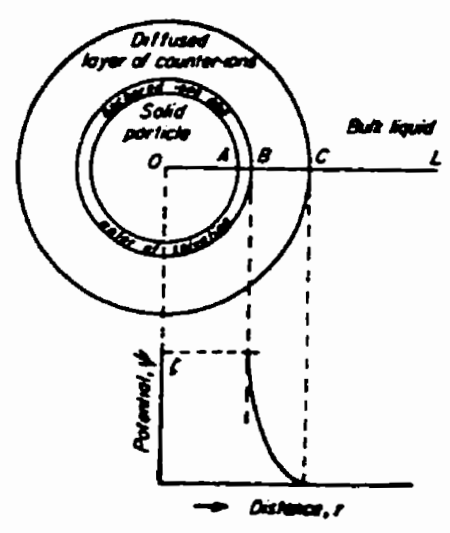

Figure 2.10 A variation of fig. 2.9 with a spherical particle. (Gaudin, 1957, p. 100)

Also shown in the figures is a plot of potential versus distance from the surface. As the particle moves in a liquid there is a shear created between the Stern layer and the diffuse layer. The potential $(\psi)$ at this point is the electrokinetic or zetapotential ( $\zeta)$; the greater the counter-ion charge and concentration, the lower the zet?-potential. Thus zeta-potential is a useful quantity in evaluating electrical effects on the layers of mineral particles in flotation. 


\subsubsection{The Surface and Structure of Molybdenite}

The material chosen to use in this investigation was molybdenite (MoS 2$)$. It is usually found as a minor constituent in disseminated copper ores. It is a naturally hydrophobic mineral and usually is allowed to float, although in some cases it is depressed using starch.

Molybdenite is a layered (or a sheet) structure. Basically it consists of hexagonal crystals in which sheets of Mo atoms are sandwiched between two sheets of $\mathrm{S}$ atoms (as shown in figure 2.11). The Mo and $\mathrm{S}$ atoms within the layers are strongly covalently bonded. But the successive layers of $\mathrm{S}$ atoms are bonded by weak van der Waals bonds. It is these bonds that give the mineral excellent cleavage parallel to the sheets and give $\mathrm{MoS}_{2}$ its hydrophobic nature.

2.11 The structure of $\mathrm{MoS}_{2}$ :

The Mo atoms are contained within the dark sheets. The edges of the sheets are hydrophilic while the surfaces are hydrophobic. (Leja, 1982, p. 148)

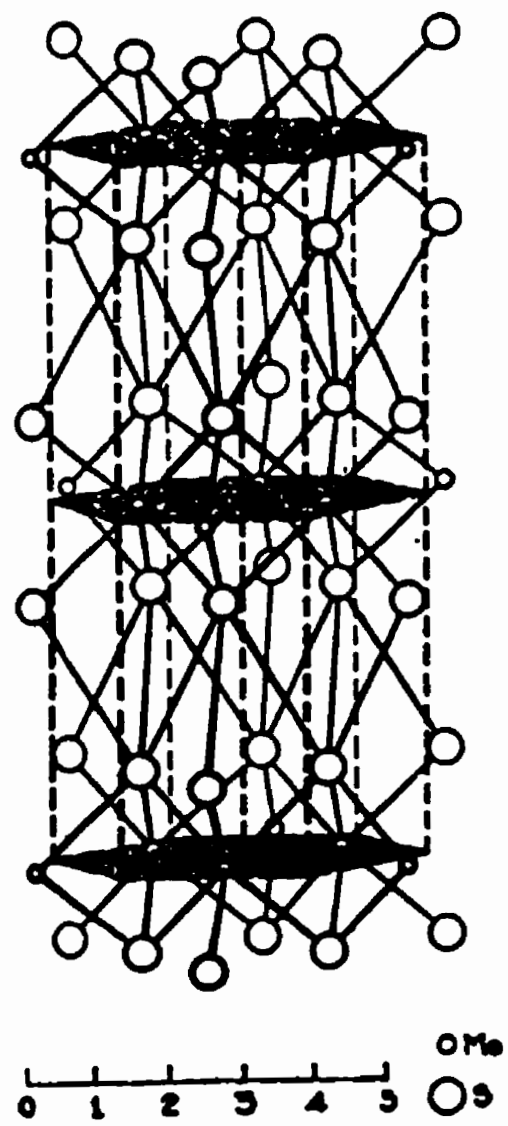




\subsubsection{Bubble Size and Particle Size Effects}

Over the past 60 years much work has been conducted to quantify the effect that both bubble and particle size have on flotation. Chapter three specifically looks at fine particles. This section will briefly review the general beliefs on the overall effects of bubble and particle size.

\subsubsection{Bubble Size}

There are many considerations when looking at the efficiency of a bubble in collecting particles; these include the actual particle size and its density. Generally, small bubbles $(<1 \mathrm{~mm})$ are beneficial since the overall total bubble surface area is large, giving the particles a lot of bubble surface onto which they can attach. Obviously a bubble cannot be too small or its ability to lift particles up into the froth will be hindered by its lack of buoyancy. Figure 2.12 shows a general relationship between collection efficiency and particle size for various bubble sizes.

Many authors provide relationships between bubble size $\left(\mathrm{d}_{\mathrm{b}}\right)$ and the flotation rate constant $(\mathrm{k})$. Some of these include:

$\mathrm{k} \propto \mathrm{d}^{-3}$ (for small bubbles, $\sim 0.1 \mathrm{~mm}$ ) and

$k \propto d_{b^{-1.66}}$ (for larger bubbles), Yoon (1993)

$k \propto d_{b}^{-1.5 t}$ (for 0.8 to $2.0 \mathrm{~mm}$ bubbles), Diaz-Penafiel (1993) 
$\mathrm{k} \propto \mathrm{d}_{\mathrm{b}}^{-2.05}$, Reay and Ratcliff (1975)

$k \propto d_{b}^{-3}$, for bubbles less than $100 \mu m$, Jameson et al (1977)

This all can be summed as follows:

$$
k \propto d_{b}^{-n}
$$

where $n=-2.5-3.0$ for small bubbles and $n=\sim 1.5-2.0$ for larger bubbles.

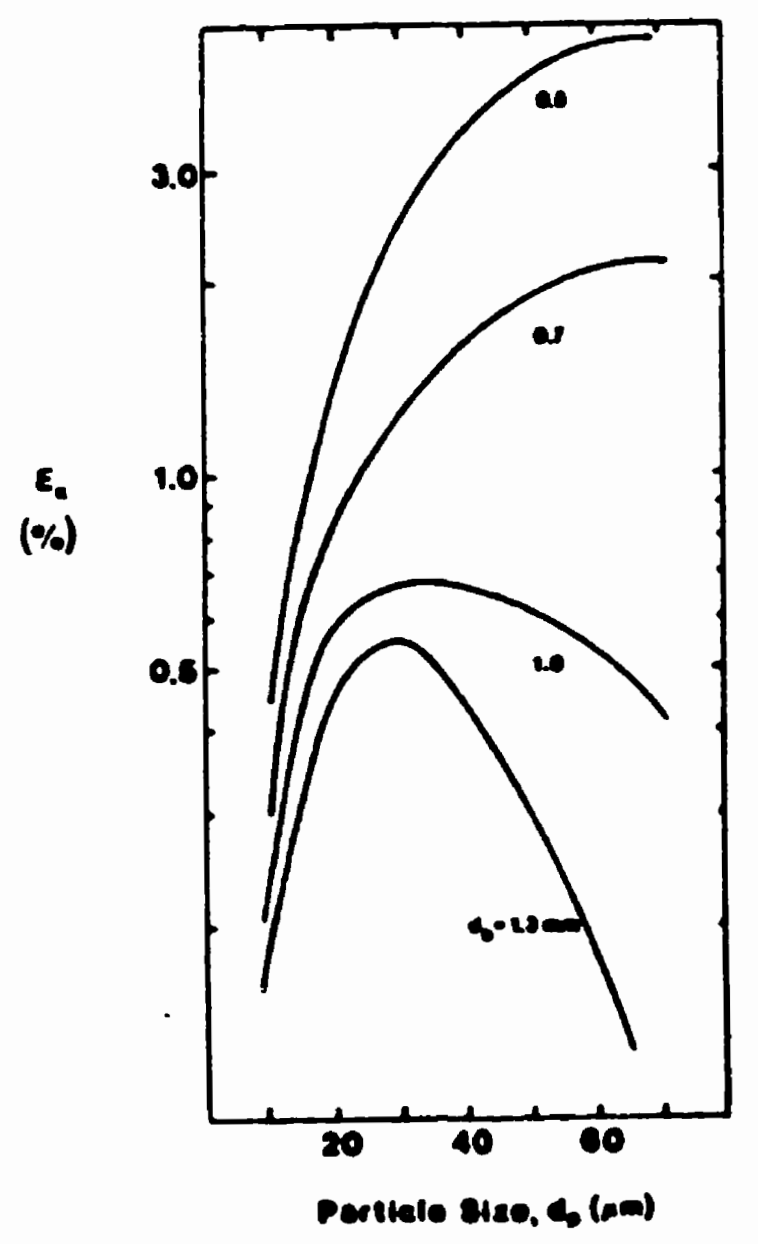

Figure 2.12 The effect of bubble diameter $\left(d_{b}\right)$ on a collection efficiency $\left(E_{K}\right)$ vs particle size $\left(d_{p}\right)$ curve (Finch and Dobby, 1990, p. 51). 


\subsubsection{Particle Size}

As opposed to bubble size, particle size generally has a positive relationship with flotation rate. In most cases (Anfruns and Kitchener, 1977; Reay and Ratcliff, 1973; Trahar, 1981), the relationship follows the following trend:

$$
\mathrm{k} \propto \mathrm{d}_{\mathrm{p}}^{\mathrm{m}}
$$

where $m=1-2$ for intermediate particle sizes.

In the experimental sections of this thesis the actual recovery of particles in terms of their particle size is examined. This is done by generating size-by-size recovery plots. Basically, these graphs show the individual recovery of a series of particle size ranges. If feed, concentrate, and tailings are each sized, then the respective particle size distributions can be normalized (using the overall recovery) to give size-by-size recoveries.

Figure 2.13 shows typical size-by-size recovery curves for four common sulfide minerals. It can be seen that there is an optimum (and distinct) size range for each mineral. Some minerals have a wide range, while others may have a more discrete range. In all cases, recovery of fine and very large particles will tail off to some degree. Reasons for this tail off in the fine particle size range are discussed in section 3.2 . 


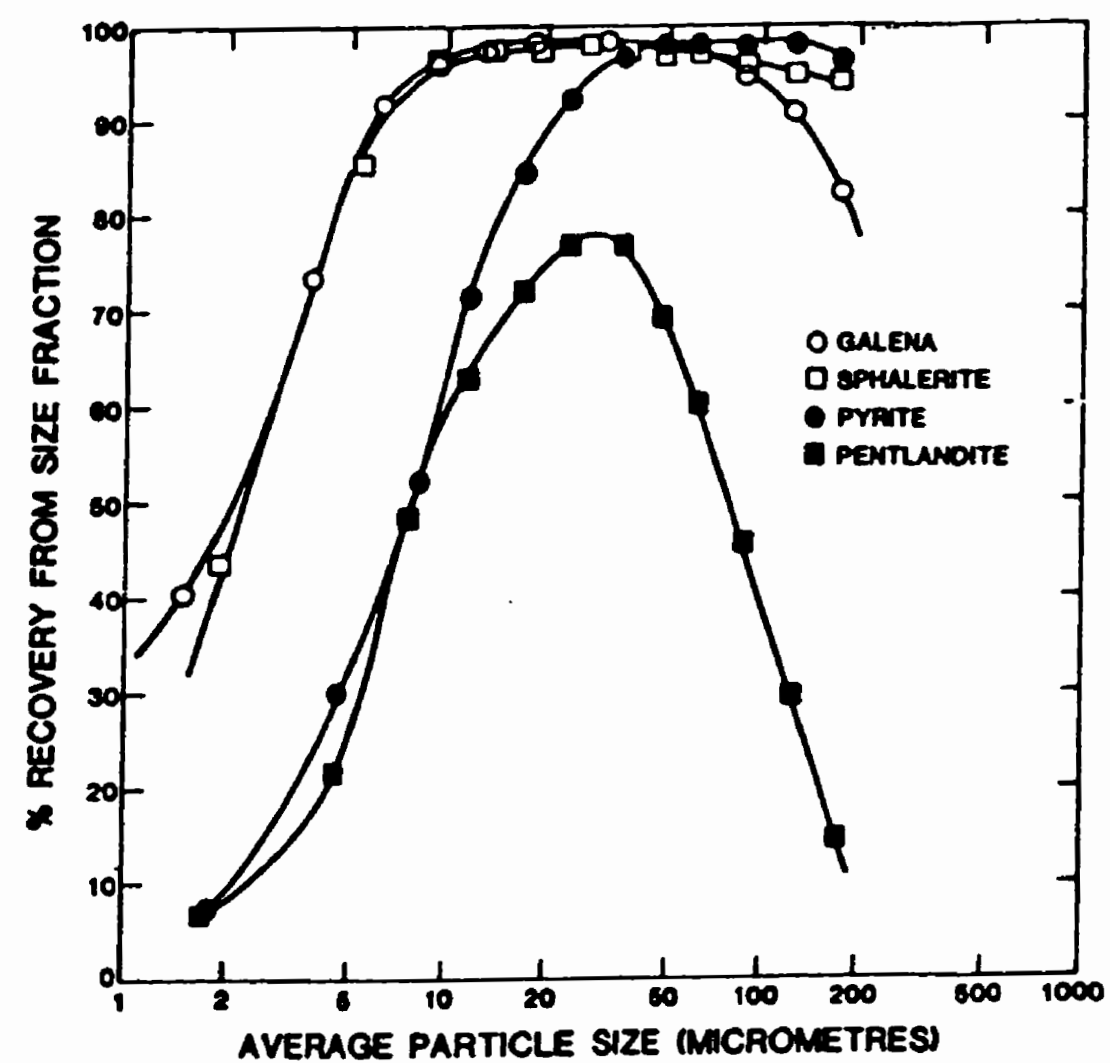

Figure 2.13 The size-by-size recovery of some common sulfide minerals (Jowett, 1980).

\subsubsection{Summary}

Jameson et al. (1977) summarize $k$ and collision efficiency $\left(E_{c}\right)$ as follows;

$$
\begin{gathered}
k \propto d_{p} m / d_{b}{ }^{n} \text { and } \\
E_{c} \propto d_{p} m / d_{b}^{n-1}
\end{gathered}
$$

where $m$ is between 1 and 2 , and $n$ is between 2.5 and 3 , with $n$ being smaller for larger bubbles. 


\subsection{Flotation Modelling and Kinetics}

In the 1930 's the importance of being able to accurately model the flotation process by use of kinetic equations was recognized. Over the past sixty years there have been many attempts to do this. Many types of models have been proposed, including both first and second order models. Generally most authors agree that the first order kinetic model is superior. Most of the recent discussion has been centred on the form and complexity of the first order model.

It should be emphasized at this point that the complexity of a model does not necessarily imply that it is superior. On the contrary, a model should be simple enough that it can be easily utilized. If a model has numerous parameters and involves lengthy calculations it will become impractical. Moreover if the model involves equations that are non-differentiable or contains complex distributions, then it will be inflexible and manipulation of the model will be difficult.

The first attempts at modelling flotation was made by Zuniga in 1935 . He assumed that the rate of flotation may be measured by the rate at which the concentration of mineral in the pulp decreases. Thus, using the analogy with first order chemical kinetics, Zuniga proposed the following simple model of concentration $(\mathrm{C})$ changing with time $(\mathrm{t})$ :

$$
\mathrm{dC} / \mathrm{dt}=-\mathrm{kC}
$$

where $\mathrm{k}$ is the flotation constant. This is similar to the form that we consider today as the conventional two parameter first order model: 


$$
\mathrm{R}=\mathrm{RI}[1-\exp (-\mathrm{kt})]
$$

where $\mathrm{R}$ is the recovery after time $\mathrm{t}$ and $\mathrm{RI}$ is the ultimate recovery.

Schuhmann (1942) accepted Zuniga's first order equation and attempted to better understand the meaning of the flotation constant, $\mathrm{k}$. He considered that the flotation rate determining step was the particle-bubble collision. Thus he defined $\mathrm{k}$ as :

$$
\mathrm{k}=\mathrm{P}_{\mathrm{c}} \mathrm{P}_{\mathrm{a}} \mathrm{F}
$$

where $P_{c}$ is the probability of collision, $P_{a}$ is the probability of adhesion, and $F$ is the 'fruitfulness' factor. The fruitfulness factor compensated for the fact that some particles which are attached can later become detached from the bubble.

Morris (1952) modified the conventional first order model and, in doing so, laid the groundwork for the version that is widely accepted today.

After integration of equation 2.10 , the rate constant can be written as :

$$
k=(1 / t) \ln \left(C_{o} / C\right)
$$

where $C_{0}$ is the original concentration (or percentage) of flotable particles, and $C$ is the concentration (or percentage) of flotable particles remaining in the flotation cell after time $t$. The $C_{0}$ term must be introduced as a result of the integration, and although some may consider this value to be the total amount of material (or $100 \%$ ), its true value is not easily derived. As Morris (1952) explains, this is because, unless every particle is flotable, $C_{o}$ cannot be $100 \%$. It is not usual for all particles to be capable of floating, because of surface oxidation, etc. Thus, in 
equation 2.11 the condition that RI must be less than 1 is added. Agar (1985) elaborates on this concept, citing the case of binary particles: The aim of grinding is to liberate the mineral. In a real system it is unrealistic to assume total liberation of every mineral particle. These inevitable binary particles will not float as readily as pure minerals and, thus, there will always be a nonrecoverable component.

Agar (1985) also proposes a time correction factor $\phi$, and the modified first order kinetic rate equation becomes:

$$
R=R I[1-\exp \{-k(t+\phi)\}]
$$

Citing various physical phenomena which affect $\phi$ in batch testing, for example, hydrophobic particles may attach to bubbles before the air flow is turned on, in which case flotation has begun before $t=0$, thus $\phi$ would be greater than zero. Also, after the air flow is turned on $(t>0)$ seconds elapse before a full depth of froth is present, thus $\phi$ would be less than zero.

Kelsall (1961) attempted to recognize the difference between fast and slow floating components of a system. He proposed the following model (assuming $R I=1)$ :

$$
R=\left(1-F_{s}\right)\left[1-\exp \left(-k_{t} t\right)\right]+F_{s}\left[1-\exp \left(-k_{s} t\right)\right]
$$

where $k_{f}$ is the fast rate constant, $k_{s}$ is the slow rate constant, and $F_{s}$ is the fraction of floating components with the slow rate constant. 
Imaizumi and Inoue (1962) propose a model based on the distributions of the flotation rates of $\mathrm{n}$ various floatable components. The recovery being:

$$
R=\Sigma R I_{h}\left[1-\exp \left(-k_{h} t\right)\right]
$$

where $\Sigma$ is from $h=1$ to $n$. This model is known as the distributed floatability model.

Also with the concept of a particle size distribution, Panu (1976) assumed a linear dependence of flotability on particle size and a "rectangular" size distribution. Thus different rate constants can be derived for lower and upper size classes. The following equation is derived by Panu:

$$
R=\frac{R I\left\{1-\left[\exp \left(-k_{0} t\right)-\exp \left(-k_{m} t\right)\right]\right\}}{\left(k_{m}-k_{0}\right) t}
$$

where $k_{o}$ is the rate constant for the lower size of rectangular size distribution, and $k_{m}$ for the upper size.

Klimpel (1980) derived the following equation for a monodisperse material and rectangular flotability distribution:

$$
R=R I\{1-[1-\exp (-k t)] /(k t)\}
$$

Where $\mathrm{k}$ can be considered as the rate constant representing the largest allowed value of rectangular distribution. A rectangular distribution of a quantity (i.e. some values) implies that there wouldn't be any tendency to any one value, all are equally possible.

The type of mixing would also, of course, have an effect on the proposed model. Equation 2.11 assumes plug flow transport, where the residence time of all elements of 
the fluid (and all mineral particles) is the same. For example, in a flotation column, plug flow means that there is a concentration gradient of floatable mineral along the axis of the column (Finch and Dobby, 1990). The opposite would involve perfect mixing where the concentration is the same throughout the column. Thus, in contrast to equation 2.11 , the recovery for a system exhibiting perfect mixing is given as:

$$
R=1-(1+k t)^{-1}
$$

where $t$ is the mean residence time. As mixing increases, the recovery will go down. For example, when $t=8$ minutes and $k=0.4 \mathrm{~min}^{-1}$, a plug flow model (eqn. 2.11) would give a recovery of $96 \%$ and the perfect mixing model (eqn. 2.20) would give a recovery of $76 \%$.

In plant columns the actual transport conditions usually lie somewhere between the two situations just described. Any transport conditions that are intermediate as such are either described as 'tanks-in-series' or 'plug flow dispersion'. Tanks-in-series modelling is well suited to a row of mechanical flotation machines; for flotation columns, the plug flow dispersion model provides a good description of the axial mixing process. (Rice, Oliver, Newman, and Wiles, 1974). 


\section{Chapter Three}

\section{OVERVIEW OF FINE PARTICLES}

This chapter reviews fine particles and their impact on the flotation process. First an overview of fine particles is given. Then a thorough examination of the difficulty in floating fines and why this difficulty exists is conducted. Also a brief discussion of the effect that fines have on the overall flotation process is given and methods by which these fines can be sized. Finally, theoretical groundwork is laid pertaining to the specific device studied, in reference to its capacity in overcoming the inherent difficulties that exist in fine particle flotation.

\subsection{Fine Particles}

With increasing demand for minerals and continuously diminishing grade of ores, it is necessary to process as much of the mined ore that is possible. In most cases, though, it is taken for granted that there is a fraction of the ore that is unrecoverable. Usually this fraction consists of particles in the finer size ranges.

The term 'fine particle' is relative. In the pharmaceutical industry a fine particle is considered to be in the colloidal range; well under a micron. In the 
micron. This is basically because of the vast differences in ores that exists. For example, some flotable coal particles can be rather large $(>1 \mathrm{~mm})$ where as clay particles are usually in the sub 10 micron range.

In this case it is convenient to consider a fine particle as a particle whose flotability is hindered by its size. Or, in other words, the fine size range begins at the point on the size-by-size recovery graph at which there begins to be a decrease in recovery. The following graph shows a hypothetical mineral in which there is a steep decrease in recovery beginning around the 40 micron particle size range. Thus in this case a fine particle would be defined as less than 40 micron:

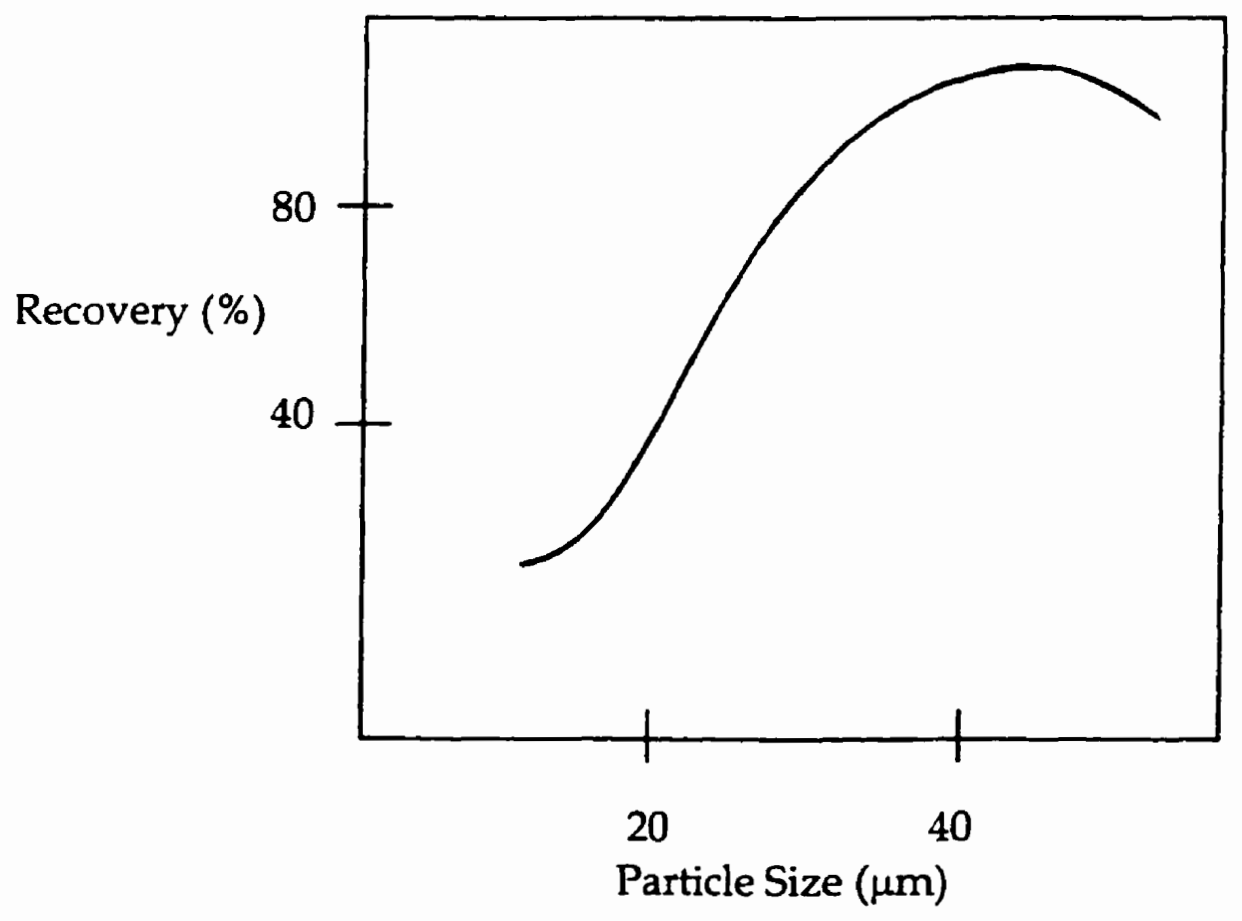

Figure 3.1 A typical Size-by-Size Recovery plot. 
Even though fine particles are created in the mining of ores, most fines are either a result of excessive grinding, soft (or brittle) material, or both. There are many cases where the desired mineral is finely disseminated. Thus to fully liberate it from the gangue (or another mineral) a high degree of grinding is required. The process of desliming is common when there exist many fines in the circuit. Desliming is necessary because fine particles will disrupt the flotation of larger particles (see section 3.3). This problem is significant: Unfortunately roughly one-fifth of the world's tungsten and one-half of the Bolivian tin are lost in slimes because of the lack of a suitable method of separation at fine particle sizes (Fuerstenau, 1980).

Due to the complex physio-chemical nature of flotation, a thorough understanding of the problems associated in fine particle flotation is required. The next two sections summarize these problems.

\subsection{The Difficulties Encountered in Fine Particle Flotation}

The probability of a particle being collected by a bubble depends on many factors. The collection of the particle basically takes place in three distinct steps. Namely, the particle surface approaching the surface of the bubble, the thinning of the film of liquid separating the bubble and the particle surface, and finally the 
rupture of this film and three phase contact taking place. In the case of a fine particle there is the possibility of 'contactless' flotation (Derjaguin and Dukhin, 1979). This occurs when the London-Van der Waals forces of molecular attraction takes place between the bubble and the particle. Though, in this work, only collection involving bubble-particle contact will be addressed.

The time taken for steps two and three mentioned above (namely film thinning and rupture forming three phase contact) is called the induction time $\left(\mathrm{t}_{\mathrm{i}}\right)$. Only while the particle is sliding around the bubble is it possible for induction to take place. This is known as the sliding or contact time $\left(t_{c}\right)$. Thus, as stated in chapter two, attachment can only take place when $t_{c}>t_{1}$.

A key factor in the ability of a particle to break through the layer surrounding the bubble is the basic physical inertial force. Any moving particle possesses this, but the magnitude of the inertial force depends significantly on the mass of the particle. Fine particles have very little mass and thus very little inertia. This is the biggest hindrance to fine particle flotation; namely the lack of inertia of the approaching fine particle. Thus, in the case of fine particles, hydrodynamic forces control the approach of the particle to the bubble instead of inertial forces (which dominate in the case of coarse particles). Figure 3.2 shows that a fine particle lacking the inherent inertia that a larger particle would have, will usually just be carried by the flow stream around the bubble. 


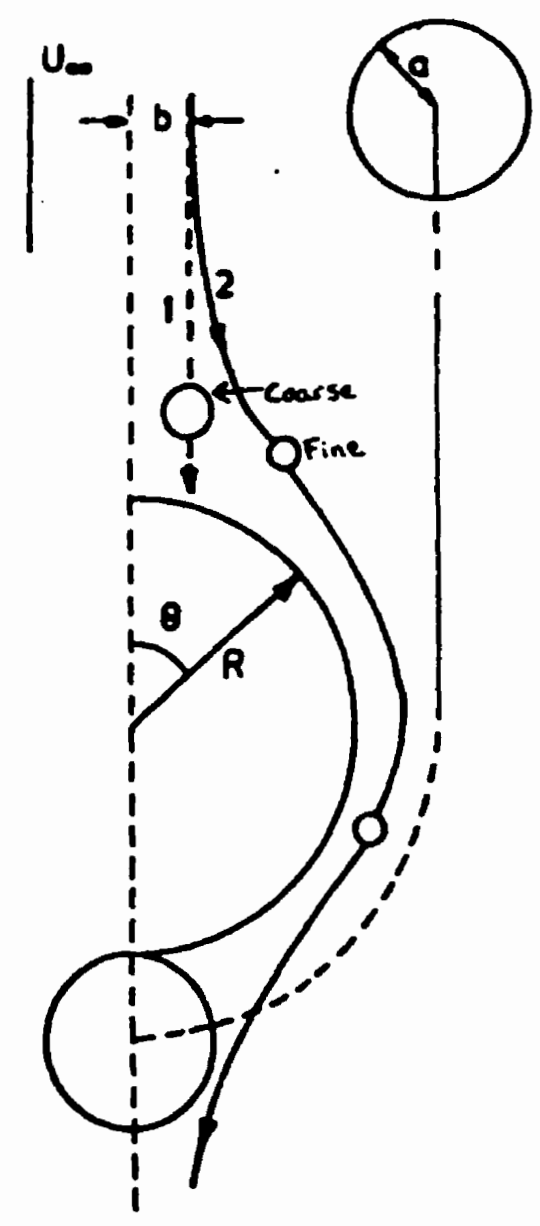

Figure 3.2 The influence of the inertia of particles on their trajectory in the vicinity of a bubble (Derjaguin and Dukhin, 1979).

During the contact time there are basic electrostatic interaction forces that exist due to the overlapping of the double layers of the particle and bubble. This electrical double layer overlap will cause a force component that will interfere with bubble-particle contact. In the case of larger particles the inertial force will usually overcome this 'disjoining' force caused by the double layers.

Other reasons why fines are difficult to float are related to the surface area of fine particles. There are two surface area terms which must be differentiated; 
namely surface area and specific surface area. The surface area of the individual fine particle is of course not very big when compared to a coarse particle. Thus there is less of a surface for the particle to attach itself onto the bubble. More importantly is the concept of increased specific surface area. Overall, the total surface area is vastly increased when particles are ground very fine. This will induce rapid oxidation of that specific mineral component in the slurry. In most cases, the existence of an oxidized layer on the surface of the mineral particle will render the particle unflotable.

In conclusion it should be stated that there are a number of variables that come into play when trying to float fine particles. A very important hindrance to the flotation of fines is the lack of 'true' bubble-particle contact. Basically fine particles do not possess the inertia required to break the flow stream around the bubble and contact directly with it (or at least the liquid layer around the bubble). In the final section of this chapter it is proposed that contact device used in this investigation could help to solve this problem. 


\subsection{Additional Problems Created by Fine Particles}

Even though the main aim of this investigation is to evaluate the ability of fine particles to float using alternative contact methods it would be beneficial at this point to digress and briefly look at the effect of fines on the flotation of other particles.

A common problem with fine particles is their tendency to become entrained in the froth. When entrainment takes place the entrained particles are not floated, rather they are physically carried into the froth by other particles and/or bubbles. This will increase the recovery of the undesired mineral and thus decrease the grade of the concentrate. This problem is dramatically reduced in column flotation in which the froth is constantly washed of these entrained particles.

Sometimes long range molecular forces between particles will cause fine particles to adhere to the larger, potentially floatable, particles. This is called a slime coating, and can be very detrimental to both grade and recovery: The larger particle can be hindered from floating due to the slime coating, resulting in reduced recovery. Or if the particle does still float, it will carry the slime coating (undesirable particles) into the froth, resulting in reduced overall grade.

The large specific surface of fine particles increases the adsorption capacity of reagents. Even small changes in particle size distribution will affect the ideal reagent dosage. Flotation is very dependent on proper reagent dosage (collector, 
modifier, activator, etc.), and will be adversely affected by inadequate amounts caused by its consumption by the fines. The specific surface energy is also higher in the case of fine particles. This may induce dissolution from the surface of the fines, introducing foreign impurities into solution. This could interfere with the 'delicate' chemistry involved in flotation. Fuerstenau (1980) provides an excellent review of the relationship between the physical and chemical properties of fine particles and their behavior in flotation, and also gives the following summary chart (figure 3.3 ):

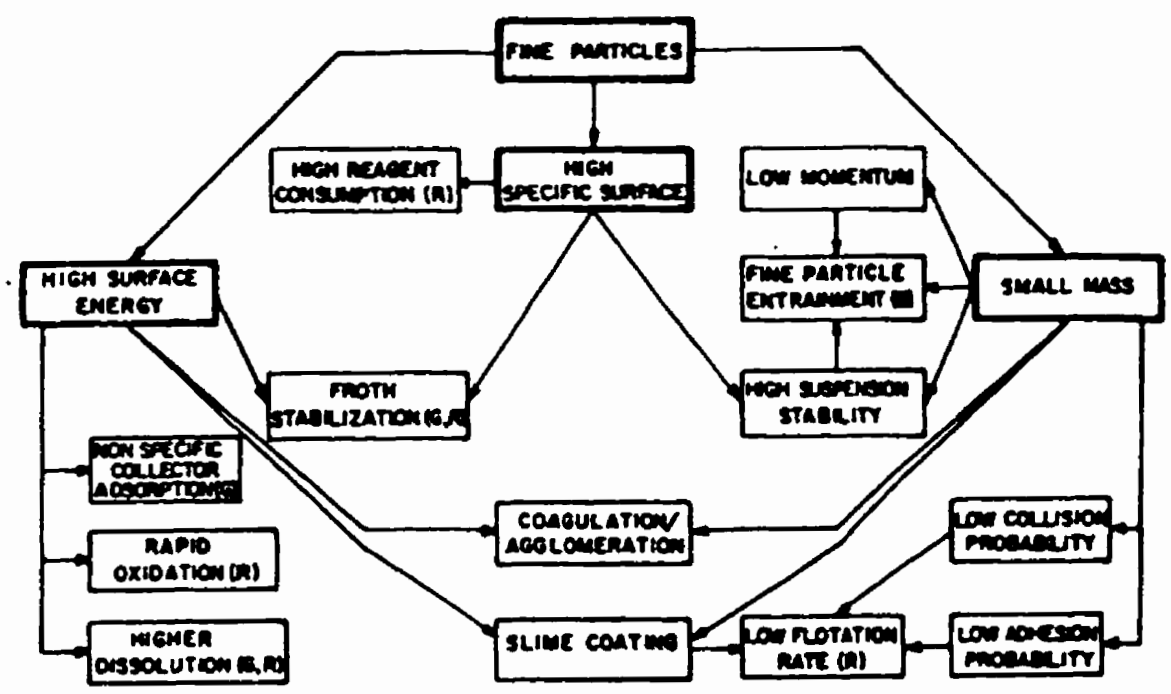

The echematic dagrae howlag the relationshlp between the phyelcal and chemical properties of fine particles and their behavior in flocation. (G) and (R) refer to whether the phenomens affects grade andor recovery. The arrows indlcate the varlous factors contributing to a particular phenowen observed in flotation of flae particles.

Figure 3.3 (Fuerstenau, 1980) 


\subsection{Fine Particle Size Measurement}

The measurement of particle size is crucial to the operation of many industrial processes. In many cases the quality of products depends to a significant degree on the particle size control when making the products. For example, many powder-based products require primary particle sizes in the less than $1 \mu \mathrm{m}$ range. In fields ranging from metallurgy to pharmaceutical, accurate particle size measurement is invaluable. Over the past two decades a large number of advanced particle sizing instruments have been developed. These work on a variety of measuring principles.

In the mineral processing industry particle size is especially crucial. As discussed in the previous section, fine particles can be quite a hindrance to flotation. As a result, accurate on-line measurement is needed to ensure that particle size is controlled in the grinding stage. Thus to be suitable for industrial mineral processing processes the sizing technique must be accurate, reliable, and commercially available as an on-line automated instrument. The following is a short review of some sizing techniques.

The most basic method of sizing particles is, of course, direct Sieving. This is simple and very low cost but usually only used for larger particles. Although recent advances in this area have provided the possibility of very fine apertures by use of porous glass. 
A very common advanced technique is the Laser Diffraction Technique. This technique involves a diffraction pattern created by an array of particles dispersed in a laser beam. Figure 3.4 shows a schematic of this device.

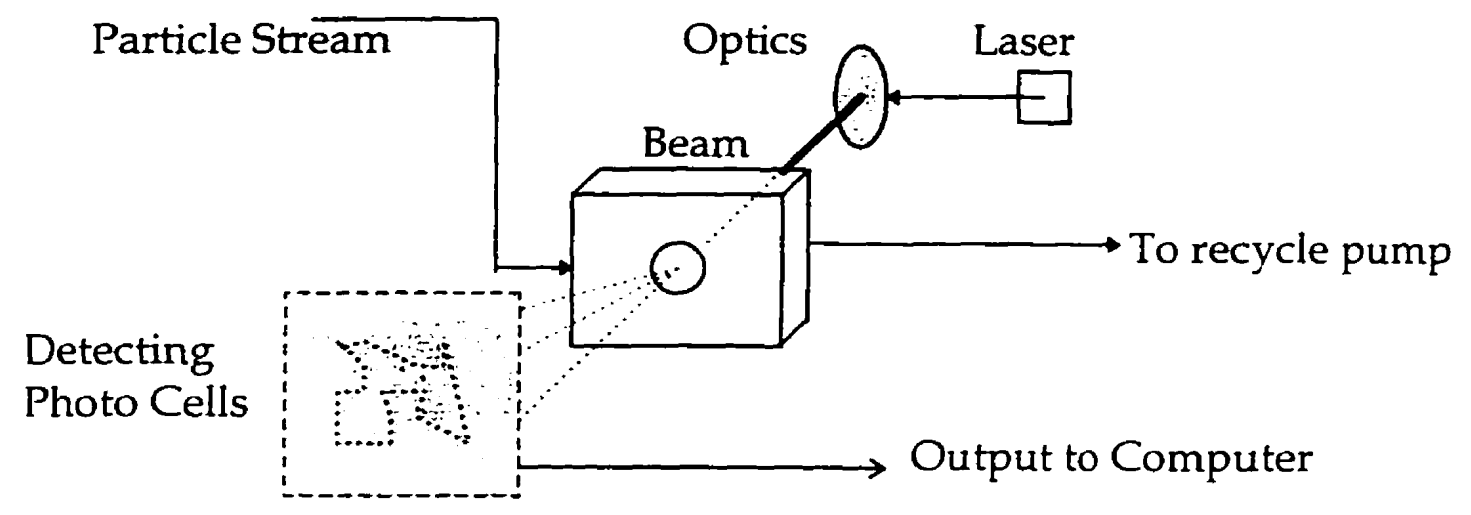

Figure 3.4 A laser diffraction particle size analyzer.

The angular variation in the intensity of the light diffracted by the particles is used to measure the size distribution of the particles. A second laser can be used to increase measurement angles, and thus allow finer particle detection. Problems will of course arise depending on the shape and orientation of the particles. For example, if the particle is plate-like (like $\mathrm{MoS}_{2}$ ) the orientation of the particle will have an effect on the measured particle 'diameter'.

There are another set of techniques known as Doppler Shift Methods: Particles that are small enough to exhibit Brownian motion can be sized using 'photon correlation spectroscopy'. A laser shines through a suspension of fine particles. The Brownian motion of the particles causes a Doppler shift in the 
reflected light. This frequency change is related to the average velocity of the fines. From this, diffusion theory and the known fluid parameters can be used to determine the particle size distribution.

Another method uses this Doppler shift to size the particles as they move across interface fringes that are produced by crossed laser beams. As they pass through these fringes 'Doppler bursts' are created by the scattered light. From this the velocity and size of the particles can be determined. Furthermore even other methods can use acoustic waves, in conjunction with Doppler effects, to measure fine particles.

Particles can be sized in an Electric Sensing Zone. This basically involves a set up in which particles which are suspended in an electrolyte are made to pass through an orifice. The orifice carries a current through two electrodes. The partial blocking of the particles (which act as resistors) will cause a voltage pulse. The pulse is, of course, related to the volume of the particle passing through the orifice at that time.

There are many other techniques that will size particles. (For example, gas adsorption and permeability techniques.) It is impossible to describe them all in this short review. Excellent reviews are found in Kaye (1995), Kaye and Trottier (1995) and Allen (1992). Now, the particle sizing technique employed in this work will be reviewed: 
The Brinkmann Particle Size Analyzer utilizes the 'Time of Flight' technique to size particles. Here, a scanning laser beam (rotating on a scanning wedge prism) focuses on a stream of particles flowing through a small rectangular cell (see figure 3.5). The size is deduced from the time of flight of a particle as the laser beam crosses it. Many particles are measured and a size distribution plot is generated. An in-depth explanation of the procedure associated with the Brinkmann is given in section 4.4 .

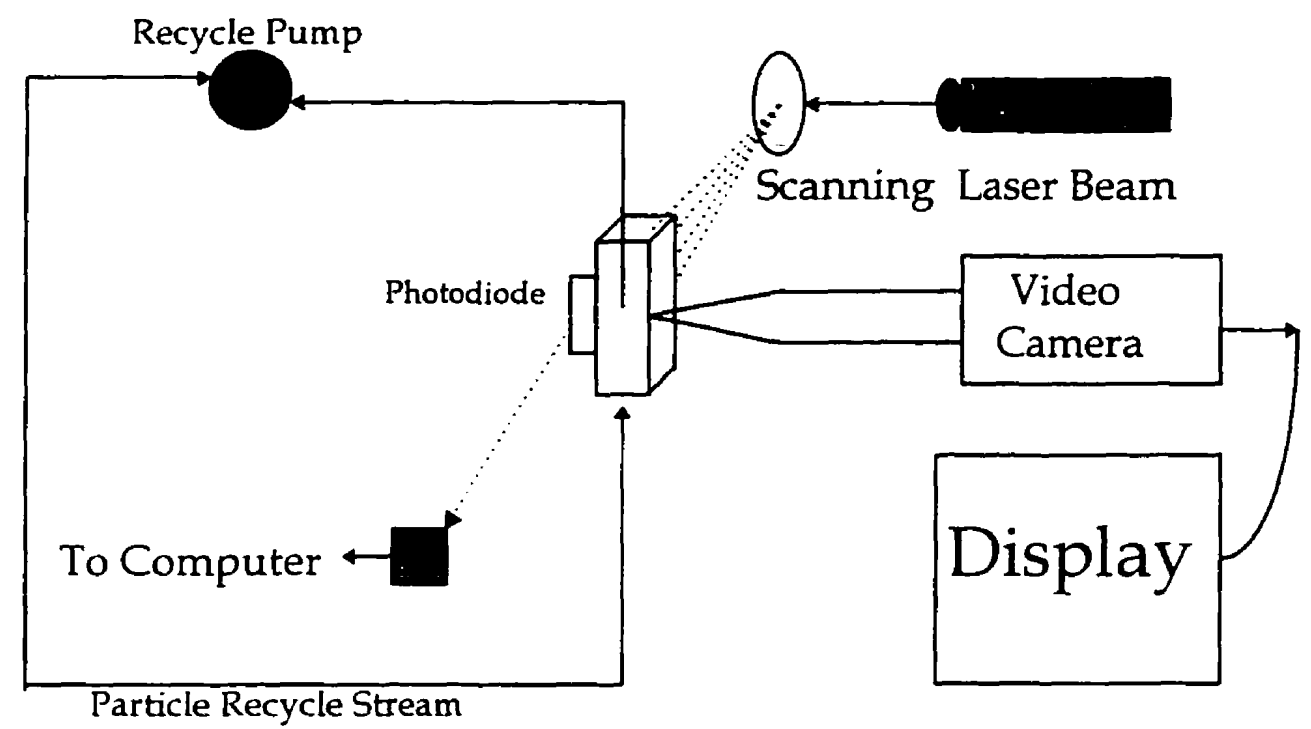

Figure 3.5 The Components of the Brinkmann Particle Size Analyzer.

The theory behind the Brinkmann can be summarized as follows: The actual scanning is made in a 300 micron diameter circle at a fixed frequency. The particles are scanned when they pass through this area. Pulses are generated by these particles (as a result of the laser beam). The pulses are detected by a 
photodiode located behind the cell. The pulse width represents the time that the surface of the particle interacts with the laser beam. The change in light intensity is related to the actual dimension (or height) of the particle. These provide direct parameters to measure the size of the particle.

Another interesting aspect to this device is the ability to visually gain a qualitative understanding of the shape of the particles. This is done using a camera and a display monitor within the device. The microscopic camera is focused inside the cell allowing direct viewing of the particles. This is helpful in determining if the particles are agglomerated or if they are oddly shaped. 


\subsection{The Aim of This Work}

As discussed in section 3.2, a key difficulty encountered when trying to float fine particles is the inherent lack of inertial force they possess. This is due to the very small mass of the particle. In a relatively passive environment, like a flotation column, the fine particle is not brought into contact with bubbles under 'relatively' turbulent conditions. Thus the coursing bubble contact that takes place in a column even enhances the inertial problems of fines. The aim of this thesis is to investigate a device which could overcome these problems.

The contact device, as mentioned in chapter two and quantitatively described in the next chapter, allows for bubble-particle contact to be made outside of the column. The high superficial velocity of the slurry flowing through the porous tube shears off the gas bubbles while they form on the inside walls of the tube. The slurry-bubble mixture is then pumped back into the column via the collection tube. The high superficial velocities inside the contact device create an extremely turbulent environment.

It is this turbulent environment that ensures two things, namely that many fine particle-bubble collisions take place, and that these collisions are high energy. This means that the passive bubble coursing contact inside the conventional column is replaced by very high energy bubble-particle collision environment in the external contact device. 
The number of collisions (and the high energy associated with the contact) greatly increases the probability of attachment of fine particles to bubbles. It is proposed that, as a result of this, the contact device is efficient as a fine particle collector. In addition to turbulence, the average bubble size can also, theoretically, be controlled by varying the superficial slurry velocity through the tube. As discussed in chapter two, it has been suggested that small bubbles are needed to float fine particles. Thus conditions inside the contact device, theoretically, can be adjusted to maximize recovery of fines.

The experiments described in the following chapters aim to investigate the contact device in its capacity as a fine particle collector. An attempt has been made to determine the conditions and parameters at which recovery of fines is maximized using the device. Design parameters such as contact tube length, pore size, superficial slurry velocity, collection tube length, and column length are all investigated. The procedure, results and conclusions are presented in the next three chapters. 


\section{Chapter 4}

\section{Experimental Design, Set-up and Procedure}

There are three major experimental parts to this investigation:

1) Column Flotation of Molybdenite utilizing the external Contact Device.

2) Flotation of Molybdenite using a conventional LEEDS cell.

3) Particle size analysis of the feed, concentrate and tailings samples generated in parts 1 and 2 using a Brinkmann Particle Size Analyzer.

A thorough review of the design, set-up and procedure of each part is given in this chapter.

\subsection{The Laboratory Flotation Column and Contact Device}

A modified flotation column was used. The modification is the utilization of an external bubble generator / particle-bubble contacting device. Here collection is induced outside of the column with the column itself acting primarily as a separation chamber. 


\subsubsection{Design and Setup of the Column}

A $3.2 \mathrm{~cm}$ by $1.8 \mathrm{~m}$ modular flotation column made of clear $6 \mathrm{~mm}$ thick Plexiglas (acrylic), and consisting of a number of $31 \mathrm{~cm}$ lengths was used for the present study. Though the column was kept at $1.8 \mathrm{~m}$ for all but one of the flotation tests, the overall length of the column can vary from 1 to $3 \mathrm{~m}$. Specialized lengths were available for the tailings output, froth overflow, and recycle stream input and output areas of the column. Two ports were located in each of the $31 \mathrm{~cm}$ lengths. These can be used as either feed injection ports or manometer ports (for automated level control). The feed injection port was kept at the $2 / 3$ to $3 / 4$ mark from the bottom of the column (or about $12 \mathrm{~cm}$ below the froth/pulp interface level). The feed was pumped from an agitated 10L feed bucket. A schematic of the laboratory column set-up is given in Figure 4.1.

Peristaltic pumps were used for the following streams: feed, tailings, recycle, and wash water. The feed and tailings pump's controls were automated using a PC. The recycle slurry rate was controlled using two pumps operated by a manual DC drive controller. A tachometer was used to monitor pump speed. The wash water pump is also manually controlled but kept at a constant volumetric flowrate. The wash water was injected by dripping it into the top layer of the froth using seven, $1 \mathrm{cc}$ syringes.

Nitrogen gas was used for all flotation testing in this investigation. The gas flowrate into the contact device was controlled by a mass flow controller which, 
in turn, was controlled using a PC. The gas rate was kept constant for all column flotation tests.

In addition to feed and tailings pumps and gas flow rate, the column set-up also allowed for computerized control of froth-pulp interface level. This level was detected using water manometers. This form of level control basically involved pressure readings taken at 3 known heights of the column (one of these, in the froth phase) using pressure transducers. Each pressure head was visually displayed on a Plexiglas 'wall' behind the column using plastic tubing. The level was constantly determined (using the transducer signals) and automatically adjusted (by varying the tailings pump rate) via a PC input/output data acquisition and analog output unit. For the $1.8 \mathrm{~m}$ long column, froth depth was maintained at approximately $30 \mathrm{~cm}$. The control scheme theory is as follows:

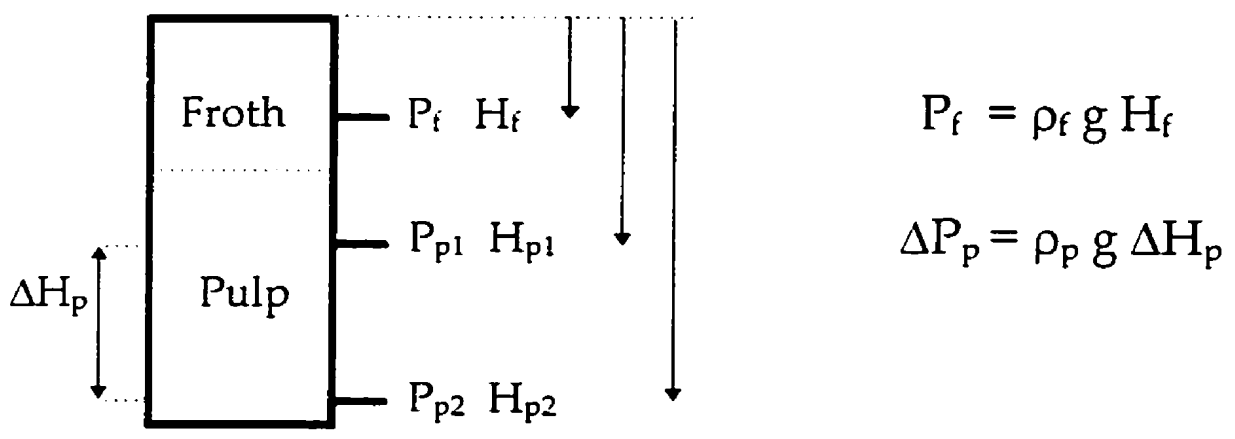

Where $\mathrm{P}$ is the pressure, $\mathrm{H}$ is the height from the overflow point of the column, and $\rho_{f}$ and $\rho_{p}$ are the respective froth and pulp densities. The interface height $\left(\mathrm{H}_{\mathrm{x}}\right)$ is found by taking a pressure balance at a point in the pulp $\left(\mathrm{H}_{\mathrm{y}}\right)$ :

$$
P_{y}=\left[\rho_{f} g H_{x}\right]+\left[\rho_{p} g\left(H_{y}-H_{x}\right)\right]
$$




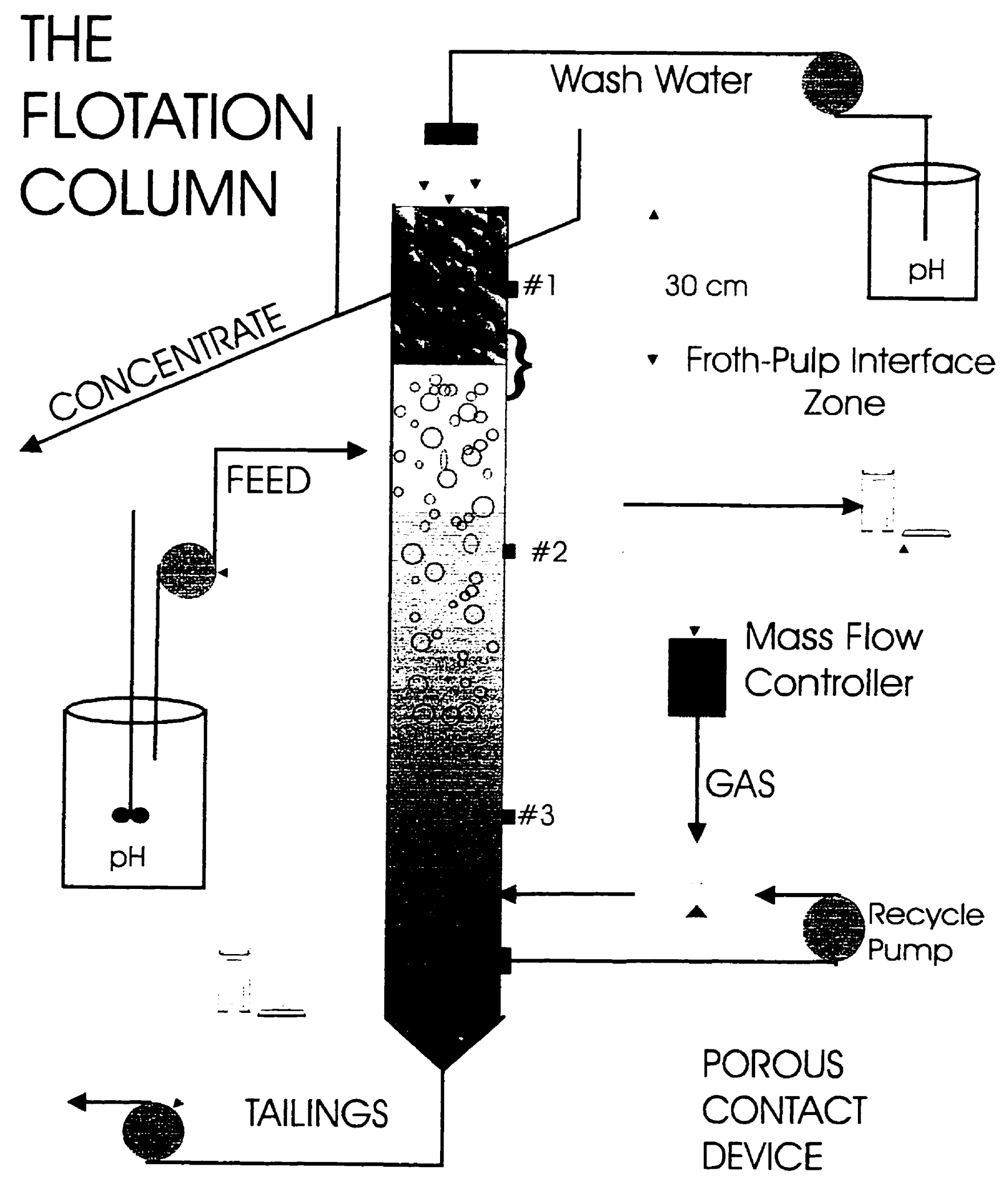

Figure 4.1 


\subsubsection{Design of the Contact Device}

As seen in figure 4.1, the Contact Device is fitted on the recycle stream taken from (and injected back into) the bottom section of the column. The device consists of 4 main parts; the porous tube, the rigid jacket, the gas line, and a length of vinyl tubing. The device is shown in figure 2.7 .

The rigid porous tube (acquired from MOTT Metallurgical Corp.) is made of stainless steel. It has an inner diameter of $6 \mathrm{~mm}$ and a wall thickness of $1.5 \mathrm{~mm}$. The jacket that fits around the porous tube is made from $2 \mathrm{~cm}$ diameter copper tubing, and consists of the tubing itself and three separate fittings; two reducing fittings at either end to allow the plastic tubing to seal it, and a three-way Tfitting in the center to allow for the gas injection. All fittings were joined using lead/tin solder.

The plastic tubing that carries the recycle stream from the column, into the contact device and back to the column, was clamped tightly on to the ends of the copper jacket. This securely closed the jacket creating an air-tight seal at both ends. The slurry, after flowing through the porous tube, then flows through a length of plastic tubing called the collection tubing. The length of this tubing is an important parameter and it was fitted such that various lengths can be used.

Three lengths of porous tube and two pore sizes were investigated. Thus a total of 6 contact devices were constructed. About $2 \mathrm{~cm}$ of the end portions of 
the porous tubes needed to be blocked by the plastic tubing in order to create a proper seal. As a result, there is a difference between the total length of the tube and the effective contact length; the effective contact length being defined as the length of porous tube in which the gas is free to diffuse through the pores and come in contact with the incoming slurry. The lengths of the porous tube were cut such that the effective contact length doubles. The following table summarizes the 6 contact devices constructed:

\begin{tabular}{l|ccc} 
Sparger \# & $\begin{array}{c}\text { Pore Size } \\
\text { (micron) }\end{array}$ & $\begin{array}{c}\text { Total Length } \\
(\mathrm{cm})\end{array}$ & $\begin{array}{c}\text { Effective Contact Length } \\
(\mathrm{cm})\end{array}$ \\
\hline 1 & 2 & 19 & 14 \\
2 & 2 & 33 & 28 \\
3 & 2 & 61 & 56 \\
4 & 10 & 19 & 14 \\
5 & 10 & 33 & 28 \\
6 & 10 & 61 & 56
\end{tabular}

Table 4.1 The six contact devices used in testing. 


\subsection{Column Experimental Procedure, Conditions and Materials}

Due to the need to investigate various parameters relating to the actual contact device, other variables (such as gas flow rate, frother dosage, feed rate) were kept constant. Preliminary testing was conducted to determine the optimum conditions related to these variables:

$5 \mathrm{ppm}$ Dowfroth $250 \mathrm{C}$ was used as the frothing agent for all tests. The feed rate of slurry into the column was kept constant at $20 \%$ of max. pump speed or $340 \mathrm{ml} / \mathrm{min}$. (The tailings pump rate was automatically adjusted to maintain level control.) Nitrogen was used for all tests and gas rate was kept at a volumetric flowrate of $800 \mathrm{~cm}^{3} / \mathrm{min}$ flowing into the contact device. The feed concentration was prepared to run at $5 \%$ solids. The wash water flow was kept constant at $130 \mathrm{ml} / \mathrm{min}$. The froth depth was maintained at around $30 \mathrm{~cm}$ (but varied $+/-\sim 2 \mathrm{~cm}$ during a test).

The preparation procedure was kept identical for each test. The feed slurry was made immediately before each test. The procedure for this involved adding a small amount of tap water to $500 \mathrm{~g}$ of dry $\mathrm{MoS}_{2}$ concentrate and mixing it in a conventional kitchen blender for about $3 \mathrm{~min}$. This succeeded in breaking up the feed which tends to 'ball up' when dry. This was added to more tap water for a total of $10 \mathrm{~L}$ of water in the agitated feed bucket. This was then dosed with the frother and lime. Lime was used to adjust the $\mathrm{pH}$ to 10.4 (required for $\mathrm{MoS}_{2}$ 
flotation). More tap water (in a separate bucket) was dosed with lime and frother to be used as wash water and initial column set-up water.

The contact device was fitted in the recycle stream and oriented vertically to discourage large bubbles from forming inside the tube. (If this is not done, the large bubbles will eventually become detached and rise through the column as a large bubble 'cap', which affects froth stability.) The operation of the controls was initiated and injection of the feed into the column was started. (The key to this is ensuring that the gas is flowing into the porous tube before the recycle slurry is initiated. If this is not done, the solids in the slurry stream will flow back through the pores, clogging them up.) Samples of the feed and tails were taken after the column had 5 minutes to stabilize at the set conditions. This was needed because whenever changes to the recycle slurry rates are made, the level control is affected. If further feed was needed, it was prepared and added to the feed bucket during operation of the column. The froth was allowed to overflow the lip of the column into the launder. When samples were taken, the overflowed froth product was quickly washed into the sample bucket. The process flowsheet for the column tests is shown in figure 4.2. 


\section{PROCESS FLOWSHEET FOR COLUMN TESTS}

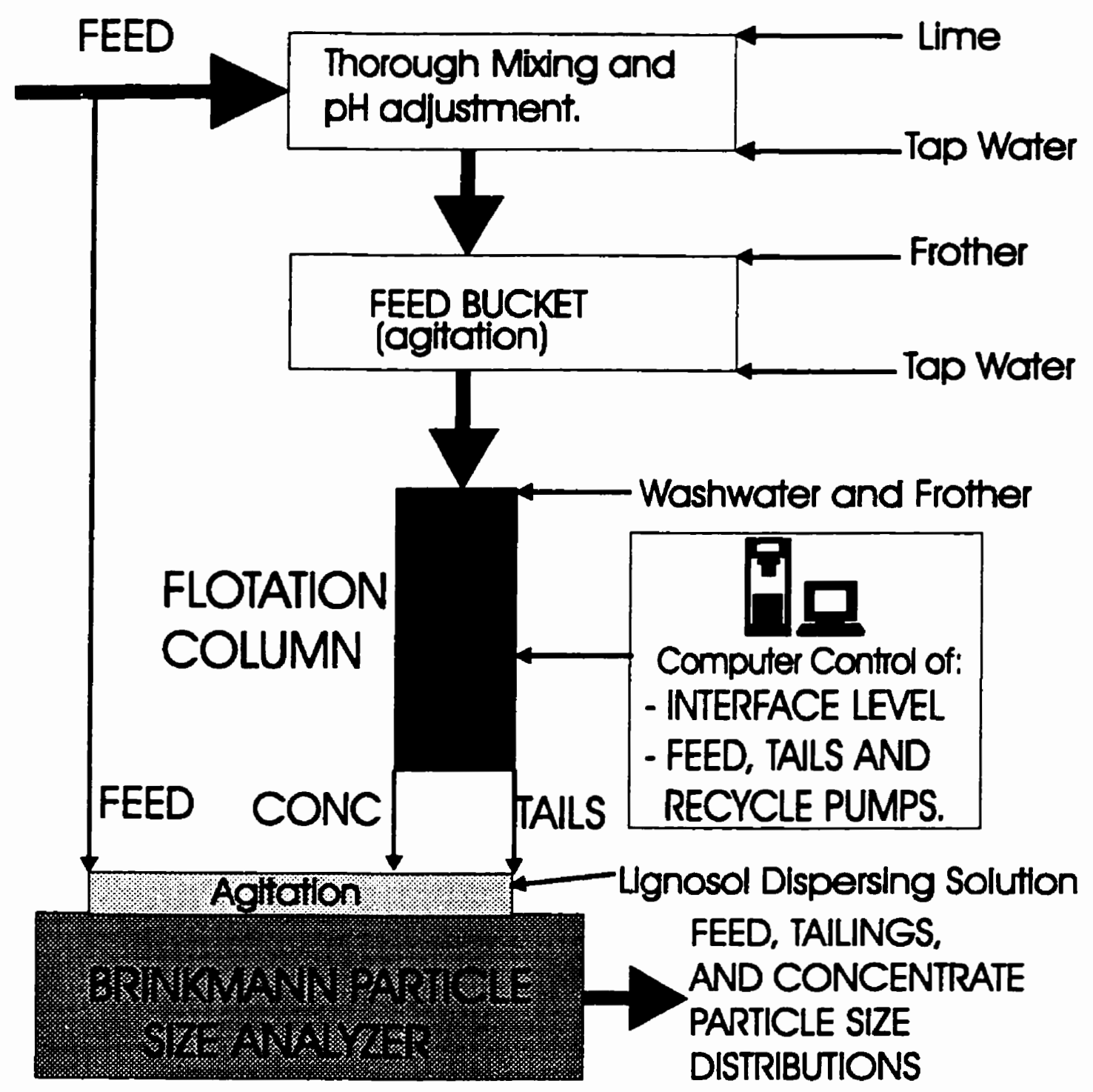

Figure 4.2

The actual testing scheme is briefly summed-up as follows:

For the tests involving the varying of recycle rates the long contact device with 2 micron pore size was used. The recycle pump set rate was varied from 2- 
16 representing a change in superficial slurry velocity (through the porous tube) of between 16 and $227 \mathrm{~cm} / \mathrm{s}$. The tests involving the varying of contact device pore size and length were carried out using six different devices (described in table 4.1) each at a slurry recycle rate of $100 \mathrm{~cm} / \mathrm{s}$. The length of the collection tube was varied from 0 to $320 \mathrm{~cm}$ at a recycle rate of $100 \mathrm{~cm} / \mathrm{s}$ using the long contact device with 2 micron pore size. Also, on-line gas holdup measurements were performed to determine the effect of superficial slurry velocity on gas holdup. The long, 2 micron contact device was used for this. After each change in recycle rate, the column was allowed to stabilize for 4 minutes before the next gas holdup measurement was taken.

The final test involved changing the feed input and column length. The feed was placed directly into the recycle stream and the column was shortened to $1 \mathrm{~m}$. The operation of the $1 \mathrm{~m}$ length column was a little different from that of the $1.8 \mathrm{~m}$ column. The level control scheme did not work at this length (probably because the recycle input to the column affected the pressure readings); thus the level was controlled by manually adjusting the tailings pump. AIl other parameters were kept the same as in the previous tests.

All concentrate and tailings samples were taken simultaneously for about 1-3 minutes, representing about $500-800 \mathrm{ml}$ of tailings and $100-200 \mathrm{ml}$ of concentrate. These were immediately sized by taking small representative amounts of each sample (see section 4.4.2 for particle sizing procedure). The samples were filtered using a venturi-type Buckner filter, dried in a drying oven, 
and weighed. The following table summarizes all the conditions and parameters involved in the column flotation tests:

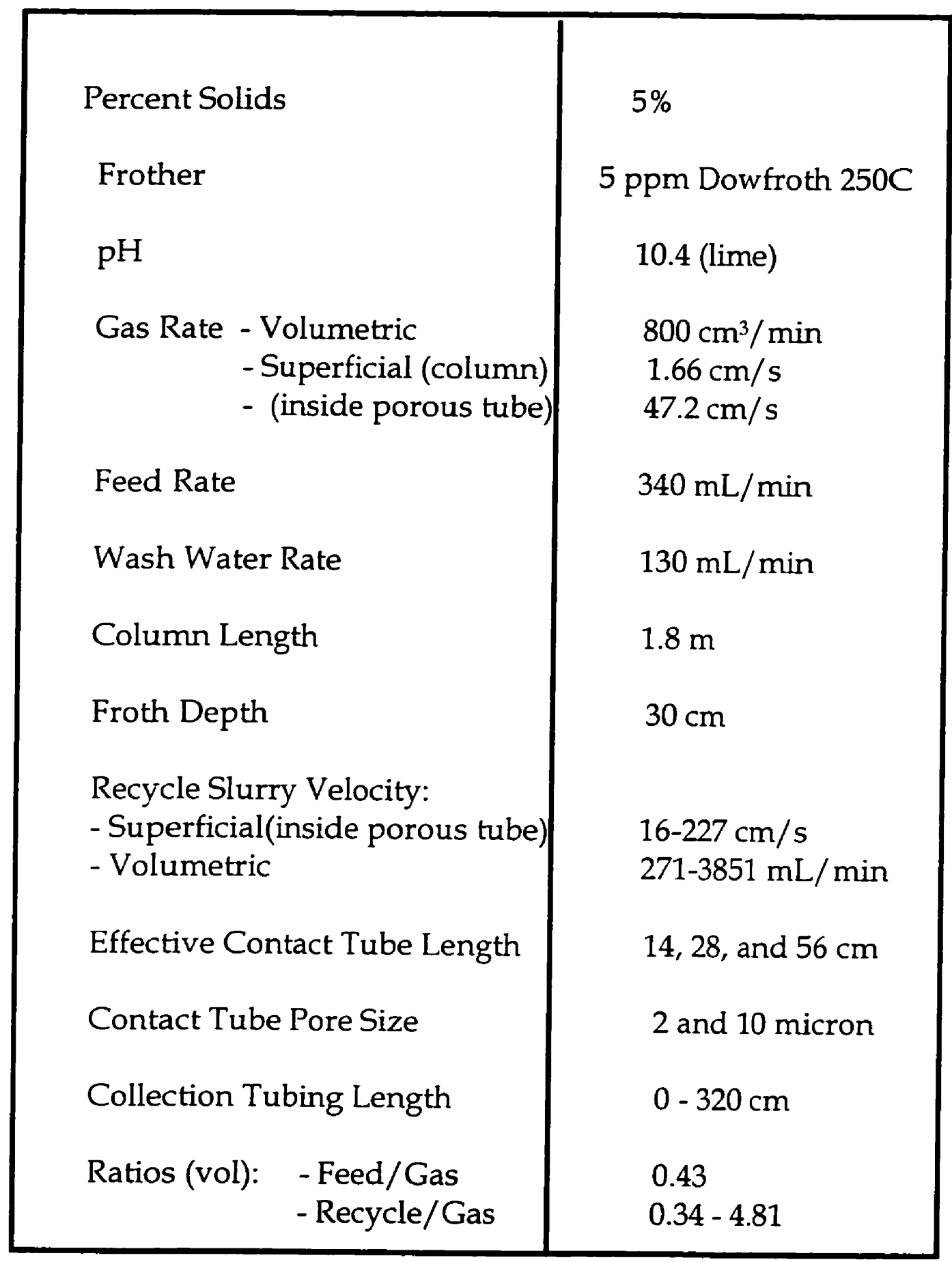

Table 4.2 The conditions and parameters of the column flotation tests. 


\subsection{The LEEDS Cell}

An interesting part of this investigation involves the utilization of a conventional flotation cell. This was done purely for comparative purposes. A LEEDS flotation cell was chosen because a bench-top model was available.

The reason for the comparison is as follows: As previously mentioned, a conventional flotation column is generally inefficient at recovering fines. This is due to the relatively non-turbulent nature of the 'coursing bubble method' of bubble-particle contact that takes place inside a column. The LEEDS cell provides a much more turbulent environment and thus a greater opportunity for 'hard to attach' fines to come in contact with and attach to bubbles. Because the Contact Device also theoretically allows for these turbulent conditions, a comparison of the size-by-size recovery between it and the LEEDS cell would prove interesting.

\subsubsection{The Set-up of the LEEDS Cell}

The LEEDS cell consists of a square, clear $14.5 \mathrm{~cm} \times 14.5 \mathrm{~cm} \times 16 \mathrm{~cm}$ high Plexiglas cell. Agitation is achieved by an impeller which comes into the cell from the bottom and is driven by a motor encased in a stainless steel compartment on which the cell sits. The agitator can be set, manually, to speeds varying from 0 to $1800 \mathrm{rpm}$. 
The nitrogen gas is injected directly into the center of the impeller region at the bottom of the cell, via a stainless steel tube. The gas flowrate can be set, manually, to rates varying from 0 to $10 \mathrm{~L} / \mathrm{min}$ using a gas flow meter and adjuster mounted above the unit.

The level of the froth-slurry interface is automatically controlled. This is done using a diaphragm that sits on the inner back wall of the cell. The liquid inside the cell exerts pressure on this diaphragm. This pressure is transferred, via a water filled length of tubing, to a pressure transducer which, in turn, controls a solenoid switch. This solenoid switches opens a valve that allows a stream of water to flow into the cell when the froth-slurry interface level is too low. The level is set to a predetermined height prior to the experiment.

The entire top of the cell is open, thus allowing the froth to overflow the lip of the front wall. The froth is skimmed at 5 second intervals using a plastic paddle. After the flotation test is completed, the material left in the cell consists of the tails and can be removed by opening a plunge valve at the bottom of the cell. A schematic of the LEEDS flotation cell is given in figure 4.3. 


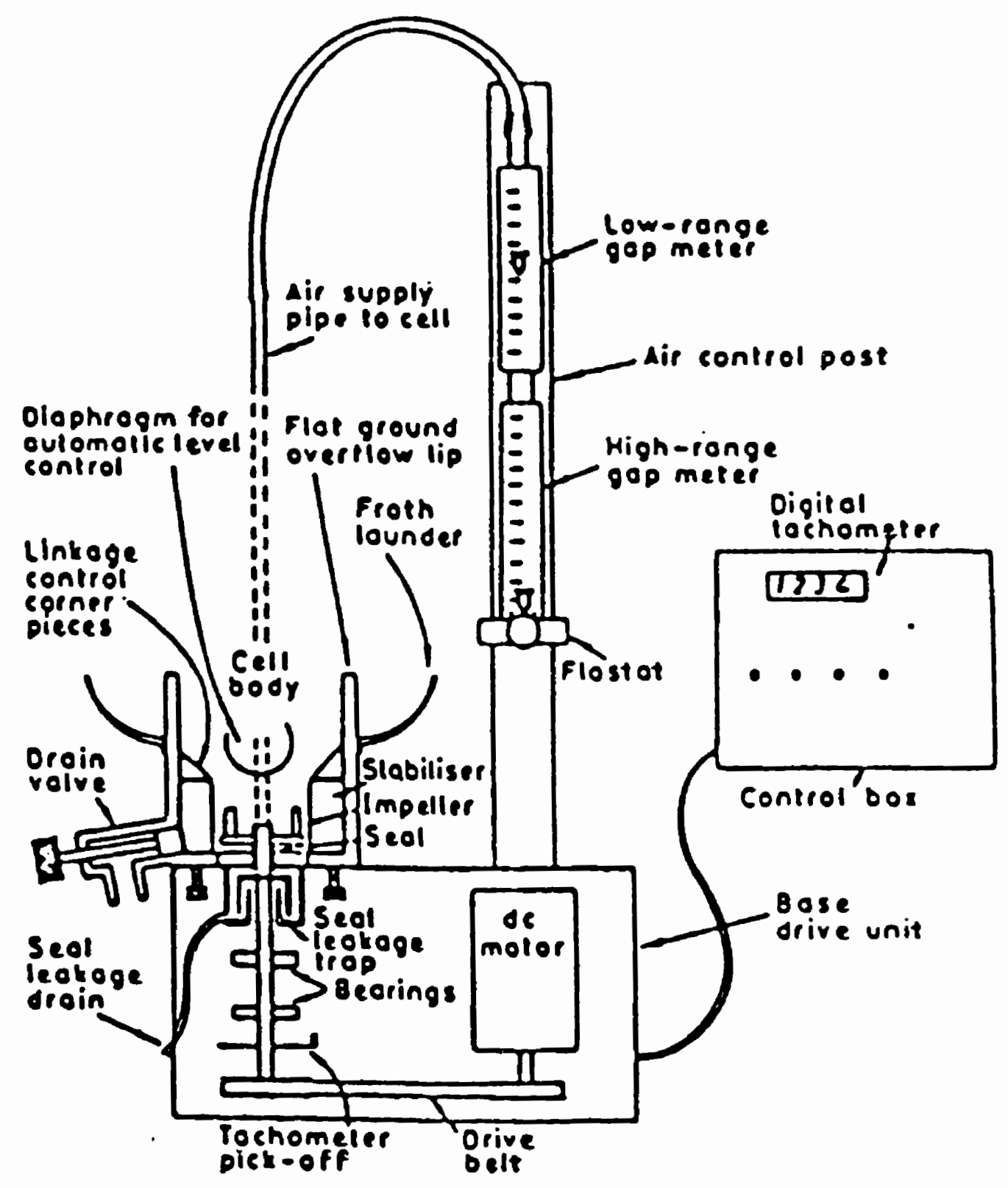

Figure 4.3 The LEEDS flotation cell. 


\subsubsection{The Procedure of LEEDS Cell Tests}

Preliminary testing with the LEEDS cell indicated an ideal froth depth of 3-4

cm. In order to achieve this, the volumetric capacity of the cell was determined to be $2.5 \mathrm{~L}$ of slurry. To create a slurry consisting of approximately $5 \%$ solids (the same as in the column tests) $\mathbf{1 2 5} \mathbf{g}$ of dry feed was used.

The Molybdenite feed was prepared in an identical manner as in the column flotation procedure. The $\mathrm{pH}$ of the slurry was adjusted to 10.4 (using lime) and $10 \mathrm{ppm}$ of Dowfroth $250 \mathrm{C}$ was used as the frothing agent. All the conditions for the LEEDS cell tests are summarized in the following table.

\begin{tabular}{|l|l|}
\hline Percent Solids & $5 \%$ \\
Frother & $10 \mathrm{ppm}$ Dowfroth $250 \mathrm{C}$ \\
$\mathrm{pH}$ & 10.4 (lime) \\
Gas Rate & $5 \mathrm{~L} / \mathrm{min}$ \\
Impeller Rate & $1700 \mathrm{rpm}$ \\
Froth Depth & $3-4 \mathrm{~cm}$ \\
\hline
\end{tabular}

Table 4.3 Conditions for the LEEDS cell flotation tests. 
Entrainment in the LEEDS cell poses a significant problem because the froth cannot be 'washed' as in the column system. In an attempt to counter this problem, the material was floated twice, that is, the concentrate from the initial float was refloated. This procedure should effectively weed out many 'unfloatable' particles that were entrained in the initial flotation.

Due to the hydrophobic nature of the feed, most of the flotation takes place within the first minute of the test. Thus a total flotation time of between 4-8 minutes was adequate to recover all of the 'floatable' material. Both flotation tests (the initial float and the refloat) were conducted for 8 minutes.

Before the initial flotation, the feed/tapwater/frother/lime slurry was conditioned for 5 minutes. During this time the cell was run at an impeller rate of $1700 \mathrm{rpm}$ without any gas. When the float was about to begin the gas was turned on to $5 \mathrm{~L} / \mathrm{min}$. The impeller rate and gas flowrate were kept constant (at $5 \mathrm{~L} / \mathrm{min}$ and $1700 \mathrm{rpm}$ ) during the test.

The six concentrate samples were taken at $15 \mathrm{sec}, 30 \mathrm{sec}, 1 \mathrm{~min}, 2 \mathrm{~min}, 4 \mathrm{~min}$, and $8 \mathrm{~min}$. Then the tailings were emptied and all the initial concentrates were returned to the cell. The cell was filled up to the $2.5 \mathrm{~L}$ mark with water and dosed with lime and frother. The refloat was done in the same manner as in the initial float. Small samples of the concentrates and a tailings sample were taken to be sized. The cell was drained and cleaned, and the refloat tails was added to the initial tails. For the initial float, a feed and a small tailings sample and 6 small concentrate samples were taken for sizing (see Particle Sizing Procedure). The 12 
main concentrate samples and the 1 main tailings sample were dewatered, dried, and weighed.

\subsection{Particle Size Analysis}

An integral part of this investigation was the determination of the effect of various parameters on the ability of the contact device to recover particles in the finer size range. Due to the need to have very accurate size analysis of particles below 100 micron (specifically 3 - 40 micron) an advanced particle sizing method was required. A Brinkmann Particle Size Analyzer was used for this purpose.

\subsubsection{The Brinkmann Particle Size Analyzer}

The Brinkmann Particle Size Analyzer (model 2010) proved to be an effective particle size measurement device for the required size range in this investigation.

The technique utilized by the Brinkmann is called a "Time-of-Flight" measurement. This technique involves a scanning laser beam probe that basically measures the 'time of flight' of a moving suspended particle. This sizing technique was reviewed in section 3.4. Also a camera is fitted inside the unit, so that a video picture of the particles is displayed on a monitor. This visual aspect of the device proved very valuable when a qualitative determination of the shape of the particle is desired. Preliminary testing involved the usage of this camera to ensure that the particles were not agglomerated. 


\subsubsection{The Particle Sizing Procedure}

When sizing any type of particles it is extremely important to ensure that the particles are dispersed. If any coagulation occurs, each agglomerated mass of particles may appear as one large particle. Thus the particle size values will not be accurate and will tend to be oversized. Due to this, an integral part of the particle sizing procedure involves ensuring that there exists a homogeneous dispersion of single particles.

In the case of molybdenite, the problem of dispersion is even more pronounced. Molybdenite is naturally very hydrophobic. Due to the need to suspend the samples in a liquid in order to size it using the Brinkmann, an effective dispersing agent was needed. A solution of Lignosol fully dissolved in water $(0.5 \mathrm{~g} / \mathrm{l})$ was used for this purpose.

The Lignosol solution was not enough to ensure a proper dispersion. Once dried, the surface of molybdenite is extremely hard to 'wet'. Thus it was important that the samples were examined immediately after flotation, while the particles were still wet. In the case of the concentrate, the froth was sampled directly. Various parts of the froth were sampled, and the samples were mixed and immediately sent through the Brinkmann. This sample was placed in $30 \mathrm{ml}$ of the Lignosol solution and agitated creating a dilute dispersion of particles.

To keep the flow through the Brinkmann constant, it was decided not to use a conventional cell (beaker) with input and output tubing lines, which may lead to 
settling of particles in the beaker. Rather a funnel was used, with only $5 \mathrm{ml}$ of liquid kept in it at all times. This essentially created a loop of flowing liquid through the Brinkmann. Very narrow tubing lines, carrying the pumped liquid samples to and from the Brinkmann, were used ensuring that the velocity of the liquid was fast enough to keep any larger particles from settling in the lines. A schematic of the particle size analyzing procedure is shown in figure 4.4 . 




Figure 4.4 
The samples were run through the Brinkmann for 5-10 minutes each (until a $95 \%$ confidence level was reached), at which point the sizing was terminated and the particle size distribution was attained.

This was done for all feed, tailings, and concentrate samples. The size distribution data was entered into a PC for analysis. The tailings and concentrate data are used, along with the known overall recoveries, to 'normalize' each particle size range. There are 22 particle size ranges which vary from 0 to 100 micron. Using the normalizing procedure, a recovery for each particle size range was determined. As a result, size-by-size recovery plots were generated. In the finer size ranges the plots show a single averaged data point to reduce clutter. The raw Brinkmann data, the individual size raige recoveries, and a review of the normalizing procedure are given in the Appendices 3 and 4 .

Also, in Appendix 7, a brief statistical analysis is presented reviewing the calibration and accuracy tests performed with the Brinkmann using particle size standards. Three standards were used spanning the desired range of particle size detection required for this work; 5,25 and $100 \mu \mathrm{m}$. It was found that deviation from the standard values were small: $+/-4.7-m$ for the $100-m$ standard, $+/-1.13-\mathrm{m}$ for the $25-\mathrm{m}$ standard, and $+/-0.74-\mathrm{m}$ for the $5-\mathrm{m}$ standard. 


\section{Chapter Five}

\section{RESULTS AND DISCUSSION}

A thorough review and analysis of the results attained from the laboratory flotation tests performed are given in this chapter.

\subsection{Initial Comments}

\subsubsection{The Feed Material Size Analysis}

The material chosen to use as the feed in the flotation tests was a high purity Molybdenite concentrate obtained from Highland Valley Copper in British Columbia, Canada. The material is almost pure $\mathrm{MoS}_{2}$ with small impurities like Bornite and other copper minerals. In choosing the feed material there were two main criteria considered: Firstly the material needed to have both an ample amount of fines and non-fines such that a comparison of the flotability of both these components could be made. This of course is necessary due to the aim of the investigation; namely, the characterization of the contact device as a fine particle collection device. The second considered criteria in choosing the feed material was the ease of handling; laboratory flotation tests are not easy to perform and, ideally, feed handling and preparation should be kept relatively simple. 
The molybdenite concentrate met both these criteria: It required no collector addition because the collector (diesel oil), used in its initial concentration, still remained on the surface of the solids. In addition, MoS is quite stable and will not oxidize quickly when exposed to air. It is also hydrophobic and readily floats, thus, it can possibly be assumed that the cause of poor fine particle flotation performance is (more or less) due to particle size. In terms of size distribution, the average (mean) particle size was about $35-40 \mu \mathrm{m}$. This is the upper range in which 'fine particles' will be defined. Therefore there is an abundance of both fine and larger particles in the feed. The size distribution of a representative sample of the feed material is shown in figure 5.1.

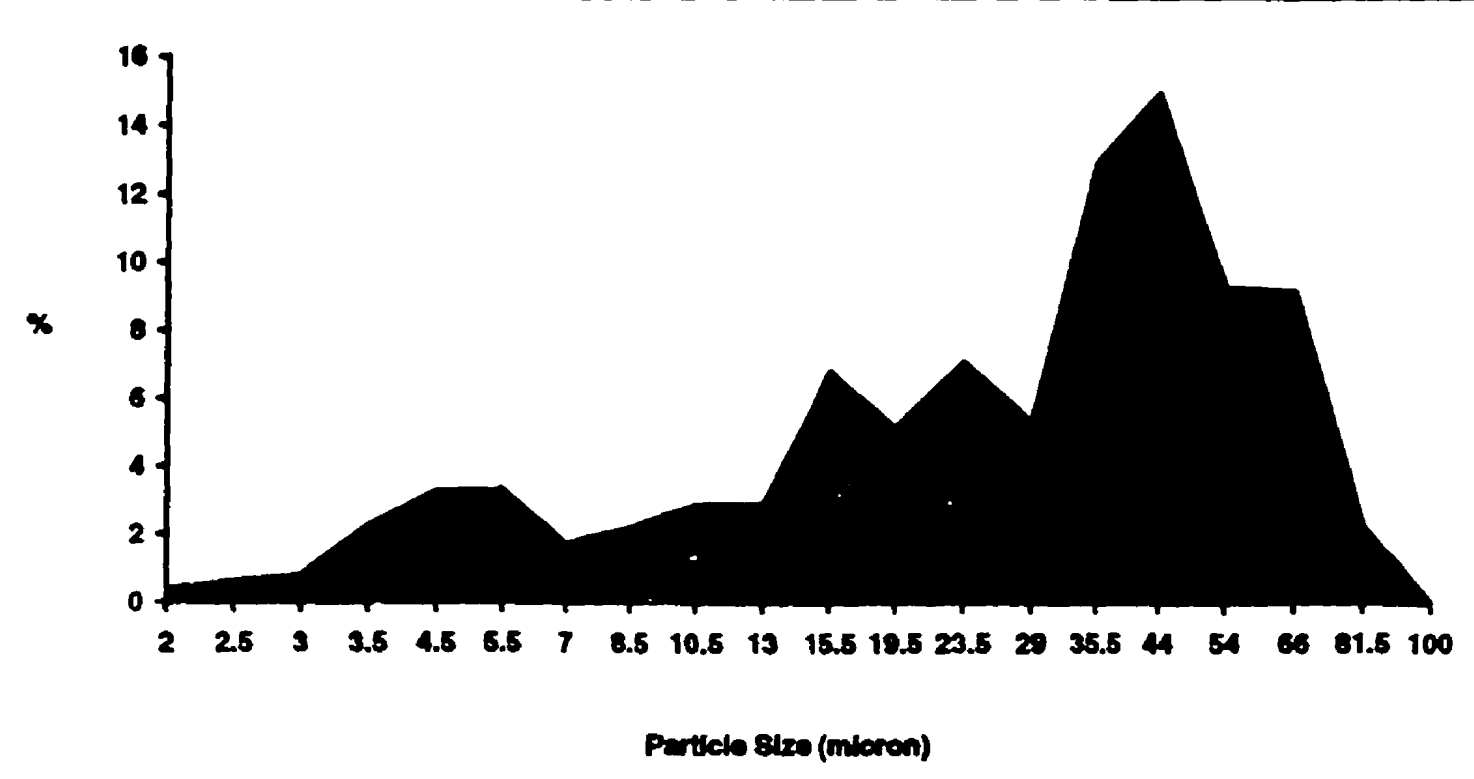

Figure 5.1 The volume percent size distribution of the feed material. 


\subsubsection{Gas Holdup}

Gas Holdup is dependent on operating variables such as frother dosage, gas rate $\left(J_{g}\right)$, percent solids, and slurry rate $\left(J_{L}\right.$, inside the column). The column setup allows for on-line gas holdup measurements to be taken at any time. Thus, the effect of superficial slurry velocity (inside the porous tube) on gas holdup was investigated. As will be discussed in the next section, it was found that a definite maximum in both overall and size-by-size fine particle recovery occured within a certain slurry velocity range. It would be useful to investigate any possible gas holdup changes around this point although, theoretically, there should be none.

Gas holdup increases with increasing slurry rate $\left(\mathrm{J}_{\mathrm{L}}\right)$, gas rate $\left(\mathrm{J}_{\mathrm{g}}\right)$, and frother dosage; and decreasing percent solids and bubble size (Finch, 1996). Except for bubble size, these parameters were kept constant during the test. Figure $\mathbf{5 . 2}$ shows the gas holdup values and overall recovery values (as percentages) plotted as a function of superficial slurry velocity through the porous tube. (The gas holdup data is given in Appendix 2.)

It can be seen that between a superficial velocity increase from 0 to about 25 $\mathrm{cm} / \mathrm{s}$, the gas holdup climbs to a value of about $25 \%$ and then levels off. Over the remaining velocities the gas holdup rises very slowly; increasing $2 \%$, to $27 \%$, by the time the superficial slurry velocity reaches $140 \mathrm{~cm} / \mathrm{s}$. 




Figure 5.2 Gas holdup and overall recovery versus superficial slurry velocity. 
The leveling off of gas holdup is typical. Increasing slurry velocity through the porous tube is postulated to affect bubble size: Smaller bubbles should be created because the faster recycle slurry will shear the bubbles off the inside wall of the tube before they have had time to grow. The slow and steady increase in gas holdup (after the levelling off has occured) appears to support this theory.

\subsubsection{A Note on Graph Presentation}

Many of the following graphs are size-by-size recovery plots. These involve many plotted data points per curve with multiple curves represented on each plot. In most cases the actual plot symbols overlap and create great clutter on the graph. Thus, when this occurs two plots are shown; one with the actual data points and one with only the regression curves representing the trends. The plots with the data points are given in Appendix 5 . In these plots the number of data points in the very fine particle size range are averaged to achieve only one value. This, also, reduced clutter on the graphs. 


\subsection{The Effect of Superficial Slurry Velocity}

The setting of the recycle pump (controlling the rate of recycle slurry taken from near the bottom of the column, sent through the contact device, and injected back into the column) was varied. This corresponds to a change in the superficial velocity of the slurry flowing through the porous tube inside the contact device. Figure 5.3 shows the effect of this change in the overall recovery results for six velocity values.

It can be seen that there appears to be a peak in recovery at around the 100 $\mathrm{cm} / \mathrm{s}$ mark. It should be noted, though, that the existence of this peak depends on the accuracy of the last value (at $140 \mathrm{~cm} / \mathrm{s}$ ); meaning that if this value is suspect, then possibly the graph may not represent a peak at $1 \mathrm{~m} / \mathrm{s}$, but rather a leveling off at this point. The size-by-size recovery plots should provide more insight into this possibility.

Figure 5.4 shows the recovery of the individual size ranges at each velocity point shown in figure 5.3. The curves are labeled, but are difficult to view. The basic aim is to determine which velocity curve lies the furthest left; in other words, at which velocity is the recovery of fines maximized. If an arbitrary horizontal line (basically a $D_{80}$ ) is drawn, and the particle size value at the point at which this line intersects each of the curves is determined, the horizontal osition of each curve relative to the other curves can be seen. This graph is shown in figure 5.5 . 


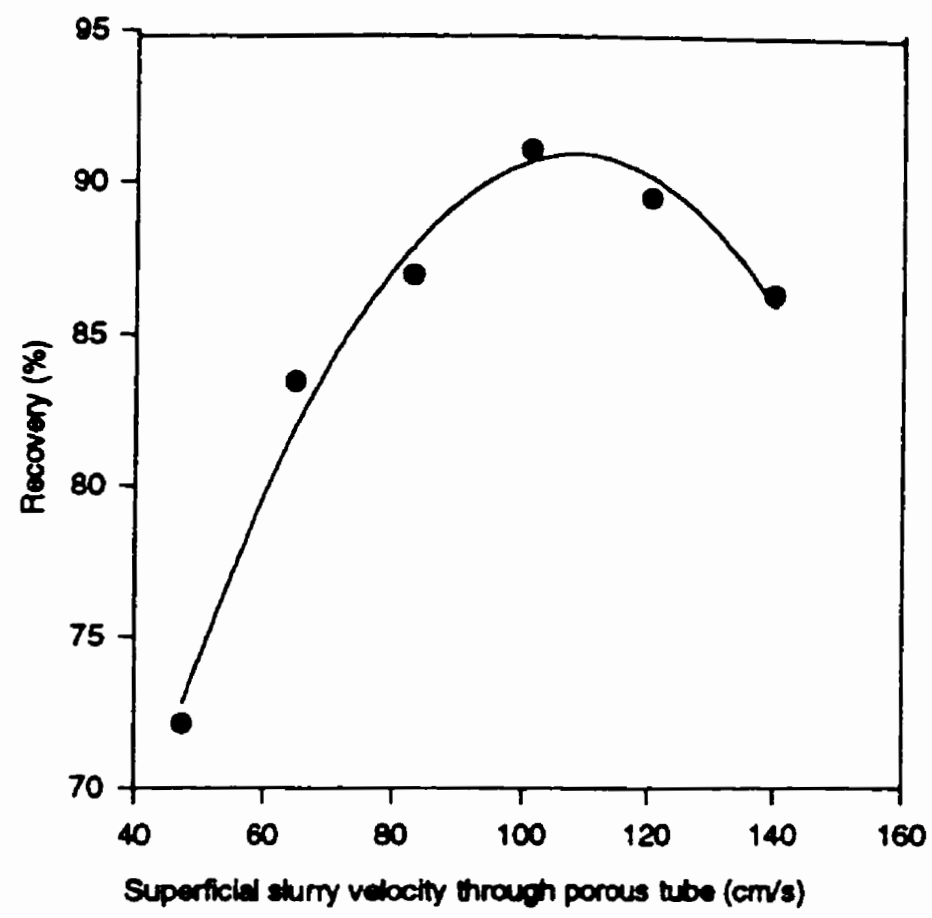

Figure 5.3 The effect of superficial slurry velocity on overall recovery.

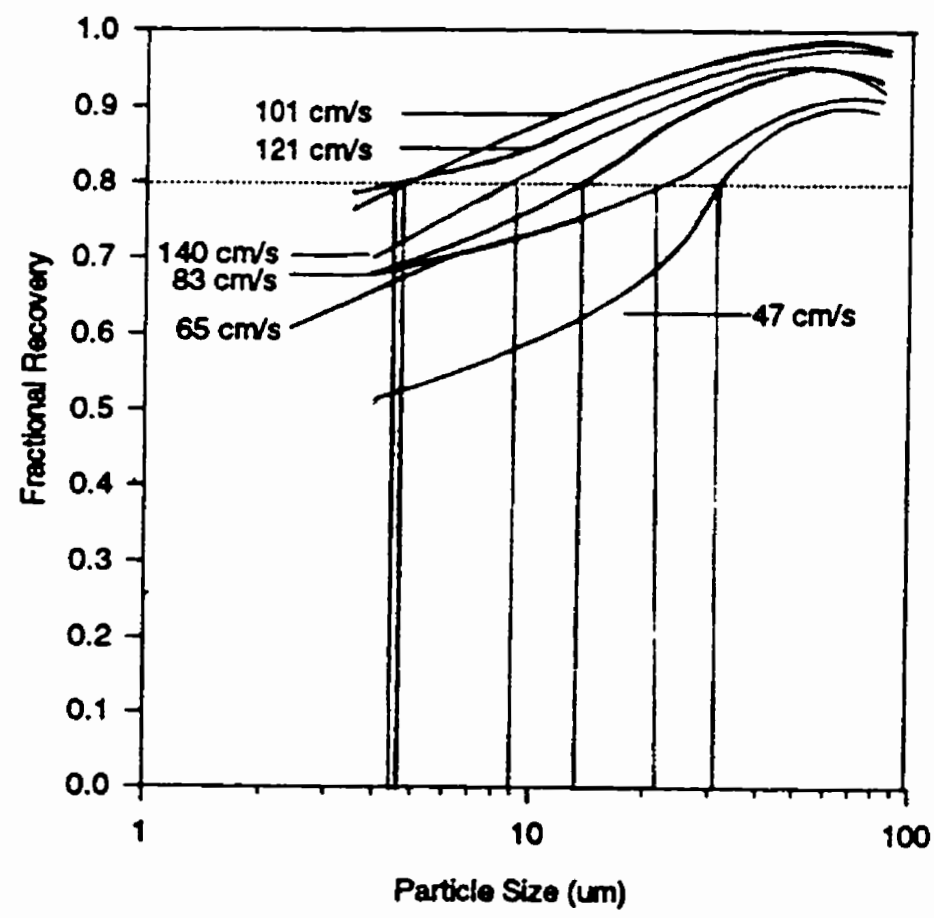

Figure 5.4 The size-by-size recoveries at various slurry superficial velocities. 


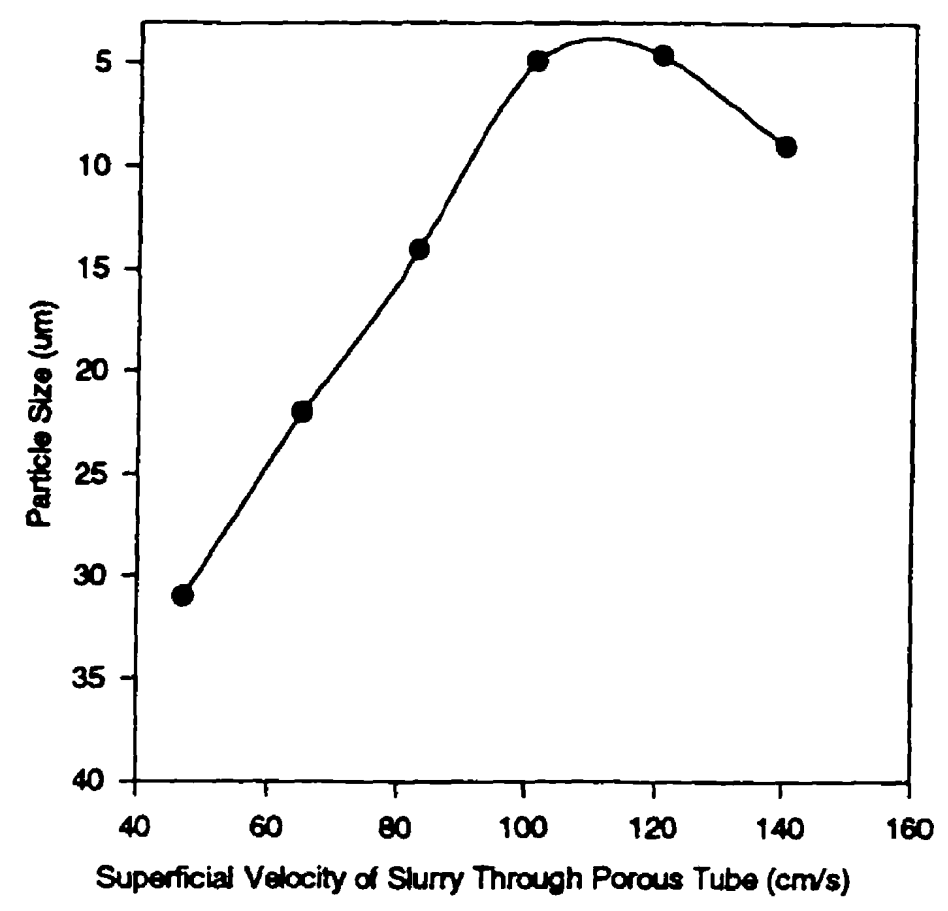

Figure 5.5 Particle size (at 50\% recovery) versus superficial slurry velocity.

There is an maximum between 100 and $120 \mathrm{~cm} / \mathrm{s}$. Which agrees with the overall recovery results shown in figure 5.3 . This implies that there is a general maximization of recovery at a superficial slurry velocity of around $1-1.2 \mathrm{~m} / \mathrm{s}$.

One reason for this optimum superficial velocity for fine particle recovery is related to bubble size effects. As discussed in chapter two, bubble size does have an effect on the flotation of fines. Possibly around the $1-1.2 \mathrm{~m} / \mathrm{s}$ range the ideal bubble size is generated (by the shearing action of the incoming slurry) to float $\mathrm{MoS}_{2}$ particles in the $25-40$ micron size range. With velocities below and above the $1-1.2 \mathrm{~m} / \mathrm{s}$ range corresponding to bubble sizes that are too big and too small, respectively. The turbulence in the contact device (the porous tube and 
collection tubing) could also have an effect. Possibly at high velocities the turbulence is too high, inducing particle-bubble detachment.

\subsection{Effect of Porous Tube Dimensions}

The effect of porous tube length and the pore size were investigated.

\subsubsection{Porous Tube Length}

The length of the porous tube used in the contact device was varied. The effective lengths tested were 14,28 , and $56 \mathrm{~cm}$. Figure 5.6 shows the effect of slurry superficial velocity on overall recovery for the three lengths tested. It is seen that generally there is better recovery with increasing tube length. Although at high velocities the data points seem to overlap.

This positive relationship between porous tube length and recovery implies that possibly ample collection takes place inside the tube itself. This result is investigated in section 5.4. Figure 5.7 shows the effect of tube length on size-bysize recovery. There is a trend implying that a longer tube is also beneficial in collecting fines. 


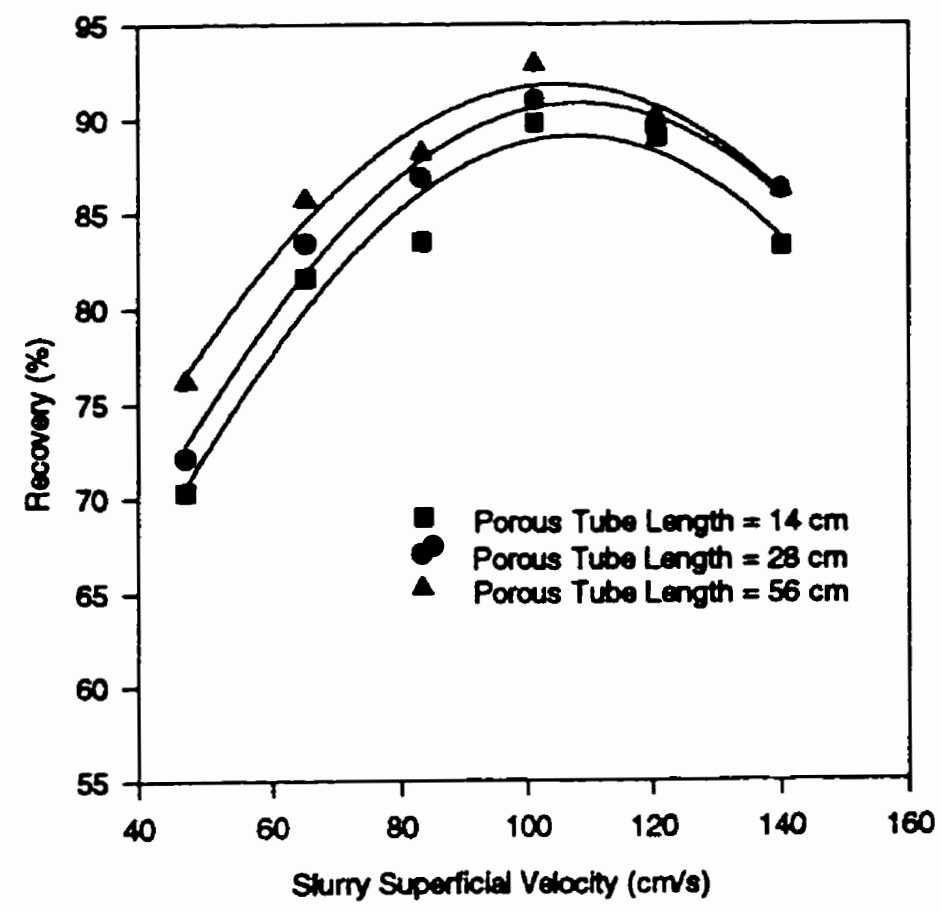

Figure 5.6 The effect of porous tube length on recovery-slurry velocity plots.

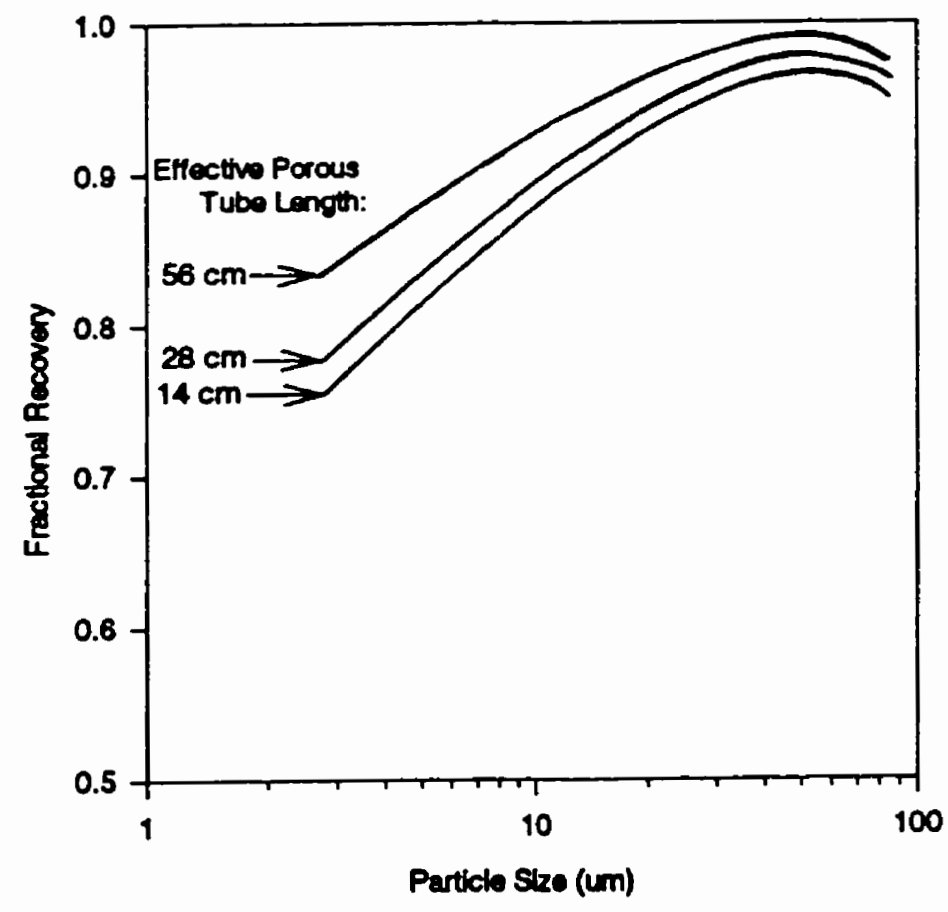

Figure 5.7 The effect of porous tube length on size-by-size recovery. 


\subsubsection{Pore Size}

Two pore sizes were investigated for all three porous tube lengths. The pore size is the average diameter of the opening through which the gas is injected into the incoming recycle slurry stream. The two pore sizes tested were 2 and 10 micron. (A pore size of 10 micron is the largest possible pore size attainable for a porous tube of only $6 \mathrm{~mm}$ ID.) A smaller pore size means, theoretically, that more bubbles of smaller diameter could be created. This implies that, because bubble size is affected by slurry superficial velocity, there should be a difference in flotation results if the velocity is kept constant. The aim of this test is to investigate this difference.

Figure 5.8 shows the effect of pore size on the overall recovery for the three lengths of contact tube (while slurry velocity is maintained constant). The results show that there is small difference in recovery when the short tube is used, and a slightly larger difference when the tube is lengthened; with the 2 micron tube showing a $1.5-3 \%$ better recovery than the 10 micron tube in all three lengths. Figure 5.9 plots the size-by-size recovery for the two pore sizes. It shows that the 2 micron tube is slightly more efficient in recovering fine particles. Although, it must be stated that in both figures 5.8 and 5.9 the difference in recoveries are too discrete to conclude any definite statistical pore size effect. 


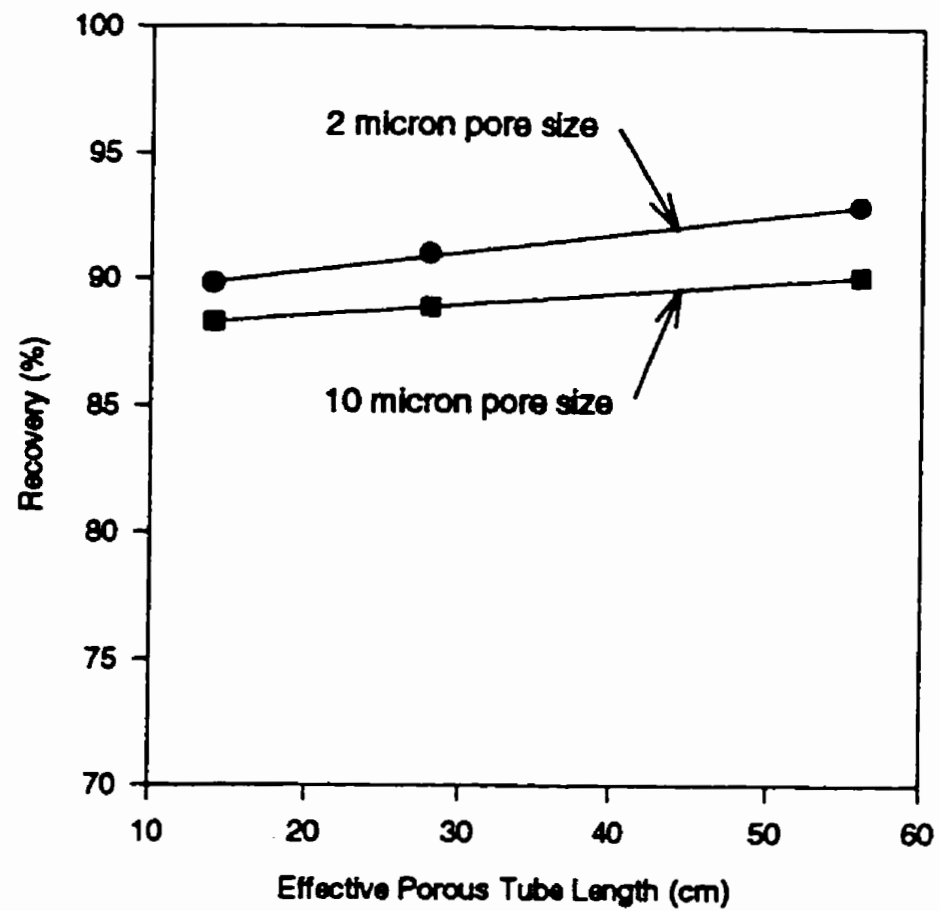

Figure 5.8 The effect of pore size on recovery for various porous tube lengths.

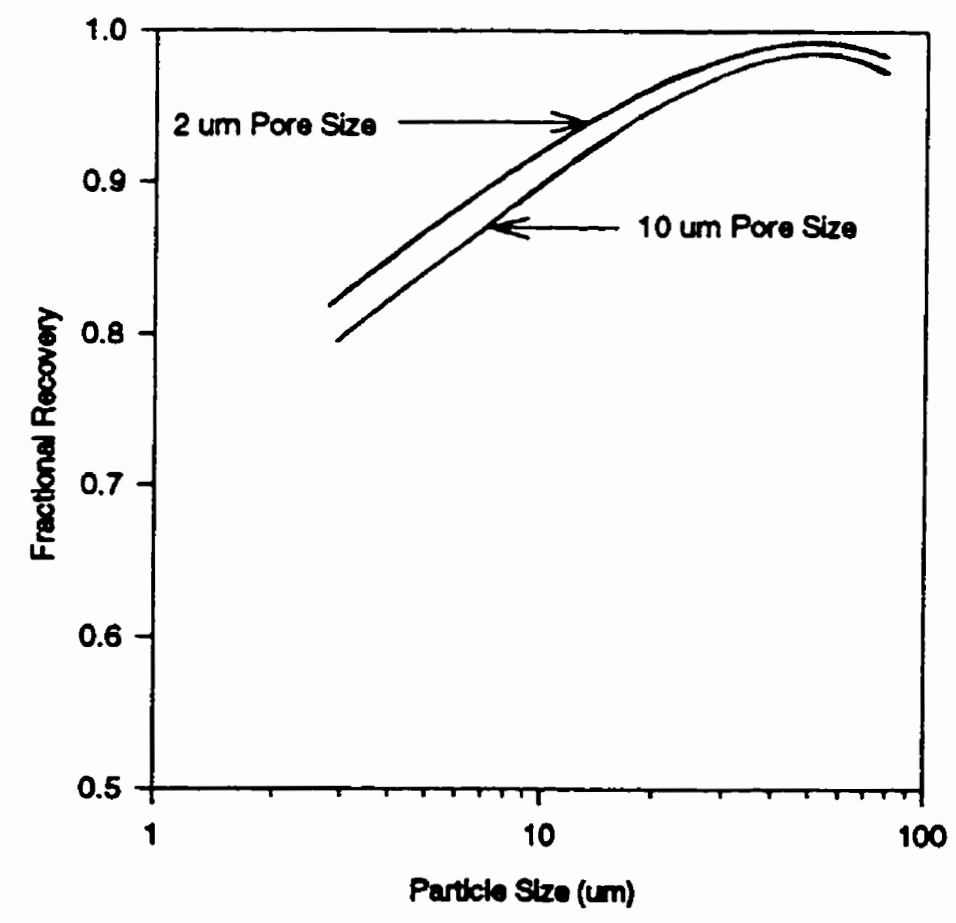

Figure 5.9 The effect of pore size on size-by-size recovery. 


\subsection{The Effect of Collection Tube Length}

After the recycle slurry steam shears off the bubbles inside the porous tube, the slurry-bubble mixture flows back to the column via the coliection tube. It is believed that actual collection of the particles by the bubbles may take place during this time. A previous study (with silica) implied that this may not be the case: Ding (1993) concluded that the length of this tubing actually has a negative effect on recovery. In other words, maximum recoveries are attained when no collection tubing is used. This implies that all collection took place inside the porous tube and possibly particles tend to fall off the bubbles in the collection tube. This demineralization, as Ding (1993) explains, may be due to the intense turbulence and friction forces that exist inside the collection tube.

Figure 5.10 shows the results obtained in this work. The length of collection tube can also be stated in terms of residence time $(\tau)$ of the slurry inside the tube. The residence time was varied from 0 to 25 seconds. It can be seen that there is a definite increase in recovery as the tube is lengthened. This increase flattens out near $2 \mathrm{~m}$ (or $\tau=14 \mathrm{~s}$ ) after which point there is no marked effect of tubing length.

Is should be stated that though there is an increase in recovery with increasing residence time, the recovery when $\tau=0$ is $88 \%$. This is only $4 \%$ below the apparent ultimate overall recovery of about $92 \%$. Thus it can be concluded that there is significant recovery in the porous tube itself. Though, this does not support the negative relationship between recovery and residence time that Ding 
found. Silica is not very hydrophobic, thus an attached silica particle is, very probabiy, not as secure as an attached MoS 2 particle. Possibly, in that case, bubbles were coalescing quickly inside the collection tube, 'throwing off' the silica particles after they had been collected; or as Ding proposed, turbulence may be a factor. Thus it is concluded here, that due to the vast differences in the surface characteristics of the minerals used in these two works, a direct comparison cannot be made.

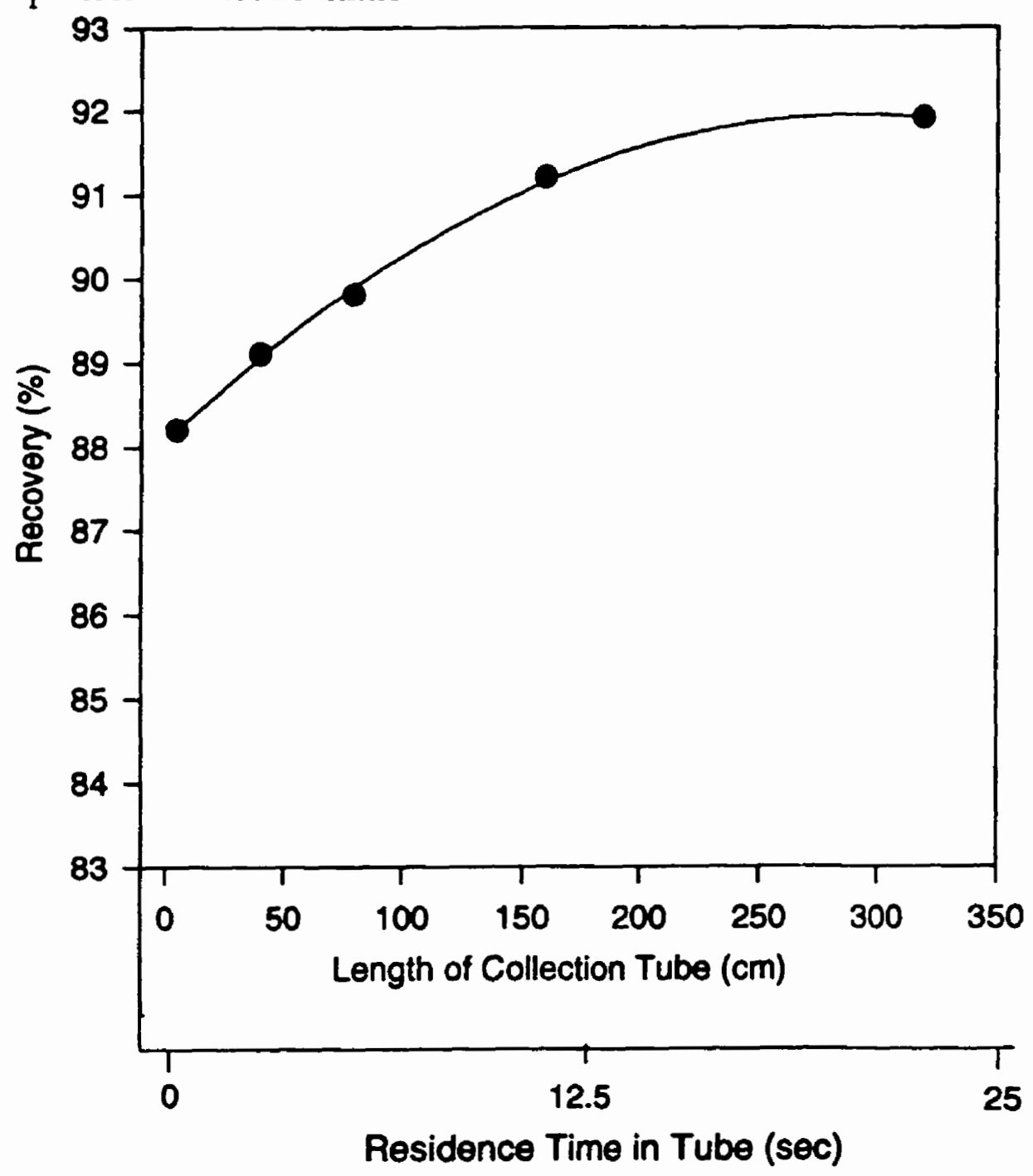

Figure 5.10 The effect of collection tube length, or pre-column slurry residence time, on recovery. 


\subsection{Comparison with a Conventional Cell}

The flotation of fine particles is enhanced when bubble-particle contact in the cell is numerous and involves higher energy collisions. The bubble-particle coursing action that takes place in a conventional flotation column is generally inefficient at this. Mechanical cells, such as the conventional LEEDS or DENVER cells do provide a more turbulent environment. Thus it is valuable to define the contact device's ability to recover fines in relation to a conventional cell.

Figure 5.11 shows the size-by-size recovery of LEEDS cell testing and of contact device-column testing. In both cases, the two plots show each flotation method run at optimum conditions. There is an obvious difference in the ability of the two devices to recover fine particles. While differences in overall recovery between the two devices averaged only about $4-8 \%$ (84-88\% for the LEEDS cell and $92 \%$ for the column), the difference in fine particle recoveries range from $5 \%$ (at $40 \mu \mathrm{m}$ ) to $30 \%$ (at $5 \mu \mathrm{m})$.

These results indicate that the porous tube contact device is significantly more efficient at recovering fine particles than the LEEDS cell. However, these two different devices require different conditions. (For example, the ideal frother dosage for the LEEDS cell is double that of the column.) Also, mid- 80 's recoveries is very low for a molybdenite concentrate. Thus possibly the vast differences in recoveries seen in laboratory testing, between the two devices, may not necessarily be observed at the industrial level. 




Figure 5.11 Comparison of size-by-size recovery results between the contact device-column system and a conventional flotation cell. 


\subsection{Conventional Bubble Coursing Versus External Collection}

In addition to the originally planned tests (just reviewed) additional testing was conducted to further investigate particle collection. Due to the fact that the feed was injected directly into the column, with only a recycle stream being externally contacted, there is the possibility that part of the overall recovery is due to the conventional bubble coursing effect present in the column itself. In attempt to determine the degree of recovery provided by the contact device alone, modifications were made to reduce this coursing contact mechanism component.

In the case of the feed, it was injected directly into the recycle stream, to limit any counter-current bubble-feed interaction within the column. Also the collection zone was reduced by shortening the column was to $1 \mathrm{~m}$, its minimum possible length. It is believed that these modifications significantly inhibited incolumn collection; rendering the $1 \mathrm{~m}$ column as truly only a separation chamber.

The size-by-size recovery results of these tests proved to be very interesting and are shown in figure 5.12. As expected, recovery is reduced when the bubble coursing component is removed. The interesting aspect of the graph lies in the fact that this difference is not large. The reduction in overall recovery is less than $5 \%$; with the reduction in size-by-size recovery ranging from 3-6\%. 
This implies that external contacting is rather efficient even without the bubble coursing component. Even though it is not obvious from figure 5.12, it can be inferred that the contact device is probably more suited for fine particle recovery. It is postulated that with a less hydrophobic material there will probably be a larger difference in the two plots in the larger particle size range $(>60 \mu \mathrm{m})$. This wou!d be due to large particle-bubble detachment as a result of the extreme turbulent conditions within the contact device.

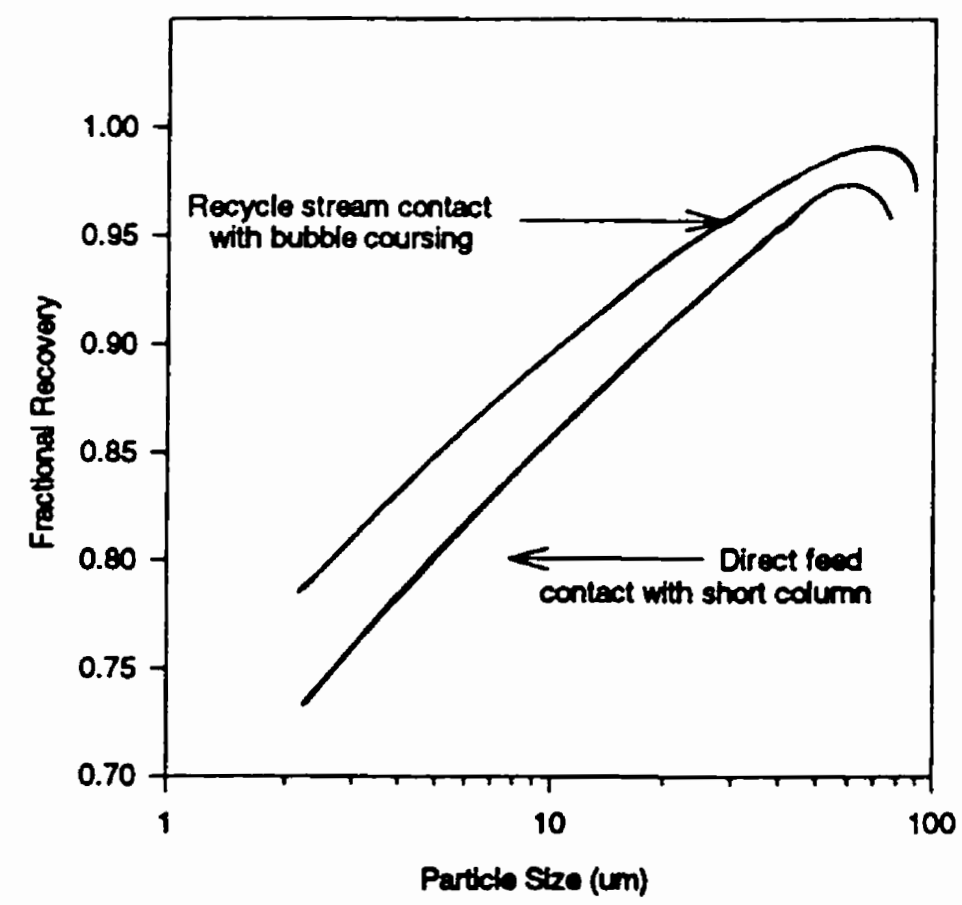

Figure 5.12 The size-by-size effect of removing the bubble coursing component by contacting the feed and shortening the column. 
Thus it can be concluded that while the contact device does collect most of the fine particles, it could possibly be relatively inefficient at collecting larger particles. These larger particles will be collected via the conventional column flotation (bubble coursing) method. If this is the case then, therefore, a combination of both external contact and conventional column operation would be ideal.

Up till this point the advantages in fine particle recovery have been attributed to factors that include design parameters such as slurry superficial velocity. It should be mentioned that it would be perfunctory to conclude that, for example, only slurry velocities of $\sim 1 \mathrm{~m} / \mathrm{s}$ are needed to utilize this device; where, in fact, such velocities require massive pumping capacities in a real plant. It should be emphasized that other factors, not addressed in this research, must also be looked at. For example, the relatively high fine particle recovery achieved with the usage of the external contact device could be a result multiple passes through the device. Future work is need to actually quantify this effect. 


\section{Chapter Six}

\section{CONCLUSIONS}

- The superficial flowrate of the slurry flowing through the contact device has a significant effect on the recovery of fine particles. It was found that an intermediate superficial velocity of $1-1.2 \mathrm{~m} / \mathrm{s}$ provided optimum overall and size-by-size recoveries. It was proposed that this effect is due to optimum bubble size (due to the shearing effect of the slurry on the forming bubbles) and conditions of turbulence created at this superficial rate.

- Gas holdup slightly increases over a large superficial slurry velocity increase. This is probably due to the negative effect (described above) that velocity has on bubble size.

- Both the length and the pore size of the porous tube seem to have an effect on recovery of fine particles, longer tubes with finer pore sizes giving better results. The effect, though, seems to be limited so a definite conclusion cannot be made at this time. 
- The length of the collection tubing that connects the porous tube to the column (after slurry-gas contact is made) has a positive effect on recovery. However beyond a certain tubing length there is no effect. Also, the effect of collection tubing length depends on the specific mineral used; with less hydrophobic minerals possibly tending to detach within the tube.

- Overall, the investigated external porous contact device was found to efficiently recover fine particles due to its ability to both; create ideal bubble sizes and provide a high energy environment for bubble-particle interaction. Thus, usage of both external contact combined with conventional coursing-bubble column flotation would appear ideal for materials with wide particle size distributions. 


\section{Chapter Seven}

\section{RECOMMENDATIONS}

There are many possibilities for further investigations. These include:

- Looking specifically at the bubble size created by various devices and its relation to slurry velocity. This, of course, would involve direct $d_{b}$ or indirect average $d_{b}$ (using drift flux analysis) measurement.

- Investigating other external contact devices (i.e the Venturi or a static in-line mixer) and determining their ability to recover fine particles.

- Investigate other parameters like gas rate, percent solids, frother dosage or residence time on the recovery of fine particles for this (or other) external contact device(s).

- Investigating the various parameters described in this paper while looking at the overall flotation kinetics rather than just overall or size-by-size recoveries.

- With respect to fines: Possibly investigating surface chemical or electrical properties which seem to significantly affect the behavior of fine particles. Or investigating the ideal number of passes through the device to achieve maximum fine particle recovery. 


\section{REFERENCES}

Agar, G.E. (1985) "The Optimization of Flotation Circuit Design from Laboratory

Rate Data", Proceedings of the XVth International Mineral Processing Congress, pp. 100-111.

Allen, T. (1992) Particle Size Analysis, 4th Ed., Chapman and Hall, London

Anfruns, J.F. and Kitchener, J.A. (1977) "Rate of Capture of Small Particles in Flotation", Trans. Inst. Min. Met., vol. 86, pp. C9-C15

Derjaguin, B.V. and Dukhin, S.S. (1979) "Kinetic Theory of the Flotation of Fine Particles", Proceedings of the 13th International Mineral Processing Congress, Warsaw. Elsevier Scientific Publishing Company and PWN-Polish Scientific Publishers, Warsaw

Diaz Penafiel, P.A. (1993) "Bubble Size Effects on the Kinetics of Flotation" Masters Thesis, University of Toronto, Toronto, Ontario, Canada

Ding, J. (1993) "A Study on Feed Slurry Aeration in Froth Flotation" Masters Thesis, University of Toronto, Toronto, Ontario, Canada

Evans, G.M., Atkinson, B.W. and Jameson, G.J. (1996) “Recent Advances in Jameson Cell Technology", in Column'96. Proceedings of the 35th Annual Conference of Metallurgists of CIM, Montreal, Canada

Finch, J.A. (1996) Notes from the "Column Flotation Workshop" at the 35th Annual Conference of Metallurgists of CIM, Montreal, Canada 
Finch, J.A. and Dobby, G.S. (1990) Column Flotation, Pergamon Press, Oxford

Fuerstenau, D.W (1980) "Fine Particle Flotation", in: P. Somasundaran (editor), Fine Particles Processing. Proceedings of the International Symposium on Fine Particles, Las Vegas, Nevada, 1980, Am. Inst. Min. Met. and Pet. Engrs., New York, vol. 1, pp. 669-705

Gaudin, A.M. (1957) Flotation, 2nd ed., McGraw-Hill Book Company Inc., New York

Hardie, C.A. (1996) "The Effects of Copper Ions on the Depression of Chalcopyrite by Cyanide", Bachelors Thesis, University of Toronto, Toronto, Ontario, Canada

Hood, G.D. and Jordan, C.E. (1993) “In-line Static Mixer Rapid Flotation System for Improved Flotation Kinetics" Minerals and Metallurgical Processing, vol. 10, pp. 182-187

Imazumi, T. and Inoue, T. (1962) "A Study of Flotation as a Rate Process", J. Min. and Met., Japan, 77 p. 987

Jameson, G.J. and Manlapig, E.V. (1991) "Applications of the Jameson Cell" in G.E. Agar et al. (editors) Column'91. Proceedings of an International Conference on Column Flotation, Sudbury, Canada, vol. 2, pp. 673-687

Jameson, G.J., Nam, S., and Moo Young, M. (1977) "Physical Factors Affecting Recovery Rates in Flotation", Mineral Scienece Engineering 9 (3), pp. 103-118 
Jowett, A. (1980) "Formation and Disruption of Particle-Bubble Aggregates in Flotation" in Fine Particles Processing, Proc. Int. Symp. on Fine Particles, Las Vegas (P. Somassundaran, ed.), AIME, New York, pp. 720-754

Kaye, B.H. (1995) "Particle Size Characterization", in Encyclopedin of

Pharmaceutical Technology, vol. 11, edited by J. Swarbrick and J. Boylan, Marcel Dekker Inc., New York

Kaye, B.H. and Trottie, R. (1995) "The Many Measures of Fine Particles", in Chemical Engineering, April 1995, pp. 78-86

Kelsall, D.F. (1961) "Application of Probability in the Assessment of Flotation Systems", Trans. Imm 70, pp. 191-204

Leja, J. (1982) Surface Chemistry of Froth Flotation, Plenum Press, New York

Meyer, T.M. (1994) "Testing of a Venturi and a Static In-line Mixer on a Feedline Aerated Flotation Column" Masters Thesis, University of Toronto, Toronto, Ontario, Canada

Morris, T.M., (1952) "Measurement and Evaluation of the Rate of Flotation as a Function of Particle Size", Trans. AIME, vol. 193 pp.794-798

Panu, I. (1976) "Mathematical models of Batch Continuous Flotation" in Flotation: A.M. Gaudin Memorial Volume, Fuerstenau M. C. ed., AIME, New York.

Reay, D. and Ratcliff, G.A. (1973) "Removal of Fine Particles from Water by Dispersed Air Flotation: Effects of Bubble Size and Particle Size on Collection Efficiency" Can. J. Chem. Eng., vol. 51, pp. 178-185 
Reay, D. and Ratcliff, G.A. (1975) “Experimental Testing of the Hydrodynamic Collision Model of fine Particle Flotation", Can J. of Chem. Eng., 53, pp. 481-486

Rice, R.G., Oliver, A.D., Newman, J.P. and Wiles, R.J. (1974) "Reduced Dispersion Using Baffles in Column Flotaion", Powder Tech., 10, pp201-210

Schuhmann, R. (1942) "Flotation Kinetics I- Methods for steady state study of Flotation Problems", J. Phys. Che. vol. 46, pp891-102

Trahar, W.J. (1981) “A Rational Interpretation of the Role of Particle Size in Flotation", Int. J. of Mineral Processing, vol. 8, pp. 289-327

Wills, B.A. (1988) Mineral Processing Technology 4th ed., Pergamon Press, Oxford

Xu, M., Quinn, P., and Stratton-Crawley, R. (1994) "Graphite/Chalcopyrite Separation Using a Rapid Column Cell" in: T. Yalcin (editor) Innovations in Mineral Processing. Proceedings of the Innovations in Mineral Processing Conference, Sudbury, Canada, pp. 181-186

Yoon, R.H. (1993) “Microbubble Flotation" Minerals Engineering, vol. 6, no. 6, pp. 619-630

Yoon, R.H. and Luttrel, G.H. (1989) "The Effect of Bubble Size on Fine Particle Flotation" in: J.S. Laskowski (editor), Frothing in Flotation, Gordon and Breach Science Publishers Inc., pp. 101-122 


\section{APPENDICES}

The following pages contain the raw and calculated data corresponding to the column, LEEDS cell, and Brinkmann tests. Also, the results of all statistical and reproducibility testing are given.

Appendix 1: The overall recovery data (for the plots given in chapter 5) are presented for the various flotation tests.

Appendix 2: The measured gas holdup values are given.

Appendix 3: The procedure by which the size-by-size recoveries are calculated is given.

Appendix 4: The Brinkmann particle size data are shown for the plots given in chapter 5 . First the size distribution of the feed, and then the flotation tests. The size-by-size local percentage values given in the 'feed' column represent the back-calculated feed percentages. These values varied $+/-\sim 25 \%$ from the true feed size values; with the $d_{50}$ values ranging from $29-33 \mu \mathrm{m}$ for the column tests to $45 \mu \mathrm{m}$ for the LEEDS cell test.

Appendix 5: Size-by-size plots showing the actual data points are given. These graphs correspond to the size-by-size graphs shown in chapter 5. Only the fitted curves were presented in chapter 5 because the many data points clutter up the plot and hinder proper viewing of the curves.

Appendix 6: A plot the variation of the results of a repeated flotation test to show the reproducibility of the column testing. (The test, repeated three times, is the varying of slurry superficial velocity $-101 \mathrm{~cm} / \mathrm{s}$.)

Appendix 7: Some statistical calculations for the Brinkmann particle size analyzer. Three size standards were used $(5,25$, and $100 \mu \mathrm{m})$. 


\section{APPENDIX 1 WEIGHTS TO DETERMINE OVERALL RECOVERY}

TEST

CONCENTRATE (g) TAILINGS (g)

RECOVERY (\%)

Leeds Cell $\# 1$

$1500 \mathrm{rpm}$, AFA $6 \mathrm{U} / \mathrm{min}, 10 \mathrm{ppm}$ frother, froth depth $2 \mathrm{~cm}$

72.054

12.587

85.1

Leods Cell *2

1500rpm, AFRe8L/min, 10ppm, foth depth $4 \mathrm{~cm}$

89.19

16.61

84.3

Leods Coll"3

$1700 \mathrm{rpm}$, AFR $=5 \mathrm{~L} / \mathrm{min}, 8 \mathrm{ppm}$, froth depth $3.5 \mathrm{~cm}$

87.66

16.1093

84.5

Leeds Coll:44

$1700 \mathrm{rpm}$, AFR $=5 \mathrm{~L} \mathrm{~min}$, 10ppm, froth depth $=3.5 \mathrm{~cm}$

54.976

8.433

86.7

Column (to vary collection tubing length)

$56 \mathrm{~cm}$ porous tube, 2 um pore, $101 \mathrm{~cm} / \mathrm{s}, 5 \mathrm{ppm}$ frother. $800 \mathrm{c} / \mathrm{m}$ in gas, superficial sturry rate $101 \mathrm{~cm} / \mathrm{s}$

Collection Tubing Length:

$$
\begin{aligned}
& 0 \mathrm{~cm} \\
& 40 \mathrm{~cm} \\
& 160 \mathrm{~cm} \\
& 180 \mathrm{~cm} \\
& 320 \mathrm{~cm}
\end{aligned}
$$

Column (to vary recycle rate)

$56 \mathrm{~cm}$ porous tube, 2 um pore, $101 \mathrm{~cm} / \mathrm{s}, 5 \mathrm{ppm}$ frother, $800 \mathrm{cc} / \mathrm{min}$ gas, $180 \mathrm{~cm}$ collection tube Superficial Slurry Rate:

$47.2 \mathrm{~cm} / \mathrm{s}$
$65.04 \mathrm{~cm} / \mathrm{s}$
$83.1 \mathrm{~cm} / \mathrm{s}$
$101.18 \mathrm{~cm} / \mathrm{s}$.
$120.6 \mathrm{~cm} / \mathrm{s}$
$140.09 \mathrm{~cm} / \mathrm{s}$

Column (to vary porous tube length)

2 um pore, $101 \mathrm{~cm} / \mathrm{s}, 5 \mathrm{ppm}$ frother, $101 \mathrm{~cm} / \mathrm{s}$ R.R.

$800 \mathrm{cc} / \mathrm{min}$ gas, $180 \mathrm{~cm}$ collection tube

Porous Tube Length (cm):

\begin{tabular}{ll} 
actual & \multicolumn{2}{c}{ effective } \\
19 & 14 \\
33 & 28 \\
61 & 56
\end{tabular}

21.32

19.617

56

Column (to vary pore size of porous tube)

$56 \mathrm{~cm}$ tube, $101 \mathrm{~cm} / \mathrm{s}, 5 \mathrm{ppm}$ frother, $101 \mathrm{~cm} / \mathrm{s}$ R.R.

$800 \mathrm{cc} / \mathrm{min}$ gas, $180 \mathrm{~cm}$ collection tube

Porous Tube pore size (micron):

$$
\begin{array}{r}
2 \\
10
\end{array}
$$




\section{APPENDIX 2}

GAS HOLDUP MEASUREMENTS

With varying recycle rates (August 30 1996)

Recycle pump set point

Superficial slurry velocity in tube (cm/s) Gas holdup (\%)

1
2
3
4
5
6
7
8
6
10

8.13

16.26

22.82

29.38

47.2

65.04

83.1

101.18

120.6

140.09

12.62

18.18

25.01

25.9

26.47

26.61

26.77

26.91

27.09

27.1

CONDITIONS:

Gas Rate $=800 \mathrm{cc} / \mathrm{min}$

Recycle Rate $=101 \mathrm{~cm} / \mathrm{s}$

Frother $=5 \mathrm{ppm}$

Percent Solids $=5 \%$

Pore size $=2$ micron

Porous tube length $=56 \mathrm{~cm}$

- Stabilized for 4 min prior to gas holdup measurements 
Appendix 3 - Procedure used to calculate size-by-size recoveries.

The following outlines the method by which the Brinkmann concentrate and tailings particle size data was normalized to generate the size-by-size recovery data shown in the next appendix:

- Each set of Brinkmann data was distributed such that they fit a log scale ranging from 0 to $100 \mu \mathrm{m}$ consisting of 20 particle size ranges (x).

- The value in each range represent a local volume peak, or a percentage of the total volume of sample that lie in that particular particle size range.

- There exists an overall recovery $(\mathbf{R})$ term for each flotation test, simply indicating the percentage of material reporting to the concentrate. The average column flotation test gave an overall recovery of around 0.90 or $90 \%$.

- Each local peak for the concentrate $\left(\mathbf{c}_{\mathbf{x}}\right)$ was multiplied by $\mathbf{R}$; and each Iocal tails peak $\left(\mathbf{t}_{\mathbf{x}}\right)$ was multiplied by $(\mathbf{1}-\mathbf{R})$.

- Assuming no losses, these values add up to the feed local peak values.

- Thus the recovery for each size range is simply the concentrate/feed.

- As an example, an arbitrary column test from Appendix 4 is taken:

For the 23.5 - $29.0 \mu \mathrm{m}$ size range, the local concentrate peak is $7.18 \%$, the local tails peak is $5.52 \%$, and the overall recovery is $89.4 \%$.

Therefore,



Tailings 23.5-29.0 $=t_{23.5-29.0} \times(1-R)=5.52 \times 0.106=0.585$

and Feed $23.5-29.0 \quad=6.419+0.585 \quad=7.004$

Thus,

The local recovery for the $23.5-29 \mu \mathrm{m}$ range $=6.419 / 7.004=0.916$ or $91.6 \%$. 


\section{APPENDIX 4}

Data Generated from Brinkmann Particle Size Analyzer:

FEED SAMPLE (June 14 1996)

Particle Size Range (microns)

$$
\begin{aligned}
& 0.0-2.0 \\
& 2.0-2.5 \\
& 2.5-3.0 \\
& 3.0-3.5 \\
& 3.5-4.5 \\
& 4.5-5.5 \\
& 5.5-7.0 \\
& 7.0-8.5 \\
& 8.5-10.5 \\
& 10.5-13.0 \\
& 13.0-15.5 \\
& 15.5-19.5 \\
& 19.5-23.5 \\
& 23.5-29.0 \\
& 29.0-35.5 \\
& 35.5-44.0 \\
& 44.0-54.0 \\
& 54.0-66.0 \\
& 66.0-81.5 \\
& 81.5-100.0 \\
& >100.0
\end{aligned}
$$

Local Peak (\%) : FEED

0.67

0.39

0.62

0.79

2.26

3.28

3.31

1.72

2.21

2.89

2.89

6.81

5.17

7.09

5.36

12.95

14.99

9.26

9.16

2.27

5.91

CONDITIONS For Brinkmann:

Use flow through cell at low pump rate

Lignosol dispersant solution $(0.5 \mathrm{~g} / \mathrm{L})$

as the liquid medium 
Data Generated from Brinkmann Particle Size Analyzer:

LEEDS CELL FLOTATION (July 5 1996)

overall recovery $86.7 \%$

Particle Size Range (microns) Local Peak (\%) : CONCENTRATE

Local Peak (\%) : TAlLS

$0.0-2.0$
$2.0-2.5$
$2.5-3.0$
$3.0-3.5$
$3.5-4.5$
$4.5-5.5$
$5.5-7.0$
$7.0-8.5$
$8.5-10.5$
$10.5-13.0$
$13.0-15.5$
$15.5-19.5$
$19.5-23.5$
$23.5-29.0$
$29.0-35.5$
$35.5-44.0$
$44.0-54.0$
$54.0-66.0$
$66.0-81.5$
$81.5-100.0$
$>100.0$

CONDITIONS:

Gas Rate $=5 \mathrm{~L} / \mathrm{min}$

Agitator $=1700 \mathrm{~mm}$

Frother $=10 \%$ (of $1 \%$ Dowfroth $250 \mathrm{C}$ )

Froth Depth $=3-4 \mathrm{~cm}$

Percent Solids $=5 \%(125 \mathrm{~g})$

Refloated the first conc. to reduce entrainment

$\begin{array}{rr}0.260 & 0.225 \\ 0.200 & 0.173 \\ 0.290 & 0.251 \\ 0.380 & 0.329 \\ 1.110 & 0.962 \\ 1.280 & 1.110 \\ 1.130 & 0.980 \\ 0.660 & 0.572 \\ 0.860 & 0.746 \\ 1.350 & 1.170 \\ 1.420 & 1.231 \\ 3.450 & 2.991 \\ 2.560 & 2.220 \\ 5.140 & 4.456 \\ 6.100 & 5.289 \\ 14.150 & 12.268 \\ 16.960 & 14.704 \\ 11.460 & 9.936 \\ 7.750 & 6.719 \\ 6.420 & 5.566 \\ 17.070 & 14.800\end{array}$

feed

0.437

0.350

0.525

0.701

1.960

2.400

2.070

1.080

1.282

1.935

1.896

3.849

3.076

5.157

5.887

13.598

15.655

10.351

6.932

5.820

15.038

$\begin{array}{rl}1.590 & 0.211 \\ 1.330 & 0.177 \\ 2.060 & 0.274 \\ 2.790 & 0.371 \\ 7.500 & 0.998 \\ 9.700 & 1.290 \\ 8.200 & 1.091 \\ 3.820 & 0.508 \\ 4.030 & 0.536 \\ 5.750 & 0.765 \\ 5.000 & 0.665 \\ 6.450 & 0.858 \\ 6.440 & 0.857 \\ 5.270 & 0.701 \\ 4.500 & 0.599 \\ 10.000 & 1.330 \\ 7.150 & 0.951 \\ 3.120 & 0.415 \\ 1.600 & 0.213 \\ 1.910 & 0.254 \\ 1.790 & 0.238\end{array}$

Av. Range

0.495

0.479

0.470

0.491

0.462

0.473

0.530

0.582

0.605

0.649

0.777

0.722

0.864

0.898

0.902

0.939

0.960

0.969

0.956

0.984
0.147 0.035

Av. Rec'y

0.034

$\begin{array}{ll}0-7 & 0.034\end{array}$

0.070

0.066

0.101

0.064

0.093

7-19.5

0.121

0.130

0.249
0.488

0.656

0.722

0.864

0.898

0.902

0.939

0.960

0.969

0.956

0.984 
Data Generated from Brinkmann Particle Size Analyzer:

COLUMN FLOTATION (August 14 1996)

Variation of poresize - 2 micron

overall recovery $\mathbf{9 2 . 9 \%}$

Particle Size Range (microns) Local Peak (\%) : CONCENTRATE

Local Peak (\%) : TAILS

$$
\begin{aligned}
& 0.0-2.0 \\
& 2.0-2.5 \\
& 2.5-3.0 \\
& 3.0-3.5 \\
& 3.5-4.5 \\
& 4.5-5.5 \\
& 5.5-7.0 \\
& 7.0-8.5 \\
& 8.5-10.5 \\
& 10.5-13.0 \\
& 13.0-15.5 \\
& 15.5-19.5 \\
& 19.5-23.5 \\
& 23.5-29.0 \\
& 29.0-35.5 \\
& 35.5-44.0 \\
& 44.0-54.0 \\
& 54.0-66.0 \\
& 66.0-81.5 \\
& 81.5-100.0 \\
& >100.0
\end{aligned}
$$

\section{CONDITIONS:}

Gas Rate $=800 \mathrm{cc} / \mathrm{min}$

Effective porous tube length $=56 \mathrm{~cm}$

Frother $=5 \mathrm{ppm}$

Percent Solids $=5 \%$

Recycle rate $=101 \mathrm{~cm} / \mathrm{s}$

$\begin{array}{rrrr}0.280 & 0.260 & 1.190 & 0.084 \\ 0.890 & 0.827 & 2.440 & 0.173 \\ 1.070 & 0.994 & 3.020 & 0.214 \\ 1.780 & 1.654 & 3.000 & 0.213 \\ 2.250 & 2.090 & 6.690 & 0.475 \\ 4.780 & 4.441 & 8.170 & 0.580 \\ 5.880 & 5.463 & 8.460 & 0.601 \\ 3.340 & 3.103 & 3.990 & 0.283 \\ 3.710 & 3.447 & 4.780 & 0.339 \\ 5.760 & 5.351 & 4.710 & 0.334 \\ 6.780 & 6.299 & 4.670 & 0.332 \\ 7.830 & 7.274 & 11.040 & 0.784 \\ 9.040 & 8.398 & 8.320 & 0.591 \\ 9.720 & 9.030 & 4.690 & 0.333 \\ 5.610 & 5.212 & 2.290 & 0.163 \\ 14.250 & 13.238 & 6.590 & 0.468 \\ 10.210 & 9.485 & 0.670 & 0.048 \\ 8.120 & 7.543 & 0.560 & 0.040 \\ 8.630 & 8.017 & 1.430 & 0.102 \\ 6.030 & 5.602 & 1.110 & 0.079 \\ 0.000 & 0.000 & 12.180 & 0.865\end{array}$

$\begin{array}{ccccc}\text { feed } & \text { rec'y } & \text { Av. Range } & & \text { Av. Rec'y } \\ 0.345 & 0.755 & & 0.216 & \\ 1.000 & 0.827 & & 0.059 & \\ 1.208 & 0.823 & & 0.059 & \\ 1.867 & 0.886 & 0-7 & 0.063 & 0.833 \\ 2.565 & 0.815 & & 0.116 & \\ 5.021 & 0.884 & & 0.126 & \\ 6.063 & 0.901 & & 0.193 & \\ 3.386 & 0.916 & & 0.110 & \\ 3.786 & 0.910 & & 0.146 & \\ 5.685 & 0.941 & 7-19.5 & 0.188 & 0.923 \\ 6.630 & 0.950 & & 0.190 & \\ 8.058 & 0.903 & & 0.289 & \\ 8.989 & 0.934 & & & 0.934 \\ 9.363 & 0.964 & & & 0.964 \\ 5.374 & 0.970 & & & 0.970 \\ 13.706 & 0.966 & & & 0.966 \\ 9.533 & 0.995 & & & 0.995 \\ 7.583 & 0.995 & & & 0.995 \\ 8.119 & 0.987 & & & 0.987 \\ 5.681 & 0.986 & & & 0.986 \\ 0.865 & 0.000 & & & \end{array}$


Data Generated from Brinkmann Particle Size Analyzer:

COLUMN FLOTATION (August 7 1996)

Variation of poresize -10 micron

overall recovery $\mathbf{9 0 . 1 \%}$

Particle Size Range (microns) Local Peak (\%) : CONCENTRATE Local Peak (\%) : TAlLS

$$
\begin{aligned}
& 0.0-2.0 \\
& 2.0-2.5 \\
& 2.5-3.0 \\
& 3.0-3.5 \\
& 3.5-4.5 \\
& 4.5-5.5 \\
& 5.5-7.0 \\
& 7.0-8.5 \\
& 8.5-10.5 \\
& 10.5-13.0 \\
& 13.0-15.5 \\
& 15.5-19.5 \\
& 19.5-23.5 \\
& 23.5-29.0 \\
& 29.0-35.5 \\
& 35.5-44.0 \\
& 44.0-54.0 \\
& 54.0-66.0 \\
& 66.0-81.5 \\
& 81.5-100.0 \\
& >100.0
\end{aligned}
$$

\section{CONDITIONS:}

Gas Rate $=800 \mathrm{cc} / \mathrm{min}$

Effective porous tube length $=56 \mathrm{~cm}$

Frother $=5 \mathrm{ppm}$

Percent Solids $=5 \%$

Recycle rate $=101 \mathrm{~cm} / \mathrm{s}$
0.300
0.910
1.110
1.670
2.340
4.660
5.910
3.290
3.670
5.550
6.890
7.810
9.140
9.690
5.550
13.230
9.244
9.120
7.890
4.780
0.000
2.108
4.199
5.325
2.964
3.307
5.001
6.208
7.037
8.235
8.731
5.001
11.920
8.329
8.217
7.109
4.307
0.000

$\begin{array}{ccc}\text { feed } & \text { rec'y } & \text { Av. Range } \\ 0.388 & 0.696 & \\ 1.061 & 0.772 & \\ 1.299 & 0.770 & \\ 1.802 & 0.835 & 0-7 \\ 2.771 & 0.761 & \\ 5.007 & 0.838 & \\ 6.162 & 0.864 & \\ 3.359 & 0.882 & \\ 3.780 & 0.875 & \\ 5.467 & 0.915 & 7-19.5 \\ 6.670 & 0.931 & \\ 8.130 & 0.866 & \\ 9.059 & 0.909 & \\ 9.195 & 0.950 & \\ 5.227 & 0.957 & \\ 12.573 & 0.948 & \\ 8.395 & 0.992 & \\ 8.273 & 0.993 & \\ 7.263 & 0.979 & \\ 4.439 & 0.970 & \\ 1.170 & 0.000 & \end{array}$
1.190
0.118
2.440
3.020
3.000
6.690
8.170
0.242
0.299
0.297
8.460
0.662
0.809
3.990
0.838
4.780
0.395
4.710
0.473
$4.670 \quad 0.462$
$11.040 \quad 1.093$
$8.320 \quad 0.824$
$4.690 \quad 0.464$
$2.290 \quad 0.227$
$6.590 \quad 0.652$
$0.670 \quad 0.066$
$0.560 \quad 0.055$
1.560
0.154
1.340
0.133
11.820
1.170

0.199

0.055

0.055

0.060

0.109

0.120

0.185

0.106

0.140

0.183

0.186

0.277

Av. Rec'y

0.782

0.892

0.909

0.950

0.957

0.948

0.992

0.993

0.979

0.970 
Data Generated from Brinkmann Particle Size Analyzer:

COLUMN FLOTATION (August 1 1996)

Variation of recycle rate: Slurry superficial velocity $=47 \mathrm{~cm} / \mathrm{s}$

overall recovery $\mathbf{7 2 . 1 \%}$

Particle Size Range (microns) Local Peak (\%) : CONCENTRATE
$0.0-2.0$
$2.0-2.5$
$2.5-3.0$
$3.0-3.5$
$3.5-4.5$
$4.5-5.5$
$5.5-7.0$
$7.0-8.5$
$8.5-10.5$
$10.5-13.0$
$13.0-15.5$
$15.5-19.5$
$19.5-23.5$
$23.5-29.0$
$29.0-35.5$
$35.5-44.0$
$44.0 \cdot 54.0$
$54.0-66.0$
$66.0-81.5$
$81.5-100.0$
$>100.0$

$\begin{array}{rr}1.000 & 0.721 \\ 0.580 & 0.418 \\ 0.850 & 0.613 \\ 1.280 & 0.923 \\ 2.880 & 2.076 \\ 4.180 & 3.014 \\ 4.410 & 3.180 \\ 2.320 & 1.673 \\ 2.300 & 1.658 \\ 3.610 & 2.603 \\ 3.120 & 2.250 \\ 4.830 & 3.482 \\ 2.670 & 1.925 \\ 4.840 & 3.490 \\ 5.250 & 3.785 \\ 15.490 & 11.168 \\ 14.270 & 10.289 \\ 5.750 & 4.146 \\ 4.390 & 3.165 \\ 4.880 & 3.518 \\ 11.100 & 8.003\end{array}$

feed

1.346

0.879

1.269

1.832

4.431

5.887

6.145

3.149

3.109

4.171

3.728

6.094

3.803

5.030

4.569

13.202

10.540

4.606

3.503

4.015

8.692 rec'y

0.536

0.476

0.483

0.504

0.469

0.512

0.517

0.531

0.533

0.624

0.603

0.571

0.506

0.694

0.828

0.846

0.976

0.900

0.904

0.876

0.921
Local Peak (\%) : TAlLS

$\begin{array}{rr}2.240 & 0.625 \\ 1.650 & 0.460 \\ 2.350 & 0.656 \\ 3.260 & 0.910 \\ 8.440 & 2.355 \\ 10.300 & 2.874 \\ 10.630 & 2.966 \\ 5.290 & 1.476 \\ 5.200 & 1.451 \\ 5.620 & 1.568 \\ 5.300 & 1.479 \\ 9.360 & 2.611 \\ 6.730 & 1.878 \\ 5.520 & 1.540 \\ 2.810 & 0.784 \\ 7.290 & 2.034 \\ 0.900 & 0.251 \\ 1.650 & 0.460 \\ 1.210 & 0.338 \\ 1.780 & 0.497 \\ 2.470 & 0.689\end{array}$

Av. Range

0.153

0.034

0.035

0.7

0.036

0.067

0.073

0.111

0.064

0.085

7-19.5

0.125

0.121

0.183

Av. Rec'y

0.508

0.577

0.506

0.694

0.828

0.846

0.976

0.900

0.904

0.876

0.921 
Data Generated from Brinkmann Particle Size Analyzer:

COLUMN FLOTATION (August 1 1996)

Variation of recycle rate: Slurry superficial velocity $=65 \mathrm{~cm} / \mathrm{s}$

overall recovery $\mathbf{8 3 . 4 \%}$

Particle Size Range (microns) Local Peak (\%) : CONCENTRATE

$0.0-2.0$
$2.0-2.5$
$2.5-3.0$
$3.0-3.5$
$3.5-4.5$
$4.5-5.5$
$5.5-7.0$
$7.0-8.5$
$8.5-10.5$
$10.5-13.0$
$13.0-15.5$
$15.5-19.5$
$19.5-23.5$
$23.5-29.0$
$29.0-35.5$
$35.5-44.0$
$44.0-54.0$
$54.0-66.0$
$66.0-81.5$
$81.5-100.0$
$>100.0$

CONDITIONS:

Gas Rate $=800 \mathrm{cc} / \mathrm{min}$

Effective porous tube length $=56 \mathrm{~cm}$

Frother $=5 \mathrm{ppm}$

Percent Solids $=5 \%$

Pore size $=2$ micron

$\begin{array}{rrrr}0.980 & 0.817 & 2.240 & 0.372 \\ 0.660 & 0.550 & 1.650 & 0.274 \\ 1.000 & 0.834 & 2.350 & 0.390 \\ 1.390 & 1.159 & 3.260 & 0.541 \\ 3.960 & 3.303 & 8.440 & 1.401 \\ 4.270 & 3.561 & 10.300 & 1.710 \\ 4.550 & 3.795 & 10.630 & 1.765 \\ 2.730 & 2.277 & 5.290 & 0.878 \\ 3.740 & 3.119 & 5.200 & 0.863 \\ 4.200 & 3.503 & 5.620 & 0.933 \\ 4.770 & 3.978 & 5.300 & 0.880 \\ 4.980 & 4.153 & 9.360 & 1.554 \\ 4.660 & 3.886 & 6.730 & 1.117 \\ 4.970 & 4.145 & 5.520 & 0.916 \\ 6.040 & 5.037 & 2.810 & 0.466 \\ 10.530 & 8.782 & 7.290 & 1.210 \\ 14.900 & 12.427 & 0.900 & 0.149 \\ 12.330 & 10.283 & 1.650 & 0.274 \\ 6.830 & 5.696 & 1.210 & 0.201 \\ 2.510 & 2.093 & 1.780 & 0.295 \\ 0.000 & 0.000 & 2.470 & 0.410\end{array}$

feed

1.189

0.824

1.224

1.700

4.704

5.271

5.559

3.155

3.982

4.436

4.858

5.707

5.004

5.061

5.504

9.992

12.576

10.557

5.897

2.389

0.410 rec'y

0.687

0.668

0.681

0.682

0.702

0.676

0.683

0.722

0.783

0.790

0.819

0.728

0.777

0.819

0.915

0.879

0.988

0.974

0.966

0.876

0.000
Av. Range

0.196

0.048

0.049

$\begin{array}{ll}0.7 & 0.049\end{array}$

0.100

0.097

0.146

0.087

0.125

$7-19.5$

0.158

0.164

0.233

0.777

0.819

0.915

0.879

0.988

0.974

0.966

0.876

Av. Rec'y

0.685

0.767 
Data Generated from Brinkmann Particle Size Aralyzer:

COLUMN FLOTATION (August 1 1996)

Variation of recycle rate: Slurry superficial velocity $=83 \mathrm{~cm} / \mathrm{s}$

overall recovery $\mathbf{8 6 . 8 \%}$

Particle Size Range (microns) Local Peak (\%) : CONCENTRATE Local Peak (\%) : TAlLS

CONDITIONS:

$0.0-2.0$

$2.0-2.5$

$2.5-3.0$

$3.0-3.5$

$3.5-4.5$

$4.5-5.5$

$5.5-7.0$

$7.0-8.5$

$8.5-10.5$

$10.5-13.0$

$13.0-15.5$

$15.5-19.5$

$19.5-23.5$

$23.5-29.0$

$29.0-35.5$

$35.5-44.0$

$44.0-54.0$

$54.0-66.0$

$66.0-81.5$

$81.5-100.0$

$>100.0$

Gas Rate $=800 \mathrm{cc} / \mathrm{min}$

Effective porous tube length $=56 \mathrm{~cm}$

Frother $=5 \mathrm{ppm}$

Percent Solids $=5 \%$

Pore size $=2$ micron

$\begin{array}{rrrr}0.840 & 0.730 & 2.240 & 0.293 \\ 0.460 & 0.400 & 1.650 & 0.216 \\ 0.690 & 0.600 & 2.350 & 0.308 \\ 1.010 & 0.878 & 3.260 & 0.427 \\ 2.480 & 2.155 & 8.440 & 1.106 \\ 2.910 & 2.529 & 10.300 & 1.349 \\ 3.520 & 3.059 & 10.630 & 1.393 \\ 1.940 & 1.686 & 5.290 & 0.693 \\ 2.540 & 2.207 & 5.200 & 0.681 \\ 3.270 & 2.842 & 5.620 & 0.736 \\ 3.000 & 2.607 & 5.300 & 0.694 \\ 5.140 & 4.467 & 9.360 & 1.226 \\ 4.690 & 4.076 & 6.730 & 0.882 \\ 6.780 & 5.892 & 5.520 & 0.723 \\ 6.870 & 5.970 & 2.810 & 0.368 \\ 16.320 & 14.182 & 7.290 & 0.955 \\ 11.480 & 9.976 & 0.900 & 0.118 \\ 6.340 & 5.509 & 1.650 & 0.216 \\ 3.010 & 2.616 & 1.210 & 0.159 \\ 5.400 & 4.693 & 1.780 & 0.233 \\ 11.310 & 9.828 & 2.470 & 0.324\end{array}$

$\begin{array}{ccccc}\text { feed } & \text { rec'y } & \text { Av. Range } & & \text { Av. Rec'y } \\ 1.023 & 0.713 & & 0.204 & \\ 0.616 & 0.649 & & 0.046 & \\ 0.907 & 0.661 & & 0.047 & \\ 1.305 & 0.673 & 0-7 & 0.048 & 0.680 \\ 3.261 & 0.661 & & 0.094 & \\ 3.878 & 0.652 & & 0.093 & \\ 4.451 & 0.687 & & 0.147 & \\ 2.379 & 0.709 & & 0.085 & \\ 2.888 & 0.764 & & 0.122 & \\ 3.578 & 0.794 & 7-19.5 & 0.159 & 0.775 \\ 3.301 & 0.790 & & 0.158 & \\ 5.693 & 0.785 & & 0.251 & \\ 4.957 & 0.822 & & & 0.822 \\ 6.615 & 0.891 & & & 0.891 \\ 6.338 & 0.942 & & & 0.942 \\ 15.137 & 0.937 & & & 0.937 \\ 10.094 & 0.988 & & & 0.988 \\ 5.726 & 0.962 & & & 0.962 \\ 2.774 & 0.943 & & & 0.943 \\ 4.926 & 0.953 & & & 0.953 \\ 10.152 & 0.968 & & & 0.968\end{array}$


Data Generated from Brinkmann Particle Size Analyzer:

COLUMN FLOTATION (August 1 1996)

Variation of recycle rate: Slurry superficial velocity $=101 \mathrm{~cm} / \mathrm{s}$

overall recovery $\mathbf{9 2 . 7 \%}$

Particle Size Range (microns) Local Peak (\%) : CONCENTRATE

$$
\begin{aligned}
& 0.0-2.0 \\
& 2.0-2.5 \\
& 2.5-3.0 \\
& 3.0-3.5 \\
& 3.5-4.5 \\
& 4.5-5.5 \\
& 5.5-7.0 \\
& 7.0-8.5 \\
& 8.5-10.5 \\
& 10.5-13.0 \\
& 13.0-15.5 \\
& 15.5-19.5 \\
& 19.5-23.5 \\
& 23.5-29.0 \\
& 29.0-35.5 \\
& 35.5-44.0 \\
& 44.0-54.0 \\
& 54.0-66.0 \\
& 66.0-81.5 \\
& 81.5-100.0 \\
& >100.0
\end{aligned}
$$

CONDITIONS:

Gas Rate $=800 \mathrm{cc} / \mathrm{min}$

Effective porous tube length $=56 \mathrm{~cm}$

Frother $=5 \mathrm{ppm}$

Percent Solids $=5 \%$

Pore size $=2$ micron

$\begin{array}{rr}0.490 & 0.454 \\ 0.310 & 0.287 \\ 0.460 & 0.426 \\ 0.580 & 0.538 \\ 1.760 & 1.632 \\ 2.340 & 2.169 \\ 2.540 & 2.355 \\ 1.770 & 1.641 \\ 1.750 & 1.622 \\ 1.830 & 1.696 \\ 2.300 & 2.132 \\ 4.420 & 4.097 \\ 2.880 & 2.670 \\ 2.630 & 2.438 \\ 3.360 & 3.115 \\ 12.040 & 11.161 \\ 9.700 & 8.992 \\ 13.520 & 12.533 \\ 6.910 & 6.406 \\ 9.050 & 8.389 \\ 19.360 & 17.947\end{array}$

$\begin{array}{ccccc}\text { feed } & \text { rec'y } & \text { Av. Range } & & \text { Av. Rec'y } \\ 0.618 & 0.735 & & 0.210 & \\ 0.408 & 0.705 & & 0.050 & \\ 0.598 & 0.713 & & 0.051 & \\ 0.776 & 0.693 & 0-7 & 0.050 & 0.732 \\ 2.248 & 0.726 & & 0.104 & \\ 2.921 & 0.743 & & 0.106 & \\ 3.131 & 0.752 & & 0.161 & \\ 2.027 & 0.809 & & 0.097 & \\ 2.002 & 0.810 & & 0.130 & \\ 2.107 & 0.805 & 7-19.5 & 0.161 & 0.831 \\ 2.519 & 0.846 & & 0.169 & \\ 4.781 & 0.857 & & 0.274 & \\ 3.161 & 0.845 & & & 0.845 \\ 2.841 & 0.858 & & & 0.858 \\ 3.320 & 0.938 & & & 0.938 \\ 11.693 & 0.954 & & & 0.954 \\ 9.058 & 0.993 & & & 0.993 \\ 12.653 & 0.990 & & & 0.990 \\ 6.494 & 0.986 & & & 0.986 \\ 8.519 & 0.985 & & & 0.985 \\ 18.127 & 0.990 & & & 0.990\end{array}$

$\begin{array}{rr}2.240 & 0.164 \\ 1.650 & 0.120 \\ 2.350 & 0.172 \\ 3.260 & 0.238 \\ 8.440 & 0.616 \\ 10.300 & 0.752 \\ 10.630 & 0.776 \\ 5.290 & 0.386 \\ 5.200 & 0.380 \\ 5.620 & 0.410 \\ 5.300 & 0.387 \\ 9.360 & 0.683 \\ 6.730 & 0.491 \\ 5.520 & 0.403 \\ 2.810 & 0.205 \\ 7.290 & 0.532 \\ 0.900 & 0.066 \\ 1.650 & 0.120 \\ 1.210 & 0.088 \\ 1.780 & 0.130 \\ 2.470 & 0.180\end{array}$

Local Peak (\%) : TAILS 
Data Generated from Brinkmann Particle Size Analyzer: COLUMN FLOTATION Repeated Test \#1

Slurry superficial velocity $=101 \mathrm{~cm} / \mathrm{s}$

overall recovery $91.4 \%$

Particle Size Range (microns) Local Peak (\%) : CONCENTRATE

$$
\begin{aligned}
& 0.0-2.0 \\
& 2.0-2.5 \\
& 2.5-3.0 \\
& 3.0-3.5 \\
& 3.5-4.5 \\
& 4.5-5.5 \\
& 5.5-7.0 \\
& 7.0-8.5 \\
& 8.5-10.5 \\
& 10.5-13.0 \\
& 13.0-15.5 \\
& 15.5-19.5 \\
& 19.5-23.5 \\
& 23.5-29.0 \\
& 29.0-35.5 \\
& 35.5-44.0 \\
& 44.0-54.0 \\
& 54.0-66.0 \\
& 66.0-81.5 \\
& 81.5-100.0 \\
& >100.0
\end{aligned}
$$

0.450

0.290

0.470

0.590

1.660

2.200

1.970

2.100

1.760

1.890

2.210

4.050

2.910

2.670

4.120

11.280

10.180

13.110

7.650

8.680

19.760

CONDITIONS:

Gas Rate $=800 \mathrm{cc} / \mathrm{min}$

Effective porous tube length $=56 \mathrm{~cm}$

Frother $=5 \mathrm{ppm}$

Percent Solids $=5 \%$

Pore size $=2$ micron
0.411

0.265

0.430

0.539

1.517

2.011

1.801

1.919

1.609

1.727

2.020

3.702

2.660

2.440

3.766

10.310

9.305

11.983

6.992

7.934

18.061

$\begin{array}{cc}\text { feed } & \text { rec'y } \\ 0.603 & 0.682 \\ 0.399 & 0.664 \\ 0.659 & 0.652 \\ 0.799 & 0.675 \\ 2.292 & 0.662 \\ 2.965 & 0.678 \\ 2.659 & 0.677 \\ 2.358 & 0.814 \\ 2.036 & 0.790 \\ 2.194 & 0.787 \\ 2.472 & 0.817 \\ 4.508 & 0.821 \\ 3.235 & 0.822 \\ 2.882 & 0.847 \\ 4.028 & 0.935 \\ 10.903 & 0.946 \\ 9.405 & 0.989 \\ 12.126 & 0.988 \\ 7.088 & 0.987 \\ 8.096 & 0.980 \\ 18.291 & 0.987\end{array}$

Local Peak (\%) : TAILS

$\begin{array}{rr}2.230 & 0.192 \\ 1.560 & 0.134 \\ 2.670 & 0.230 \\ 3.020 & 0.260 \\ 9.010 & 0.775 \\ 11.090 & 0.954 \\ 9.980 & 0.858 \\ 5.100 & 0.439 \\ 4.970 & 0.427 \\ 5.430 & 0.467 \\ 5.260 & 0.452 \\ 9.380 & 0.807 \\ 6.690 & 0.575 \\ 5.140 & 0.442 \\ 3.050 & 0.262 \\ 6.900 & 0.593 \\ 1.170 & 0.101 \\ 1.670 & 0.144 \\ 1.110 & 0.095 \\ 1.890 & 0.163 \\ 2.680 & 0.230\end{array}$

Av. Range

0.195

0.047

0.047

$0-7 \quad 0.048$

0.095

0.097

0.145

0.098

0.126

7-19.5 0.157

0.163

0.263

Av. Rec'y

0.674

0.808

0.822

0.847

0.935

0.946

0.989

0.988

0.987

0.980

0.987 
Data Generated from Brinkmann Particle Size Analyzer:

COLUMN FLOTATION Repeated Test $\# 2$

Slurry superficial velocity $=101 \mathrm{~cm} / \mathrm{s}$

overall recovery $\mathbf{9 2 . 8 \%}$

Particle Size Range (microns) Local Peak (\%) : CONCENTRATE

$$
\begin{aligned}
& 0.0-2.0 \\
& 2.0-2.5 \\
& 2.5-3.0 \\
& 3.0-3.5 \\
& 3.5-4.5 \\
& 4.5-5.5 \\
& 5.5-7.0 \\
& 7.0-8.5 \\
& 8.5-10.5 \\
& 10.5-13.0 \\
& 13.0-15.5 \\
& 15.5-19.5 \\
& 19.5-23.5 \\
& 23.5-29.0 \\
& 29.0-35.5 \\
& 35.5-44.0 \\
& 44.0-54.0 \\
& 54.0-66.0 \\
& 66.0-81.5 \\
& 81.5-100.0 \\
& >100.0
\end{aligned}
$$

CONDITIONS:

Gas Rate $=800 \mathrm{cc} / \mathrm{min}$

Effective porous tube length $=56 \mathrm{~cm}$

Frother $=5 \mathrm{ppm}$

Percent Solids $=5 \%$

Pore size $=2$ micron

$\begin{array}{rr}0.530 & 0.492 \\ 0.460 & 0.427 \\ 0.600 & 0.557 \\ 0.610 & 0.566 \\ 1.980 & 1.837 \\ 2.560 & 2.376 \\ 2.670 & 2.478 \\ 1.670 & 1.550 \\ 1.740 & 1.615 \\ 1.780 & 1.652 \\ 2.280 & 2.116 \\ 4.410 & 4.092 \\ 2.480 & 2.301 \\ 2.590 & 2.404 \\ 3.490 & 3.239 \\ 11.890 & 11.034 \\ 10.500 & 9.744 \\ 12.960 & 12.027 \\ 6.780 & 6.292 \\ 8.810 & 8.176 \\ 19.210 & 17.827\end{array}$

feed

0.650

0.533

0.714

0.778

2.305

3.051

3.334

1.937

1.990

2.076

2.556

4.818

2.804

2.788

3.432

11.602

9.830

12.113

6.379

8.328

17.983

$\begin{array}{lc}\text { rec'y } & \text { Av. Range } \\ 0.757 & \\ 0.800 & \\ 0.780 & \\ 0.728 & 0-7 \\ 0.797 & \\ 0.779 & \\ 0.743 & \\ 0.800 & \\ 0.811 & \\ 0.796 & 7-19.5 \\ 0.828 & \\ 0.849 & \\ 0.821 & \\ 0.862 & \\ 0.944 & \\ 0.951 & \\ 0.991 & \\ 0.993 & \\ 0.986 & \\ 0.982 & \\ 0.991 & \end{array}$

Local Peak (\%) : TAlLS

$\begin{array}{rr}2.190 & 0.158 \\ 1.480 & 0.107 \\ 2.180 & 0.157 \\ 2.940 & 0.212 \\ 6.490 & 0.467 \\ 9.380 & 0.675 \\ 11.890 & 0.856 \\ 5.380 & 0.387 \\ 5.210 & 0.375 \\ 5.890 & 0.424 \\ 6.120 & 0.441 \\ 10.070 & 0.725 \\ 6.980 & 0.503 \\ 5.340 & 0.384 \\ 2.690 & 0.194 \\ 7.890 & 0.568 \\ 1.190 & 0.086 \\ 1.200 & 0.086 \\ 1.210 & 0.087 \\ 2.110 & 0.152 \\ 2.170 & 0.156\end{array}$

2.170

Av. Rec'y

0.216

0.057

0.056

0.052

0.114

0.111

0.159

0.096

0.130

$0.159 \quad 0.822$

0.166

0.272

0.766

0.821

0.862

0.944

0.951

0.991

0.993

0.986

0.982

0.991 
Data Generated from Brinkmann Particle Size Analyzer:

COLUMN FLOTATION (August 1 1996)

Variation of recycle rate: Slurry superficial velocity $=120 \mathrm{~cm} / \mathrm{s}$

overall recovery $\mathbf{8 9 . 4 \%}$

Particle Size Range (microns) Local Peak (\%) : CONCENTRATE
CONDITIONS:

Gas Rate $=800 \mathrm{cc} / \mathrm{min}$

Effective porous tube length $=56 \mathrm{~cm}$

Frother $=5 \mathrm{ppm}$

Percent Solids $=5 \%$

Pore size $=2$ micron

1.100
0.650
0.990
1.310
2.730
4.700
5.270
3.480
3.320
3.670
5.920
6.850
7.880
7.180
3.720
16.300
8.040
8.230
7.240
3.370
0.000

0.983

0.581

0.885

1.171

2.441

4.202

4.711

3.111

2.968

3.281

5.292

6.124

7.045

6.419

3.326

14.572

7.188

7.358

6.473

3.013

0.000
Local Peak (\%) : TAILS

$\begin{array}{rr}2.240 & 0.237 \\ 1.650 & 0.175 \\ 2.350 & 0.249 \\ 3.260 & 0.346 \\ 8.440 & 0.895 \\ 10.300 & 1.092 \\ 10.630 & 1.127 \\ 5.290 & 0.561 \\ 5.200 & 0.551 \\ 5.620 & 0.596 \\ 5.300 & 0.562 \\ 9.360 & 0.992 \\ 6.730 & 0.713 \\ 5.520 & 0.585 \\ 2.810 & 0.298 \\ 7.290 & 0.773 \\ 0.900 & 0.095 \\ 1.650 & 0.175 \\ 1.210 & 0.128 \\ 1.780 & 0.189 \\ 2.470 & 0.262\end{array}$

$\begin{array}{ccc}\text { feed } & \text { rec'y } & \text { Av. Range } \\ 1.221 & 0.806 & \\ 0.756 & 0.769 & \\ 1.134 & 0.780 & \\ 1.517 & 0.772 & 0-7 \\ 3.335 & 0.732 & \\ 5.294 & 0.794 & \\ 5.838 & 0.807 & \\ 3.672 & 0.847 & \\ 3.519 & 0.843 & \\ 3.877 & 0.846 & 7-19.5 \\ 5.854 & 0.904 & \\ 7.116 & 0.861 & \\ 7.758 & 0.908 & \\ 7.004 & 0.916 & \\ 3.624 & 0.918 & \\ 15.345 & 0.950 & \\ 7.283 & 0.987 & \\ 7.533 & 0.977 & \\ 6.601 & 0.981 & \\ 3.201 & 0.941 & \\ 0.262 & 0.000 & \end{array}$

Av. Rec'y

0.230

0.055

0.056

0.055

0.105

0.113

0.173

0.102

0.135

0.169

0.181

0.275
0.787

0.862

0.908

0.916

0.918

0.950

0.987

0.977

0.981

0.941 
Data Generated from Brinkmann Particle Size Analyzer:

COLUMN FLOTATION (August 1 1996)

Variation of recycle rate: Slurry superficial velocity $=140 \mathrm{~cm} / \mathrm{s}$

overall recovery $\mathbf{8 6 . 2 \%}$

Particle Size Range (microns) Local Peak (\%) : CONCENTRATE

Local Peak (\%) : TAlLS

$$
\begin{aligned}
& 0.0-2.0 \\
& 2.0-2.5 \\
& 2.5-3.0 \\
& 3.0-3.5 \\
& 3.5-4.5 \\
& 4.5-5.5 \\
& 5.5-7.0 \\
& 7.0-8.5 \\
& 8.5-10.5 \\
& 10.5-13.0 \\
& 13.0-15.5 \\
& 15.5-19.5 \\
& 19.5-23.5 \\
& 23.5-29.0 \\
& 29.0-35.5 \\
& 35.5-44.0 \\
& 44.0-54.0 \\
& 54.0-66.0 \\
& 66.0-81.5 \\
& 81.5-100.0 \\
& >100.0
\end{aligned}
$$

\section{CONDITIONS:}

Gas Rate $=800 \mathrm{cc} / \mathrm{min}$

Effective porous tube length $=56 \mathrm{~cm}$

Frother $=5 \mathrm{ppm}$

Percent Solids $=5 \%$

Pore size $=2$ micron

$\begin{array}{rr}1.020 & 0.879 \\ 0.500 & 0.431 \\ 0.850 & 0.733 \\ 1.100 & 0.948 \\ 3.110 & 2.681 \\ 3.610 & 3.112 \\ 3.880 & 3.345 \\ 2.910 & 2.508 \\ 3.250 & 2.802 \\ 4.180 & 3.603 \\ 5.120 & 4.413 \\ 6.570 & 5.663 \\ 4.620 & 3.982 \\ 5.900 & 5.086 \\ 3.940 & 3.396 \\ 18.450 & 15.904 \\ 14.660 & 12.637 \\ 8.210 & 7.077 \\ 5.750 & 4.957 \\ 2.000 & 1.724 \\ 0.370 & 0.319\end{array}$

feed

1.188

0.659

1.057

1.398

3.846

4.533

4.812

3.238

3.519

4.379

5.145

6.955

4.911

5.848

3.784

16.910

12.761

7.305

5.123

1.970

0.660 rec'y

0.740

0.654

0.693

0.678

0.697

0.686

0.695

0.775

0.796

0.823

0.858

0.814

0.811

0.870

0.898

0.941

0.990

0.969

0.967

0.875

0.483

$\begin{array}{rr}2.240 & 0.309 \\ 1.650 & 0.228 \\ 2.350 & 0.324 \\ 3.260 & 0.450 \\ 8.440 & 1.165 \\ 10.300 & 1.421 \\ 10.630 & 1.467 \\ 5.290 & 0.730 \\ 5.200 & 0.718 \\ 5.620 & 0.776 \\ 5.300 & 0.731 \\ 9.360 & 1.292 \\ 6.730 & 0.929 \\ 5.520 & 0.762 \\ 2.810 & 0.388 \\ 7.290 & 1.006 \\ 0.900 & 0.124 \\ 1.650 & 0.228 \\ 1.210 & 0.167 \\ 1.780 & 0.246 \\ 2.470 & 0.341\end{array}$

Av. Range

$0-7$

Av. Rec'y

0.211

0.047

0.050

0.048

0.100

0.098

0.149

0.093

0.127

0.165

0.172

0.261

0.703

0.817

0.811

0.870

0.898

0.941

0.990

0.969

0.967

0.875

0.483 
Data Generated from Brinkmann Particle Size Analyzer:

COLUMN FLOTATION (August 7 1996)

Variation of effective porous tube length $=14 \mathrm{~cm}$

overall recovery $\mathbf{8 9 . 8 \%}$

Particle Size Range (microns) Local Peak (\%) : CONCENTRATE

Local Peak (\%) : TAILS

$$
\begin{aligned}
& 0.0-2.0 \\
& 2.0-2.5 \\
& 2.5-3.0 \\
& 3.0-3.5 \\
& 3.5-4.5 \\
& 4.5-5.5 \\
& 5.5-7.0 \\
& 7.0-8.5 \\
& 8.5-10.5 \\
& 10.5-13.0 \\
& 13.0-15.5 \\
& 15.5-19.5 \\
& 19.5-23.5 \\
& 23.5-29.0 \\
& 29.0-35.5 \\
& 35.5-44.0 \\
& 44.0-54.0 \\
& 54.0-66.0 \\
& 66.0-81.5 \\
& 81.5-100.0 \\
& >100.0
\end{aligned}
$$

CONDITIONS:

Gas Rate $=800 \mathrm{cc} / \mathrm{min}$

Recycle Rate $=101 \mathrm{~cm} / \mathrm{s}$

Frother $=5 \mathrm{ppm}$

Percent Solids $=5 \%$

Pore size $=2$ micron

$\begin{array}{rr}0.260 & 0.233 \\ 0.890 & 0.799 \\ 1.030 & 0.925 \\ 1.560 & 1.401 \\ 2.220 & 1.994 \\ 4.670 & 4.194 \\ 6.130 & 5.505 \\ 3.230 & 2.901 \\ 3.220 & 2.892 \\ 5.410 & 4.858 \\ 5.950 & 5.343 \\ 6.560 & 5.891 \\ 8.010 & 7.193 \\ 8.670 & 7.786 \\ 4.420 & 3.969 \\ 12.560 & 11.279 \\ 9.470 & 8.504 \\ 8.670 & 7.786 \\ 7.450 & 6.690 \\ 5.670 & 5.092 \\ 0.000 & 0.000\end{array}$

$\begin{array}{ccc}\text { feed } & \text { rec'y } & \text { Av. Range } \\ 0.355 & 0.658 & \\ 1.060 & 0.754 & \\ 1.230 & 0.752 & \\ 1.733 & 0.808 & 0-7 \\ 2.712 & 0.735 & \\ 5.123 & 0.819 & \\ 6.480 & 0.850 & \\ 3.427 & 0.846 & \\ 3.483 & 0.830 & \\ 5.346 & 0.909 & 7-19.5 \\ 5.832 & 0.916 & \\ 7.114 & 0.828 & \\ 8.101 & 0.888 & \\ 8.399 & 0.927 & \\ 4.253 & 0.933 & \\ 11.939 & 0.945 & \\ 8.617 & 0.987 & \\ 7.957 & 0.978 & \\ 6.925 & 0.966 & \\ 5.313 & 0.958 & \\ 0.036 & 0.000 & \end{array}$

$\begin{array}{rr}1.190 & 0.121 \\ 2.560 & 0.261 \\ 2.990 & 0.305 \\ 3.260 & 0.333 \\ 7.040 & 0.718 \\ 9.110 & 0.929 \\ 9.560 & 0.975 \\ 5.160 & 0.526 \\ 5.800 & 0.592 \\ 4.780 & 0.488 \\ 4.790 & 0.489 \\ 11.990 & 1.223 \\ 8.900 & 0.908 \\ 6.010 & 0.613 \\ 2.780 & 0.284 \\ 6.470 & 0.660 \\ 1.110 & 0.113 \\ 1.680 & 0.171 \\ 2.300 & 0.235 \\ 2.170 & 0.221 \\ 0.350 & 0.036\end{array}$

Av. Rec'y

0.188

0.054

0.054

0.058

0.105

0.117

0.182

0.102

0.133

0.182

0.183

0.265

0.864

0.888

0.927

0.933

0.945

0.987

0.978

0.966

0.958 
Data Generated from Brinkmann Particle Size Analyzer:

COLUMN FLOTATION (August 7 1996)

Variation of effective porous tube length $=28 \mathrm{~cm}$

overall recovery $91.0 \%$

Particle Size Range (microns) Local Peak (\%) : CONCENTRATE

$$
\begin{aligned}
& 0.0-2.0 \\
& 2.0-2.5 \\
& 2.5-3.0 \\
& 3.0-3.5 \\
& 3.5-4.5 \\
& 4.5-5.5 \\
& 5.5-7.0 \\
& 7.0-8.5 \\
& 8.5-10.5 \\
& 10.5-13.0 \\
& 13.0-15.5 \\
& 15.5-19.5 \\
& 19.5-23.5 \\
& 23.5-29.0 \\
& 29.0-35.5 \\
& 35.5-44.0 \\
& 44.0-54.0 \\
& 54.0-66.0 \\
& 66.0-81.5 \\
& 81.5-100.0 \\
& >100.0
\end{aligned}
$$

\section{CONDITIONS:}

Gas Rate $=800 \mathrm{cc} / \mathrm{min}$

Recycle Rate $=101 \mathrm{~cm} / \mathrm{s}$

Frother $=5 \mathrm{ppm}$

Percent Solids $=5 \%$

Pore size $=2$ micron

$\begin{array}{rr}0.210 & 0.191 \\ 0.670 & 0.610 \\ 0.980 & 0.892 \\ 1.290 & 1.174 \\ 2.710 & 2.466 \\ 4.510 & 4.104 \\ 5.240 & 4.768 \\ 3.500 & 3.185 \\ 3.270 & 2.976 \\ 5.350 & 4.869 \\ 6.030 & 5.487 \\ 6.810 & 6.197 \\ 7.560 & 6.880 \\ 7.890 & 7.180 \\ 3.300 & 3.003 \\ 12.200 & 11.102 \\ 8.770 & 7.981 \\ 8.980 & 8.172 \\ 7.680 & 6.989 \\ 4.890 & 4.450 \\ 0.000 & 0.000\end{array}$

$\begin{array}{ccc}\text { feed } & \text { rec'y } & \text { Av. Range } \\ 0.303 & 0.631 & \\ 0.768 & 0.794 & \\ 1.134 & 0.786 & \\ 1.479 & 0.794 & 0-7 \\ 3.066 & 0.804 & \\ 4.849 & 0.846 & \\ 5.569 & 0.856 & \\ 3.662 & 0.870 & \\ 3.447 & 0.863 & \\ 5.288 & 0.921 & 7-19.5 \\ 5.918 & 0.927 & \\ 7.188 & 0.862 & \\ 7.500 & 0.917 & \\ 7.579 & 0.947 & \\ 3.170 & 0.947 & \\ 11.490 & 0.966 & \\ 8.061 & 0.990 & \\ 8.322 & 0.982 & \\ 7.168 & 0.975 & \\ 4.590 & 0.969 & \\ 1.125 & 0.000 & \end{array}$

Local Peak (\%) : TAILS

$\begin{array}{rr}1.240 & 0.112 \\ 1.760 & 0.158 \\ 2.690 & 0.242 \\ 3.390 & 0.305 \\ 6.670 & 0.600 \\ 8.280 & 0.745 \\ 8.890 & 0.800 \\ 5.300 & 0.477 \\ 5.240 & 0.472 \\ 4.660 & 0.419 \\ 4.780 & 0.430 \\ 11.010 & 0.991 \\ 6.890 & 0.620 \\ 4.430 & 0.399 \\ 1.850 & 0.167 \\ 4.310 & 0.388 \\ 0.890 & 0.080 \\ 1.670 & 0.150 \\ 1.990 & 0.179 \\ 1.560 & 0.140 \\ 12.500 & 1.125\end{array}$

Av. Rec'y

0.180

0.057

0.056

0.057

0.115

0.121

0.183

0.104

0.138

0.184

0.185

0.276

0.888

0.917

0.947

0.947

0.966

0.990

0.982

0.975

0.969 
Data Generated from Brinkmann Particle Size Analyzer:

COLUMN FLOTATION (August 14 1996)

Variation of effective porous tube length $=56 \mathrm{~cm}$

overall recovery $92.8 \%$

Particle Size Range (microns) Local Peak (\%) : CONCENTRATE

Local Peak (\%) : TAILS
$0.0-2.0$
$2.0-2.5$
$2.5-3.0$
$3.0-3.5$
$3.5-4.5$
$4.5-5.5$
$5.5-7.0$
$7.0-8.5$
$8.5-10.5$
$10.5-13.0$
$13.0-15.5$
$15.5-19.5$
$19.5-23.5$
$23.5-29.0$
$29.0-35.5$
$35.5-44.0$
$44.0-54.0$
$54.0-66.0$
$66.0-81.5$
$81.5-100.0$
$>100.0$

CONDITIONS:

Gas Rate $=800 \mathrm{cc} / \mathrm{min}$

Recycle Rate $=101 \mathrm{~cm} / \mathrm{s}$

Frother $=5 \mathrm{ppm}$

Percent Solids $=5 \%$

Pore size $=2$ micron

$\begin{array}{rr}0.280 & 0.260 \\ 0.890 & 0.827 \\ 1.070 & 0.994 \\ 1.780 & 1.654 \\ 2.250 & 2.090 \\ 4.780 & 4.441 \\ 5.880 & 5.463 \\ 3.340 & 3.103 \\ 3.710 & 3.447 \\ 5.760 & 5.351 \\ 6.780 & 6.299 \\ 7.830 & 7.274 \\ 9.040 & 8.398 \\ 9.720 & 9.030 \\ 5.610 & 5.212 \\ 14.250 & 13.238 \\ 10.210 & 9.485 \\ 8.120 & 7.543 \\ 8.630 & 8.017 \\ 6.030 & 5.602 \\ 0.000 & 0.000\end{array}$

$\begin{array}{ccc}\text { feed } & \text { rec'y } & \text { Av. Range } \\ 0.345 & 0.755 & \\ 1.000 & 0.827 & \\ 1.208 & 0.823 & \\ 1.867 & 0.886 & 0-7 \\ 2.565 & 0.815 & \\ 5.021 & 0.884 & \\ 6.063 & 0.901 & \\ 3.386 & 0.916 & \\ 3.786 & 0.910 & \\ 5.685 & 0.941 & 7-19.5 \\ 6.630 & 0.950 & \\ 8.058 & 0.903 & \\ 8.989 & 0.934 & \\ 9.363 & 0.964 & \\ 5.374 & 0.970 & \\ 13.706 & 0.966 & \\ 9.533 & 0.995 & \\ 7.583 & 0.995 & \\ 8.119 & 0.987 & \\ 5.681 & 0.986 & \\ 0.865 & 0.000 & \end{array}$

$\begin{array}{rr}1.190 & 0.084 \\ 2.440 & 0.173 \\ 3.020 & 0.214 \\ 3.000 & 0.213 \\ 6.690 & 0.475 \\ 8.170 & 0.580 \\ 8.460 & 0.601 \\ 3.990 & 0.283 \\ 4.780 & 0.339 \\ 4.710 & 0.334 \\ 4.670 & 0.332 \\ 11.040 & 0.784 \\ 8.320 & 0.591 \\ 4.690 & 0.333 \\ 2.290 & 0.163 \\ 6.590 & 0.468 \\ 0.670 & 0.048 \\ 0.560 & 0.040 \\ 1.430 & 0.102 \\ 1.110 & 0.079 \\ 12.180 & 0.865\end{array}$

Av. Rec'y

0.216

0.059

0.059

0.063

0.116

0.126

0.193

0.110

0.146

0.188

0.190

0.289

0.923

0.934

0.964

0.970

0.966

0.995

0.995

0.987

0.986 
Data Generated from Brinkmann Particle Size Analyzer:

COLUMN FLOTATION (September 11 1996)

Contacted Feed Instead of Recycle and Shortened Column to $1 \mathrm{~m}$ overall recovery $\mathbf{8 8 . 1 \%}$

Particle Size Range (microns) Local Peak (\%) : CONCENTRATE

Local Peak (\%) : TAlLS

$$
\begin{aligned}
& 0.0-2.0 \\
& 2.0-2.5 \\
& 2.5-3.0 \\
& 3.0-3.5 \\
& 3.5-4.5 \\
& 4.5-5.5 \\
& 5.5-7.0 \\
& 7.0-8.5 \\
& 8.5-10.5 \\
& 10.5-13.0 \\
& 13.0-15.5 \\
& 15.5-19.5 \\
& 19.5-23.5 \\
& 23.5-29.0 \\
& 29.0-35.5 \\
& 35.5-44.0 \\
& 44.0-54.0 \\
& 54.0-66.0 \\
& 66.0-81.5 \\
& 81.5-100.0 \\
& >100.0
\end{aligned}
$$

CONDITIONS:

Gas Rate $=800 \mathrm{cc} / \mathrm{min}$

Recycle Rate $=101 \mathrm{~cm} / \mathrm{s}$

Frother $=5 \mathrm{ppm}$

Percent Solids $=5 \%$

Pore size $=2$ micron

Porous tube length $=56 \mathrm{~cm}$

MANUAL LEVEL CONTROL

$\begin{array}{rr}0.190 & 0.167 \\ 0.870 & 0.766 \\ 0.990 & 0.872 \\ 1.270 & 1.119 \\ 2.110 & 1.859 \\ 3.940 & 3.471 \\ 5.350 & 4.713 \\ 3.220 & 2.837 \\ 3.020 & 2.661 \\ 4.960 & 4.370 \\ 5.540 & 4.881 \\ 6.580 & 5.797 \\ 8.890 & 7.832 \\ 9.050 & 7.973 \\ 4.890 & 4.308 \\ 12.120 & 10.678 \\ 8.130 & 7.163 \\ 8.730 & 7.691 \\ 7.450 & 6.563 \\ 3.660 & 3.224 \\ 0.000 & 0.000\end{array}$

$\begin{array}{ccc}\text { feed } & \text { rec'y } & \text { Av. Range } \\ 0.276 & 0.607 & \\ 1.043 & 0.735 & \\ 1.190 & 0.733 & \\ 1.473 & 0.759 & 0-7 \\ 2.509 & 0.741 & \\ 4.416 & 0.786 & \\ 5.733 & 0.822 & \\ 3.327 & 0.853 & \\ 3.253 & 0.818 & \\ 4.939 & 0.885 & 7-19.5 \\ 5.384 & 0.907 & \\ 7.255 & 0.799 & \\ 8.734 & 0.897 & \\ 8.632 & 0.924 & \\ 4.758 & 0.905 & \\ 11.499 & 0.929 & \\ 7.295 & 0.982 & \\ 7.824 & 0.983 & \\ 6.775 & 0.969 & \\ 3.466 & 0.930 & \\ 1.065 & 0.000 & \end{array}$

$\begin{array}{rl}0.910 & 0.108 \\ 2.320 & 0.276 \\ 2.670 & 0.318 \\ 2.980 & 0.355 \\ 5.460 & 0.650 \\ 7.940 & 0.945 \\ 8.570 & 1.020 \\ 4.120 & 0.490 \\ 4.980 & 0.593 \\ 4.780 & 0.569 \\ 4.230 & 0.503 \\ 12.250 & 1.458 \\ 7.580 & 0.902 \\ 5.540 & 0.659 \\ 3.780 & 0.450 \\ 6.900 & 0.821 \\ 1.110 & 0.132 \\ 1.120 & 0.133 \\ 1.780 & 0.212 \\ 2.030 & 0.242 \\ 8.950 & 1.065\end{array}$

Av. Rec'y

0.173

0.053

0.052

0.054

0.106

0.112

0.176

0.102

0.131

0.177

0.181

0.256

0.847

0.897

0.924

0.905

0.929

0.982

0.983

0.969

0.930 


\section{APPENDIX 5}

Figure 5.4, showing data points

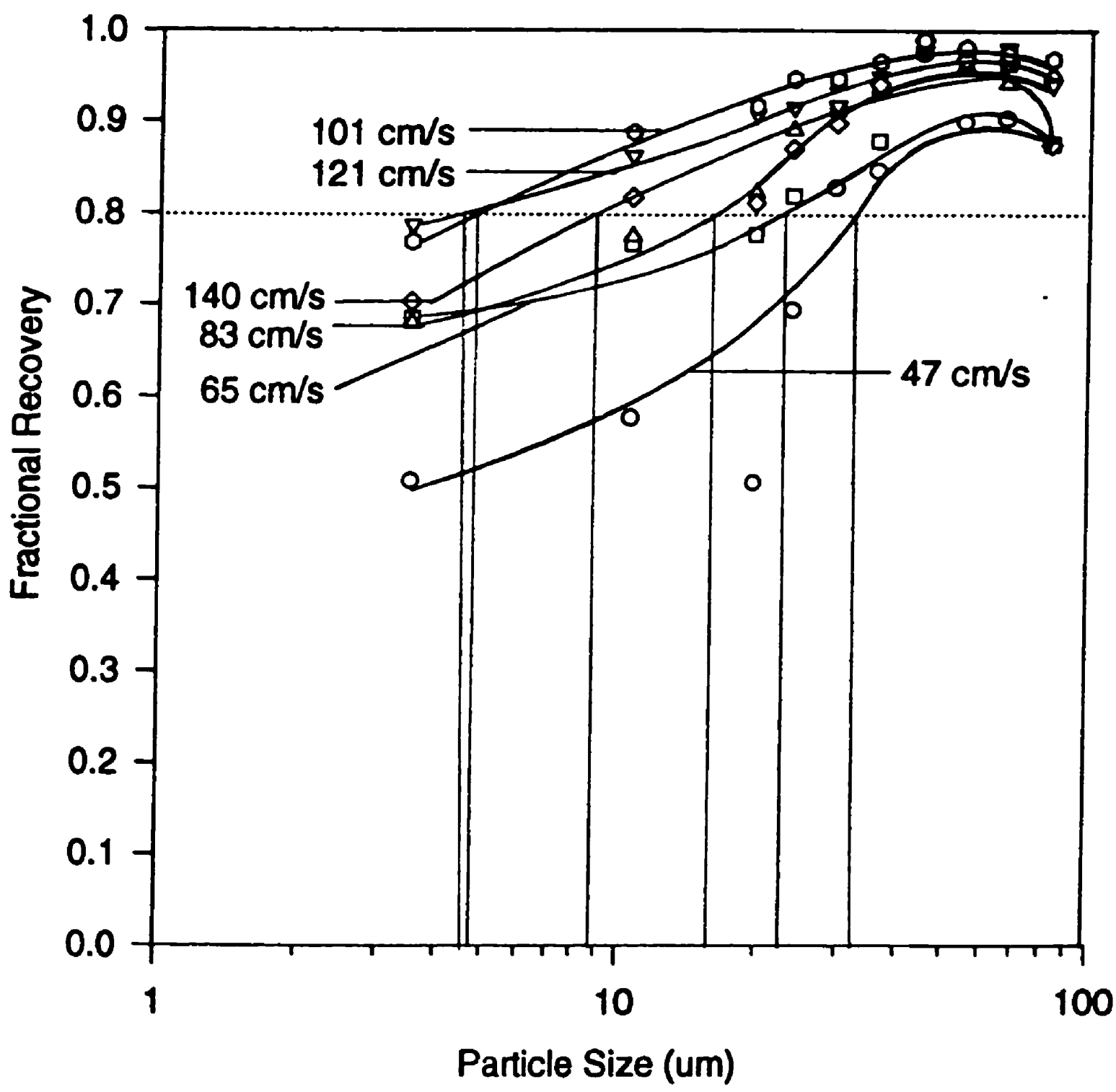


Figure 5.7, showing data points




Figure 5.9, showing data points

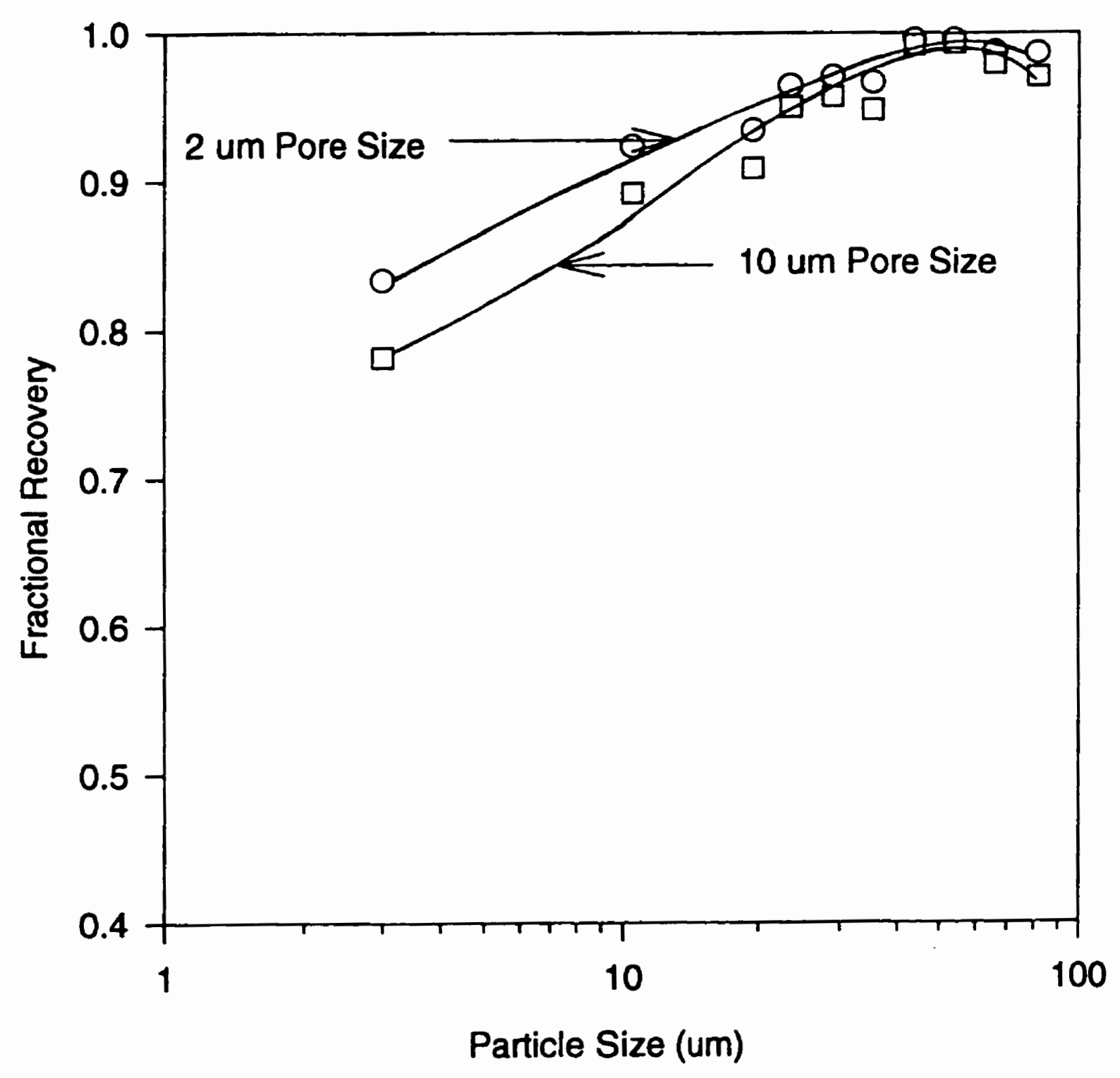


Figure 5.11, showing data points

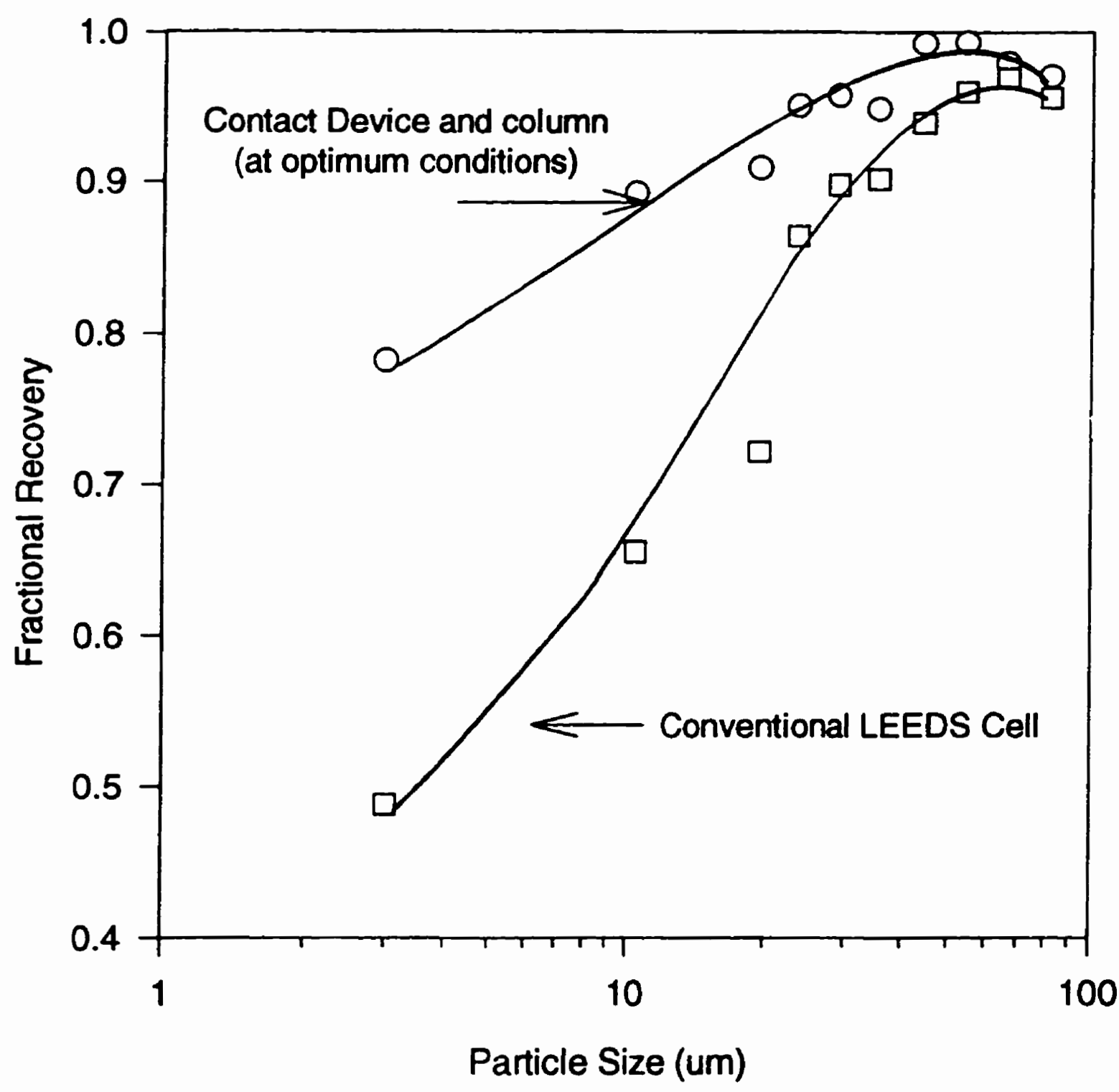


Figure 5.12, with data points

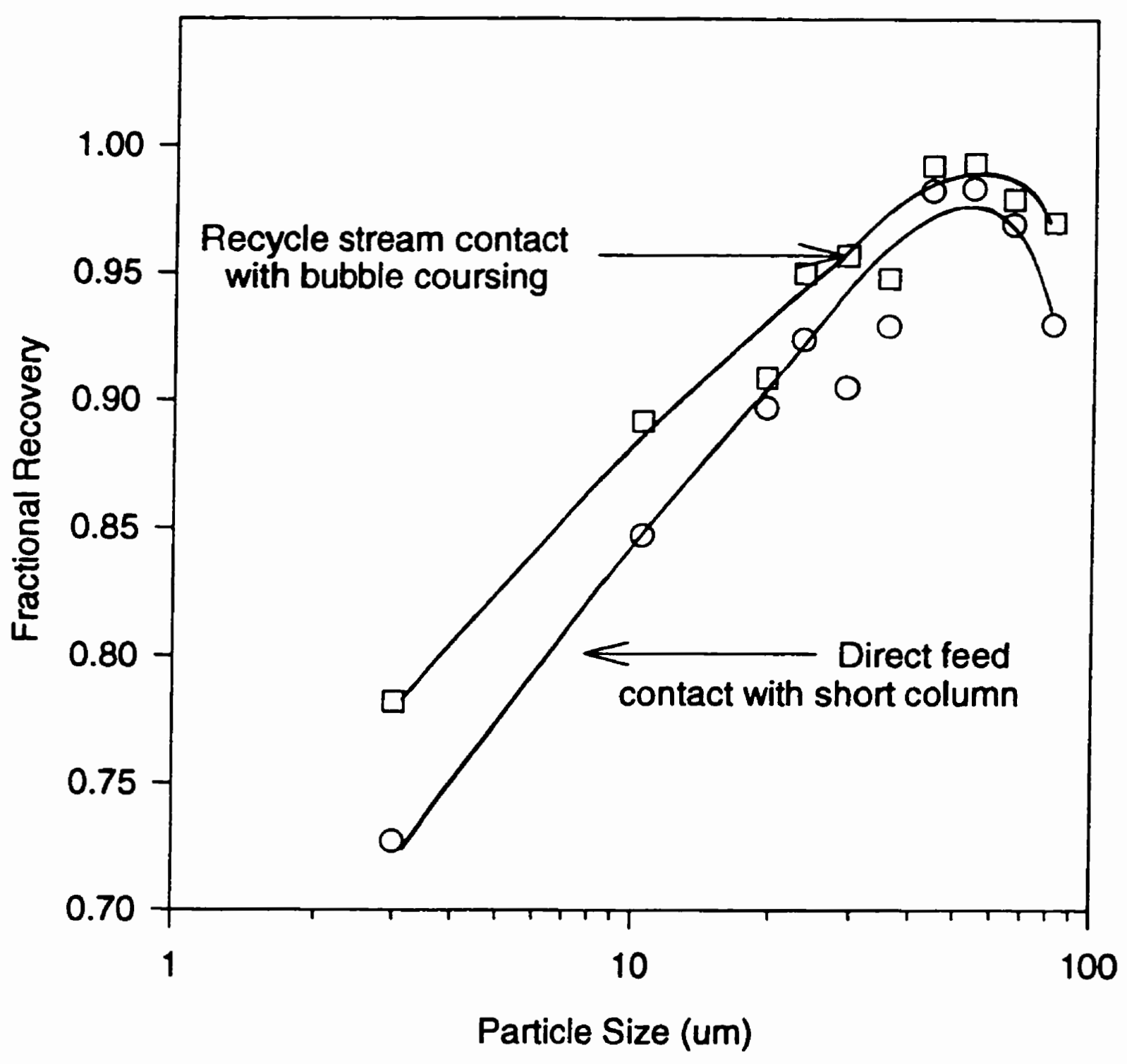




\section{Appendix 6 - Reproducibility Testing ${ }^{\star}$}

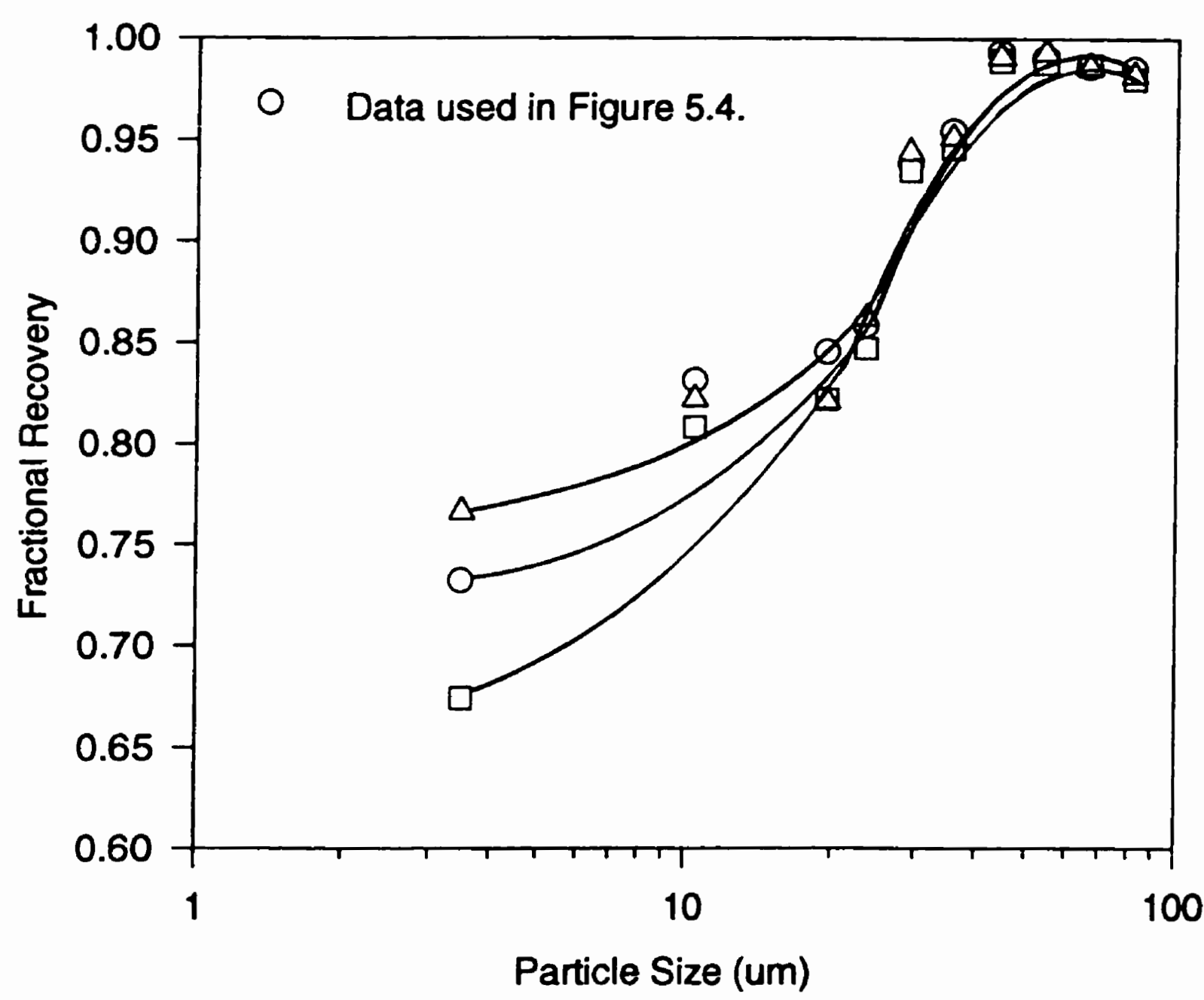

* Additional tests were run at identical conditions to the 'varying superfical velocity tests' at $101 \mathrm{~cm} / \mathrm{s}$. 


\section{APPENDIX 7}

Statistical calculations for Brinkmann. Using three $(5,25$, and $100 \mathrm{um})$ size standards.

stats for 100 micron standard:

ave. $d^{\prime \prime}$

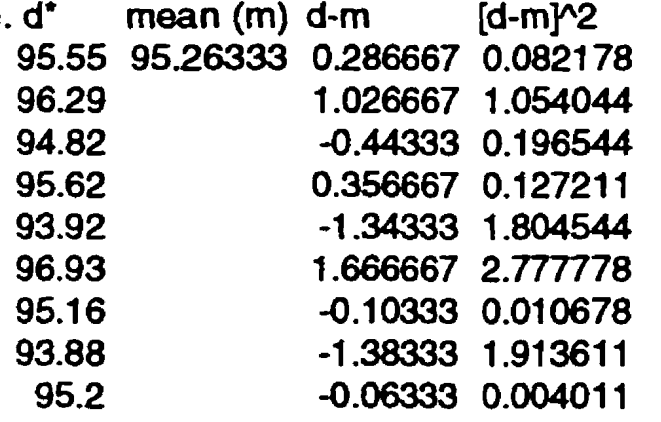

dev. from standard value:

sum sum/8 $s^{* *}$

$\begin{array}{lll}7.971 & 0.996 & 0.998\end{array}$

\subsection{5}

3.71

5.18

4.38

6.08

3.07

4.84

6.12

4.80

stats for 25 micron standard:

\begin{tabular}{|c|c|c|c|c|c|c|c|c|c|}
\hline ave. $d^{*}$ & mean $(\mathrm{m})$ & $d-m$ & {$[d-m]^{\wedge} 2$} & sum & sum/8 & - & \multicolumn{3}{|c|}{ dev. from standard value: } \\
\hline 24.85 & 25.95556 & -1.10556 & 1.222253 & 13.623 & 1.703 & 1.305 & & & Avera \\
\hline 27.58 & & 1.624444 & 2.63882 & & & & -0.15 & 0.15 & 1.13 \\
\hline 24.99 & & -0.96556 & 0.932298 & & & & 2.58 & 2.58 & \\
\hline 24.36 & & -1.59556 & 2.545798 & & & & -0.01 & 0.01 & \\
\hline 25.4 & & -0.55556 & 0.308642 & & & & -0.64 & 0.64 & \\
\hline 25.56 & & -0.39556 & 0.156464 & & & & 0.40 & 0.40 & \\
\hline 27.68 & & 1.724444 & 2.973709 & & & & 0.56 & 0.56 & \\
\hline 25.58 & & -0.37556 & 0.141042 & & & & 2.68 & 2.68 & \\
\hline 27.6 & & 1.644444 & 2.704198 & & & & 0.58 & 0.58 & \\
\hline & & & & & & & 2.60 & 2.60 & \\
\hline
\end{tabular}

stats for 5 micron standard:

ave $d^{*}$$$
\text { mean }(m) d-m
$$

[d-m] 2

$\begin{array}{lllll}5.79 & 5.743333 & 0.046667 & 0.002178\end{array}$

5.85

5.72

5.74

5.73

5.6

5.83

5.66

5.77 $\begin{array}{lll}0.106667 & 0.011378\end{array}$

$\begin{array}{lll}-0.02333 & 0.000544\end{array}$

$-0.00333 \quad 1.1 \mathrm{E}-05$

$\begin{array}{lll}-0.01333 & 0.000178\end{array}$

$\begin{array}{lll}-0.14333 & 0.020544\end{array}$

$0.086667 \quad 0.007511$

$-0.083330 .006944$

0.0266670 .000711 sum sum/8 s**

$\begin{array}{lll}0.050 & 0.006 & 0.079\end{array}$ dev. from standard value:
0.79
0.85
0.72
0.74
0.73
0.60
0.83
0.66
0.77

- the mean particle size for each test

** standard deviation 


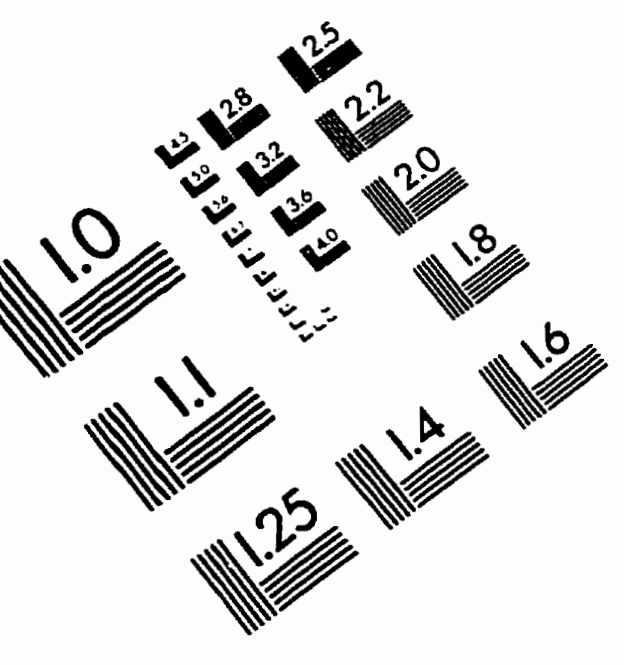

\section{IMAGE EVALUATION \\ TEST TARGET (QA-3)}
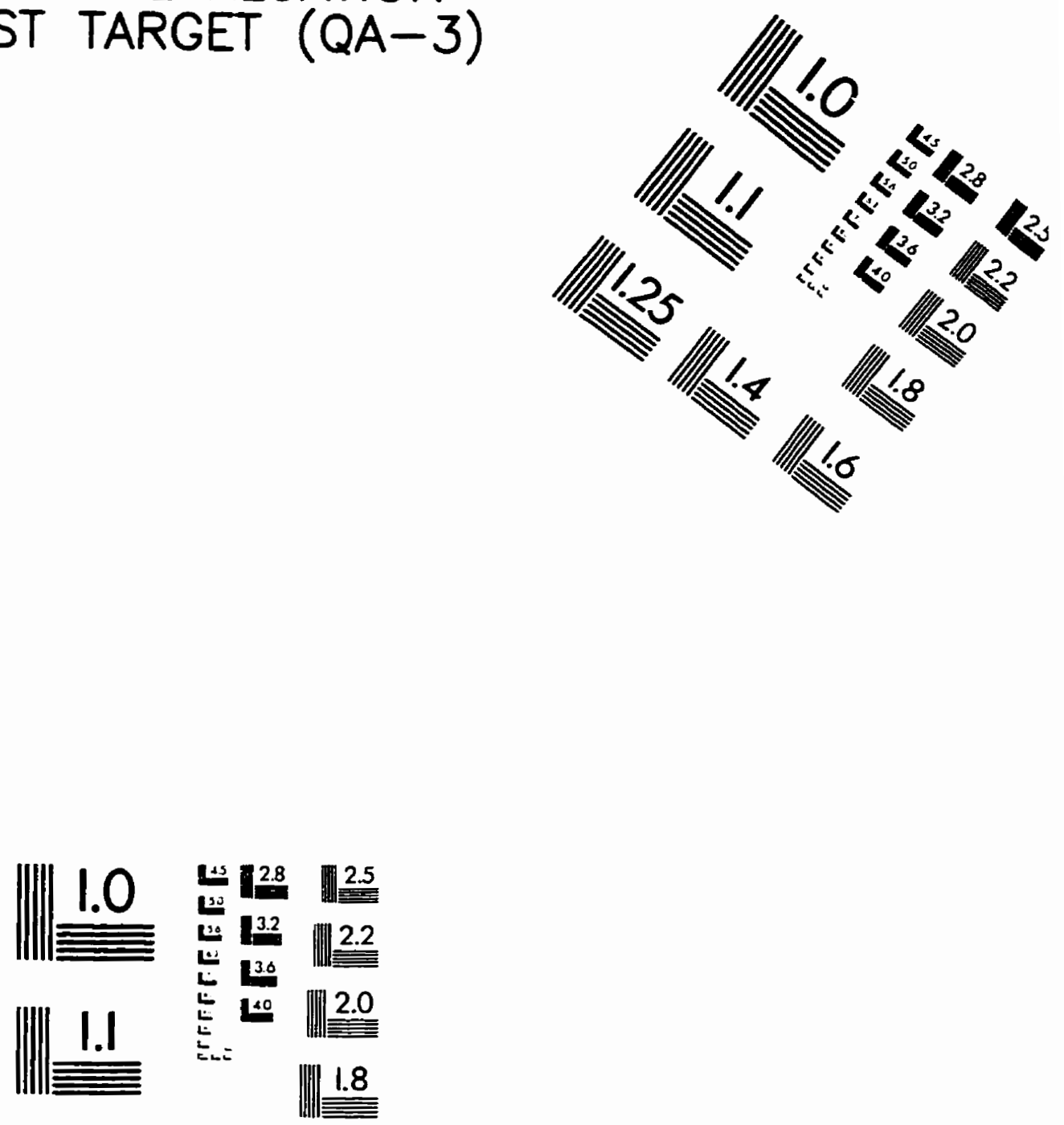

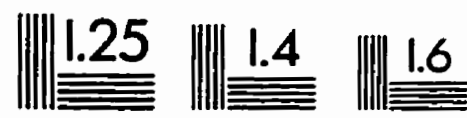
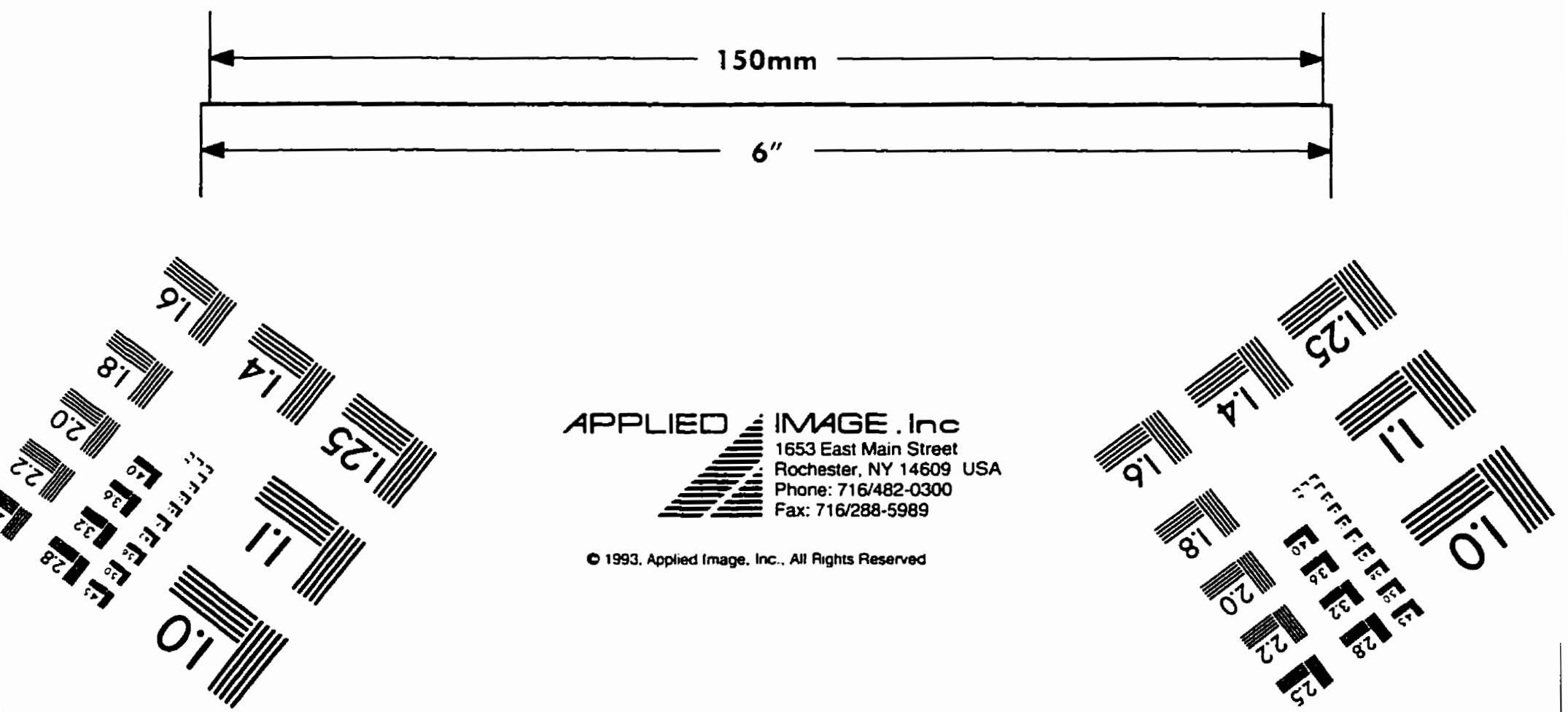

- 1993. Applied Image. Inc., All Rights Reserved 